\title{
Technological Innovation, Food Safety and Economic Development in Lower Middle-Income Countries
}

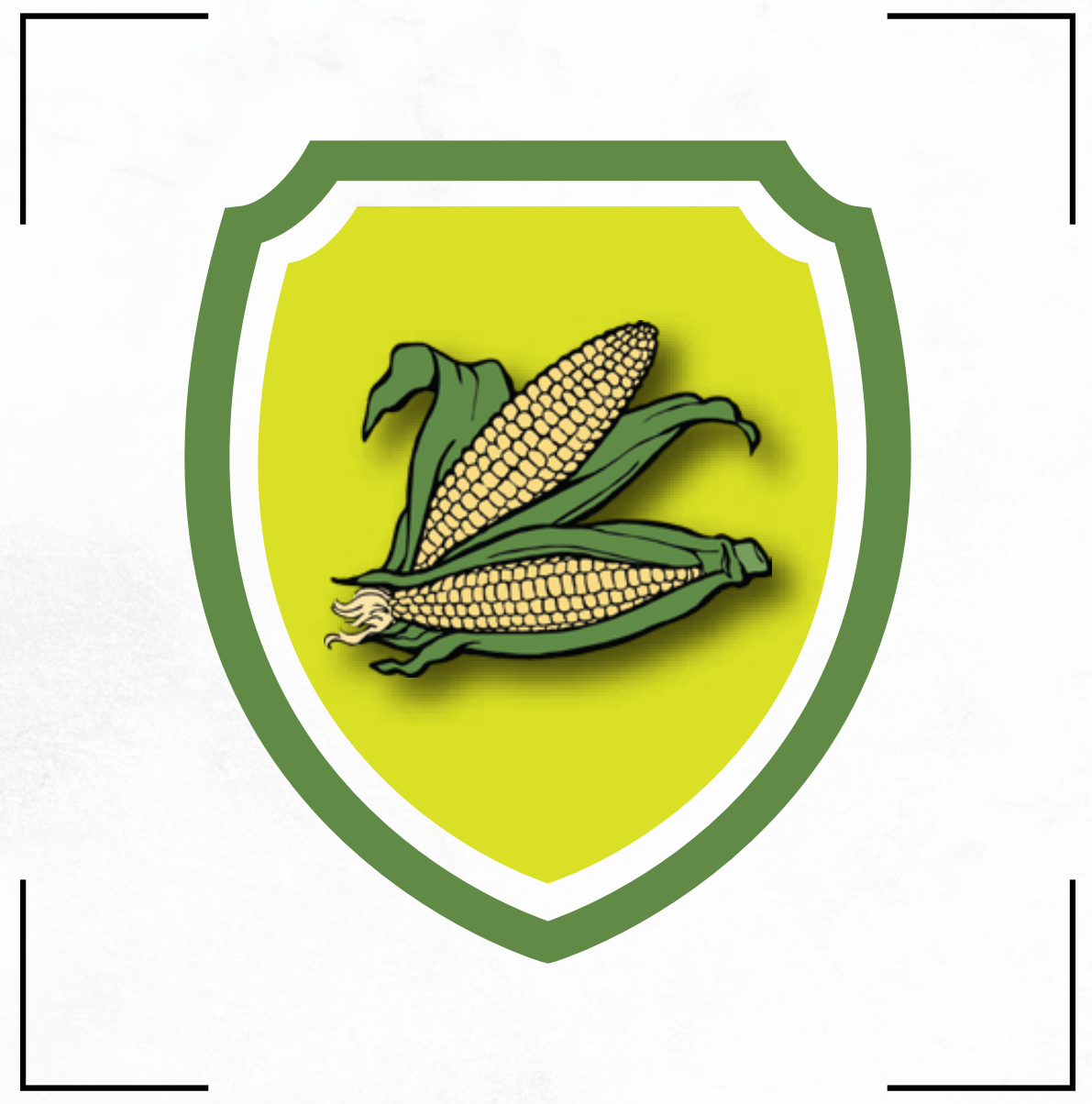

Sarah Wairimu Kariuki 


\section{Propositions}

1. Consumers in lower and middle-income countries always believe that any branded food product in the market is safe.

(this thesis)

2. Food safety in lower-middle-income countries can only be sufficiently achieved through government regulation.

(this thesis)

3. Intensification of animal production is the biggest threat to animal welfare.

4. High yielding hybrid seeds are good; drought-tolerant seeds are better.

5. Becoming a researcher makes one to be critical of every tiny detail of life.

6. Ph.D. candidates spend more energy worrying than doing the actual work.

Propositions belonging to the thesis, entitled

Technological Innovation, Food Safety, and Economic Development in Lower MiddleIncome Countries

Sarah Wairimu Kariuki 

Technological Innovation, Food Safety and Economic Development in Lower MiddleIncome Countries

Sarah Wairimu Kariuki 


\section{Thesis Committee}

\section{Promotor}

Prof. Dr E.H. Bulte

Professor of Development Economics

Wageningen University \& Research

\section{Co-promotors}

Dr Janneke Pieters

Assistant Professor, Development Economics Group

Wageningen University \& Research

Dr Vivian Hoffmann

Research fellow, Markets Trade and Institutions Division

International Food Policy Research Institute, Nairobi, Kenya

\section{Other members}

Dr W.J.J. Bijman, Wageningen University \& Research

Prof. Dr M. Qaim, Georg-August-University Goettingen, Germany

Dr C. Moser, Western Michigan University, Kalamazoo, United States of America

Dr H.A.J. de Groote, International Maize and Wheat Improvement Center (CIMMYT),

Nairobi, Kenya

This research was conducted under the auspices of Wageningen School of Social Sciences (WASS). 
Technological Innovation, Food Safety and Economic Development in Lower MiddleIncome Countries

Sarah Wairimu Kariuki

\section{Thesis}

submitted in fulfilment of the requirements for the degree of doctor

at Wageningen University

by the authority of the Rector Magnificus,

Prof. Dr A.P.J. Mol,

in the presence of the

Thesis Committee appointed by the Academic Board

to be defended in public

on Tuesday 08 December 2020

at 01:30 p.m. in the Aula. 
Sarah Wairimu Kariuki

Technological Innovation, Food Safety and Economic Development in Lower Middle-Income Countries,

200 pages.

$\mathrm{PhD}$ thesis, Wageningen University, Wageningen, the Netherlands (2020)

With references, with summary in English

ISBN 978-94-6395-571-3

DOI https://doi.org/10.18174/532210 
To my late parents, Mr. and Mrs. Kariuki, who taught me the value of hard work. 



\section{Contents}

Chapter $1 \quad$ General Introduction 1

Chapter 2 Can Information Drive Demand for Safe Food? $\quad 17$

Chapter 3 Safe Food for Me - and Maybe for You 65

Chapter $4 \quad$ Role of Producer Organizations in Technology Adoption 101

Chapter $5 \quad$ Impact of Farmer Training on Efficacy of Food Safety Technology 137

$\begin{array}{lll}\text { Chapter } 6 & \text { General Discussion } & 157\end{array}$

$\begin{array}{ll}\text { References } & 173\end{array}$

$\begin{array}{ll}\text { Summary } & 195\end{array}$

Acknowledgments 197 



\section{Chapter 1}

General Introduction

Sarah Wairimu Kariuki 


\subsection{Food safety and economic development}

Unsafe food has significant implications for economic development. First, unsafe food may make people ill and, in extreme cases, result in death. In 2010 alone, thirty-one food safety hazards were associated with 600 million illnesses and 420,000 deaths worldwide, translating to an estimated disease burden of 33 million Disability-Adjusted Years (DALYs) (WHO 2015). This disease burden translates to high economic costs to both individuals and governments in lost productivity, prevention costs, and other medical costs (Jaffee et al. 2018). Second, unsafe food may affect people's nutritional outcomes, either directly through effects such as stunting (Checkley et al. 2008; Gong et al. 2002; Häsler et al. 2017; McMillan et al. 2018; Turner et al. 2005) or indirectly through avoidance of nutritious food due to safety concerns (Hoffmann, Moser, and Saak 2019). Lastly, unsafe food may result in significant trade-related losses (Jaffee et al. 2018). These losses can be in the form of rejection of consignments or lost trading opportunities (Bovay 2016; Otsuki, Wilson, and Sewadeh 2001; UNIDO 2015). At the micro-level, resource-poor farmers may be excluded from high-value export or domestic markets, resulting in lost income opportunities (Hoffmann et al. 2019; Unnevehr 2015).

Food safety management is thus an essential part of economic development as it contributes towards the general health and well-being of people, improved nutrition, and reduced poverty, as envisioned in the Sustainable Development Goals (SDGs) 3, 2, and 1.

Until recently, there has been limited policy attention to the safety of foods consumed in the Lower and Middle-Income Countries (LMICs). Most of the previous efforts by the governments, donors, and the research community has been towards meeting the food safety requirements in the export markets (GFSP 2019). While compliance to international food safety standards has generally resulted in better livelihood outcomes for the producers in LMICs 
(Hoffmann et al. 2019; Unnevehr 2015), there have been limited spillovers in terms of improved safety of the foods consumed locally (Donovan, Caswell, and Salay 2001) ${ }^{1}$.

A major factor that has led to the low prioritization of the safety of foods consumed in the LMICs is limited evidence on the health burden and economic costs due to Food-Borne Diseases (FBD). To address this gap, the World Health Organization (WHO), in 2006, launched an initiative to estimate the global FBD burden. At the time, most High-Income Countries (HICs) had national studies on the FBD burden (Flint et al. 2005; Havelaar et al. 2000; Mead et al. 1999). However, such studies were non-existent in most of the LMICs (WHO 2006).

Ten years later, the WHO assessment results showed that in 2010 (base year), 31 hazards were responsible for a disease burden comparable to that of tuberculosis and malaria (Havelaar et al. 2015). More importantly, the estimates pointed to a stark difference in the FBD burden across the regions of the world. Most of the global food-borne disease burden was borne by the LMICs in Sub-Saharan Africa and Asia, accounting for about 72\% of the total FBD in 2010 (Jaffee et al. 2018). The public health burden due to FBD in these countries translates to economic costs of approximately USD 110.2 billion per year (Jaffee et al. 2018).

The disproportionate burden of FBD is a reflection of the difference in food safety management in the LMICs and the HICs. While the food safety management systems are relatively developed in the HICs, the same remains under-developed in most of the LMICs (Jaffee et al. 2018). Most of the LMICs are characterized by low public sector capacity (in terms of infrastructure and human capacity) and a lack of comprehensive food safety policies (Jaffee et al. 2018). Besides, most of the countries in the lower-middle-income category are undergoing rapid

\footnotetext{
${ }^{1}$ Some studies found improved health benefits for farmers due to use of protective gear during pestcide application, which was part of the requirement for in the export market
} 
transformation and urbanization that has increased the consumption of a wider variety of foods, increased consumption of processed food, led to longer food value chains, and intensified the production systems (Jaffee et al. 2018; McDermott and De Brauw 2020). These transformations expose consumers to a broader range of hazards. Thus, if the current management system in the LMICs is unchanged, the FBD burden is likely to be higher than it was in 2010 .

The WHO report has stimulated action by the research community, donors, and governments in the LMICs towards improving the safety of the foods consumed in the LIMCs. Examples include the Consultative Group for International Agricultural Research (CGIAR) research program on Agriculture for Nutrition and Health (A4NH), the WHO through its Foodborne Disease Burden Epidemiology Reference Group (FERG), the World Bank (WB), and several initiatives from other donors.

Part of the effort has been to develop new food safety technologies and to test the potential of the existing technologies to improve the safety of food consumed in these settings (Bandyopadhyay et al. 2016; Hell et al. 2000; Kassam and Barat 2008; Wild, Miller, and Groopman 2015; Williams, Baributsa, and Woloshuk 2014). This thesis aims to provide some evidence on this subject. The thesis's main contribution is to test the impact of market-based solutions and rural institutions on the adoption of food safety technology to facilitate production and supply of safe food.

\subsection{Market-based solutions}

A major problem of food safety is imperfect information during market transactions. As an attribute of food, safety is mostly not observed during purchase. Specialized tests can be done to detect the presence of specific hazards. However, these are expensive relative to the value of the 
food purchased, thus may not be feasible in every transaction. Consumers, therefore, may have incomplete information about the quality and safety of food during purchase. Sellers may have private information on the quality and safety of the supplied food since, in most cases, they are knowledgeable about how the food was produced or processed. This creates an information asymmetry between the buyer and the seller in the market. In some cases, the seller may not have information on the quality and safety of the supplied foods, creating imperfect information for both the buyers and the sellers.

Under certain conditions, market forces can resolve the problem of information asymmetry. First, firms that want to protect their brand equity can invest in providing safer foods and charge a higher price as a signal for higher quality (safety) (Hoffmann and Moser 2017). Second, product labeling and certification can be used to provide information on food quality and safety to the consumers, thus resolving the information asymmetry (Antle 1996). Both reputation and labeling mechanisms are conditional on having a sufficient number of knowledgeable consumers (Antle 1996), so that the firm can incur the cost of supplying higher quality products and communicating this information to the consumers.

In the case of inadequate or absence of certification, reputation, and consumer knowledge, public regulation is recommended to ensure the supply of safe foods (Antle 1996). Public regulation may include product liability laws, performance standards (for example, stating the allowable levels of a hazard in a final product), design standards (outlining how a product should be produced), or prohibition laws (banning of specific products or processes) (Antle 1996; Garcia Martinez et al. 2007).

Given the weak public regulation capacity in the LMICs, the low consumer demand for food safety, lack of credible product certification, and the dominance of informal market 
conditions (Hoffmann et al. 2019; Jaffee et al. 2018), food safety is mostly undersupplied in these contexts (Grace 2017). However, the rapid transformation, urbanization, and rising incomes in the lower-middle-income countries provide an opportunity that can be used to harness the market forces to improve food safety. Market-based solutions have been proposed as one of the approaches to improving food safety in the LMICs (ANH 2017; GFSP 2019; Hoffmann et al. 2019; Jaffee et al. 2018).

In this thesis, I define market-based solutions as "policy tools that encourage behavioral change through market signals by providing economic incentives rather than through traditional regulations" (Aramyan et al. 2016). This definition implies a deliberate effort by the public sector to create an enabling environment for the private sector's involvement in food safety management.

\subsection{Impact of market-based solutions to food safety in lower and middle-income countries}

Some evidence exists on the impact of market-based solutions in lower-middle-income settings. The International Livestock Research Institute (ILRI) and other partners have been working on a market-based institutional innovation that involves training, certification, and branding of informal milk vendors and butchers in Kenya, India, and Nigeria. These interventions have resulted in improved knowledge and skills of the trainees, higher quality and safer products, and increased economic benefits for the chain actors (Johnson et al. 2015; Kaitibie et al. 2010; Lapar et al. 2014; Omore and Baker 2009). The intervention in Kenya also led to a policy change that resulted in a shift in the regulators' approach from that of policing and harassment to ensuring and facilitating compliance by the vendors (Kaitibie et al. 2008). However, in all cases, the vendors were not able to charge a premium price for their products (Jaffee et al. 2018). Other motivations like getting a license, thus reducing harassment by the local authorities (this lowered the vendors' transaction 
costs), or increased public recognition, acted as incentives for the traders to participate in the program.

One of the limitations of the above studies is the lack of credible counterfactuals needed to attribute the observed outcomes to the interventions. Without rigorous evaluations, we are not confident that the observed changes were solely due to the interventions and not other confounding factors. Also, the main incentives for behavior change were training and certification (that reduced harassment or increased recognition). This thesis adds to these studies by using field experiments to test the potential for price based incentives (driven by consumer demand, thus likely to be more efficient and sustainable) to improve food safety and livelihoods.

Lastly, the intervention in this thesis targets a different value chain actor - the small-scale producers $^{2}$. First, the food safety hazard studied occurs at the farm level, thus best managed at the farm. Second, as agri-food value chains evolve and markets for safe food arise, there is a risk of exclusion of small scale farmers from these chains (Hoffmann et al. 2019; Reardon et al. 2009; Unnevehr 2015). Their small scale nature of production implies high training, monitoring and product testing costs that may discourage the private sector from working with such farmers.

\subsubsection{Impact of efforts to stimulate consumer demand for food safety}

Consumer awareness and willingness to pay for food safety were the primary drivers of markets for safer foods in the HICs (Jaffee and Henson 2004). However, most consumers in the LMICs are not willing or able to pay for food safety (Hoffmann, Moser, \& Saak 2019; Jaffee et al. 2018).

\footnotetext{
${ }^{2}$ Some field experiments have examined the role of price incentives in stimulating supply of safe food by small-scale farmers. I discuss these studies later in the text
} 
Whether consumer demand in these countries can be stimulated to drive food safety is still an open question.

Some studies have examined the Willingness To Pay (WTP) for food safety claims by consumers in LMICs using hypothetical or actual choice experiments. These studies find that consumers are generally willing to pay more for safety attributes (Hoffmann et al. 2019; Ortega and Tschirley 2017). However, emerging evidence shows that these studies' methodological approach may result in an upward bias since WTP is measured immediately after focusing participants' attention to food safety (Hoffmann, Moser, and Herrman 2020). In the study by Hoffmann et al. (2020), the authors tested the effect of marketing efforts on sales of a labeled certified maize flour brand over time and found no lasting effects after the week of active marketing. When combined with a price discount, the effect of marketing lasted longer, but also eventually faded. Since consumers' willingness to pay for food safety may vary depending on the source of information (Hoffmann et al. 2019; Jaffee et al. 2018), more studies are needed to complement the study by Hoffmann et al. (2020). These include studies in which the information provided to consumers is from an independent source and not a marketing claim made by a specific firm; and in which consumers' behavior is observed in their natural setting.

Studies on the role of information in stimulating demand for preventive health and water treatment technologies have shown that the effect of information may depend on the type of information supplied. Providing risk information is more effective than general information (Dupas 2011; Dupas and Miguel 2017). The role of different types of information, and especially risk information, in stimulating demand for safer foods has not been examined. 


\subsubsection{Impact of price incentives on the adoption of food safety technology}

Over the years, significant effort has been put into developing new food safety technologies as well as testing the potential of the existing technologies to manage food safety risks at the farm level (Bandyopadhyay et al. 2019; Hell et al. 2000; Kaaya and Kyamuhangi 2010; Kassam and Barat 2008; Pretari, Hoffmann, and Tian 2019; Wild et al. 2015; Williams et al. 2014). However, as with other agricultural technologies, the adoption of promising technologies by small-scale producers in developing countries is constrained by market inefficiencies ${ }^{3}$, information and learning constraints, and behavioral biases (Ashraf, Giné, and Karlan 2009; Duflo, Kremer, and Robinson 2011; Hanna, Mullainathan, and Schwartzstein 2017; Jack 2013). Adoption may also be low due to low returns to technologies in farmers' conditions (Foster and Rosenzweig 2010). This thesis examines the role of output market inefficiencies and potential returns on the adoption (potential adoption) of a food safety technology.

Most small scale farmers market their produce in the informal markets where produce from numerous farmers is aggregated by the traders, limiting traceability. The prices in these markets do not reflect the unobservable attributes of the product, including food safety (Hoffmann, Mutiga, et al. 2020). Due to the weak regulatory environment, especially in these informal markets, there is no testing and thus no reward for quality. Therefore, most producers do not invest in quality (including food safety) enhancing technologies for their marketed produce (Hoffmann and Jones 2018; Kadjo et al. 2019).

Some studies have shown that providing market incentives can stimulate the adoption of quality or safety-enhancing technologies by small-scale farmers (Bernard et al. 2017; Hoffmann,

\footnotetext{
${ }^{3}$ Include inefficiencies in output and input markets, financial services markets, risk markets, land markets (Jack 2013).
} 
Magnan, et al. 2018; Hoffmann and Jones 2018; Saenger et al. 2013; Treurniet 2019b). Existing studies are mainly on produce grown mostly for the market (Bernard et al. 2017; Saenger et al. 2013; Treurniet 2019b) or involve an unrealistic high price premium (Hoffmann and Jones 2018), or a modest premium to incentivize the adoption of a non-divisible technology (Hoffmann, Magnan, et al. 2018). The role of small incentives on the adoption of a divisible technology by subsistence farmers who mainly produce for home consumption but sell some surplus has not been studied. Additionally, there is scant evidence on the effectiveness of food safety technologies under farmers' conditions and practice, and the role of farmer training on this efficacy.

\subsection{Objective and research questions}

The overarching objective of this thesis is to examine the potential of technological innovation to improve i) the livelihood of farmers and ii) the safety of food consumed by consumers in lowermiddle-income countries. Specifically, the thesis aims at assessing the impact of market-based solutions and rural institutions on the production and supply of safe food through the adoption of food safety technology. These objectives are evaluated through the following research questions:

1. What is the impact of food safety information on consumer demand for safe food? What type of information is more effective in stimulating consumer demand for safe food? (Chapter 2)

2. What is the impact of a market-based instrument-a premium price for safe food- on the adoption of a food safety technology by small-scale farmers? (Chapter 3)

3. Does the effectiveness (and thus returns) of a new food safety technology in farmers' fields depend on the level of farmer training and support? (Chapter 5) 
4. What characteristics of producer organizations are correlated with individual member's adoption of a food safety technology? (Chapter 4)

\subsection{Study context}

The research in all the four core chapters was conducted in Kenya, a country ranked as a lowermiddle-income country. This section provides some background information on the food safety hazard studied in this thesis and the available technologies to manage the hazard.

The main focus of this thesis is aflatoxin contamination, a naturally occurring toxin common in the tropics. Aflatoxin mostly affects maize, peanuts, cottonseed, and tree nuts (Klich 2007). The toxin can also be present in livestock products like milk, eggs, meat if livestock consumes contaminated feed. Much of the exposure in Kenya is through maize due to high levels of the toxin in maize and high consumption of maize (Johnson and Grace 2015). Although typically lower compared to contamination levels in maize, aflatoxin contamination in milk is also of great public health concern due to the high consumption of milk by young children.

Chronic exposure to moderate levels of aflatoxin is known to cause liver cancer, suspected of causing about 25-155 thousand cases of liver cancer worldwide each year (Liu and Wu 2010). Chronic exposure is also associated with stunting in children (Gong et al. 2002; McMillan et al. 2018; Turner et al. 2007) and the inhibition of the immune system (Wild et al. 2015). Ingestion of high levels of aflatoxin can result in acute poisoning and death, of which hundreds of cases have been reported in Kenya (Azziz-baumgartner et al. 2005).

In addition to the adverse health effects, aflatoxin contamination has other economic costs. First, once present in food, it is almost impossible to eliminate. Disposal of contaminated products, which occasionally occurs in Kenya (Bandyopadhyay et al. 2016; EAC 2017), is costly and 
reduces food availability among food insecure populations. Second, failure to produce aflatoxin safe maize may lock out farmers from high-value chains that demand aflatoxin safe maize. In Kenya, some premium exists for safe maize among some formal millers (Hoffmann and Moser 2017). However, these millers avoid sourcing maize from aflatoxin prone regions.

Aflatoxin is only detectable via tests. Consumers cannot differentiate aflatoxin safe products from unsafe products by just looking at the products. The Kenyan government has a regulation on the amount of aflatoxin that is acceptable in grains sold for human consumption. While there is no continuous monitoring of the prevalence of aflatoxin in foods in Kenya, several studies have found food products with levels above the regulatory limit in both the formal and informal markets (Hoffmann and Moser 2017; Lewis et al. 2005; Mutegi, Cotty, and Bandyopadhyay 2018; Mutiga et al. 2014). Unsafe levels have also been found in farmers maize before harvest and during storage (Mahuku et al. 2019; Pretari et al. 2019). These studies highlight the weak enforcement of the existing regulation and inadequate management of the hazard at the farm level.

Technological solutions for aflatoxin management exists at all stages of crop production; pre and post-harvest. Some of the pre-harvest technologies include biocontrol, Good Agricultural Practices (GAP), and resistant varieties. Post-harvest technologies include drying technologies, sorting, and storage technologies. These technologies differ in cost (monetary, labor, and effort) and efficacy in reducing contamination.

This thesis focuses on biocontrol technology. Biocontrol for aflatoxin contamination involves the use of naturally occurring atoxigenic fungal strains to competitively displace aflatoxin producers in the soil, thus reducing aflatoxin levels in the treated crop. Biocontrol is highly effective in reducing aflatoxin contamination (up to $100 \%$ effective) in field trials and farmers' 
fields (Atehnkeng et al. 2014; Bandyopadhyay et al. 2019; Senghor et al. 2020). Besides, it protects crops in the field and after harvest. However, this technology has significant cost implications, both monetary and effort costs. The technology also requires precise application in terms of timing and dosage to achieve the desired results (Weaver et al. 2015).

Biocontrol for use in Africa, under the brand name Aflasafe ${ }^{\mathrm{TM}}$, has been under development since 2003 by scientists from the International Institute of Tropical Agriculture (IITA), one of the CGIAR centers, in collaboration with other partners, among them the Agricultural Research Service of the United States Department of Agriculture. In Kenya, the biocontrol product was registered in 2015 (Bandyopadhyay et al. 2016). A local manufacturing factory has been set-up in one of the national research centers, Kenya Agricultural and Livestock Research Organization (KALRO). The Kenyan government has so far been the primary buyer of the biocontrol from the KALRO factory, mainly for use in target areas. Plans to engage the private sector in the manufacturing and distribution of the biocontrol are underway (Konlambigue et al. 2019).

\subsection{Methodology}

Three field experiments were conducted to evaluate the potential for market-based solutions and institutions to improve food safety and livelihoods through technology adoption. The main data sources were household surveys, PO surveys, administrative records, laboratory tests of aflatoxin contamination in maize.

A randomized trial was conducted among consumers in a county capital in the Eastern region of Kenya to examine the role of different types of information in stimulating demand for safer foods. Households were randomly assigned to receive one of the three types of information 
offered, namely general information, brand-specific recommendations, or brand-specific plus test result showing a person's exposure to the hazard. The random assignment of households to various treatments allowed us to test the causal effect of information on consumer behavior. The impact of information was assessed nine weeks after information was provided to avoid any potential bias of measuring consumers' willingness to pay for safety immediately after focusing their attention on food safety.

To test the role of market incentives on subsistence farmers' adoption of the aflatoxin biocontrol, a Randomized Cotroled Trial (RCT) was conducted in Kenya's Eastern region. The project worked with farmers who are members of existing POs in the region. Half of the POs were randomly assigned to receive a price premium for maize treated with the biocontrol and aggregated at the PO level. Again, the random assignment of the treatment allows us to causally isolate the effect of the price premium on farmers' adoption decisions in our setting. Chapter 4 uses data collected in this project to examine how the POs' structural characteristics are correlated with the individual member's adoption decisions. The PO characteristics studied include the PO's size, member heterogeneity, linkage to larger organizations, leadership training, groups' main activities, and gender composition of the PO.

Lastly, an experiment varying the level of training and support offered to farmers was used to test the effectiveness of the biocontrol under these varied levels of training.

\subsection{Outline}

The rest of the thesis is organized as follows. Chapter 2, which is based on joint work with Vivian Hoffmann, examines the role of information in stimulating demand for safer foods in Kenya. Chapter 3 is based on joint work with Vivian Hoffmann, Janneke Pieters, and Mark Treurniet. We 
test the impact of price premiums for safe maize on the adoption of the aflatoxin biocontrol by subsistence farmers in Kenya. In Chapter 4, I examine whether a producer group's structural characteristics are correlated with members' adoption of the biocontrol. Chapter 5 is joint work with Vivian Hoffmann and scientists from IITA and examines the effectiveness of the biocontrol under varied levels of farmer training and support. Lastly, Chapter 6 provides a synthesis of the available evidence, provides policy recommendations, and offers suggestions for further research. 


\section{Chapter 2}

\section{Can Information Drive Demand for Safe Food? Impact of Brand-Specific Recommendations and Test Results on Product Choice}

\section{Sarah Wairimu Kariuki and Vivian Hoffmann}

As a mostly unobservable attribute, food safety is likely to be under-provided by markets in LMICs where regulatory enforcement is weak. In these settings, stimulating consumer demand for safer food can potentially encourage market actors to invest in food safety. We test the impact of informing consumers about which maize flour brands are most likely to comply with the Kenyan regulatory standard for aflatoxin, a carcinogenic fungal byproduct. Providing information on safer brands alone does not significantly affect consumption behavior. However, when the same information is combined with a test performed on the maize flour currently stocked by the household, both the likelihood that a safer brand is consumed and per-unit expenditures on maize flour are higher two months later, relative to a comparison group. Our findings show that providing salient information on hazard exposure can increase the effectiveness of efforts to promote safer food. 


\subsection{Introduction}

Foodborne illness is a major health problem globally, responsible for a burden of disease on par with tuberculosis and higher than maternal mortality (WHO 2015). Consumer demand for food safety is typically weak in low-income settings, resulting in low prioritization of this issue by both the market and governments (Hoffmann, Moser, \& Saak 2019; Jaffee et al. 2018). Middle-income countries thus bear a disproportionate share of the global food safety burden, as adherence to and enforcement of food safety standards lags behind rapidly transforming food systems ( Jaffee et al. 2018). Stimulating consumer demand for safer food has the potential to catalyze action within the food industry and by policymakers. In this chapter, we study the impact of providing consumers in a mid-sized Kenyan city with information about relatively safe brands within a product class, and about their personal hazard exposure, on subsequent product choice.

Since food safety is a mostly unobservable attribute that is not easily evaluated by consumers, it tends to be undersupplied especially in poorly regulated markets. Previous research conducted in the same region of Kenya as the present study has found high rates of contamination with the carcinogenic fungal byproduct aflatoxin in formally marketed maize flour (Hoffmann \& Moser 2017). In this study, the rate of non-compliance varied dramatically across brands, from $5 \%$ to $85 \%$, and negatively with price, suggesting that quality differentiation can lead to heterogeneity in terms of food safety.

Despite this variation, firms with better food safety track records do not generally use this information to market their products, citing challenges in achieving $100 \%$ compliance, and the risk that food safety claims could result in heightened regulatory scrutiny. A recent experimental study showed no lasting impact on sales of a maize flour marketing campaign focused on food safety, indicating little upside of making food safety claims (Hoffmann, Moser, et al. 2020). On the other 
hand, media exposés of contamination and government food safety recalls are met with widespread concern and, according to news reports, dampened consumer demand (BBC News 2019; The Star 2019), suggesting that consumers may respond differently to negative vs. positive food safety information.

The wide variation in food safety across brands in this setting, together with lack of public awareness of this variation and consumer concern about aflatoxin contamination suggests a potential opportunity to both reduce exposure to this hazard, and increase the pressure on firms to invest in the safety of their products through the provision of information by a credible third party.

We test the impact of providing information on aflatoxin safety on consumer product choice through an experiment conducted in a mid-sized town in Eastern Kenya. A comparison group was read a general statement about aflatoxin and the effects of consuming contaminated food. One treatment group (T1) was in addition informed about the relationship between aflatoxin contamination and maize flour price and given the names of two brands previously found to be most likely to comply with the regulatory aflatoxin standard. A second treatment group (T2) was given the same information as T1 households, and in addition was offered the opportunity to have the maize flour in their home tested for aflatoxin.

Results show positive effects of both treatments on people's awareness about heterogeneity in aflatoxin contamination across maize flour brands and the likelihood that a respondent recalled the safer brands' names. However, the effect of information on consumption of one of the safer brands mentioned and on the price of the brand consumed at follow-up nine weeks later was significant only for the group that received information plus a test result (T2). Testing maize flour increased the likelihood that aflatoxin safety was a factor in people's choice of maize flour, relative to those who only received information on safer brands alone. Thus, while providing information 
on safer brands alone did affect people's knowledge, we conclude that information on the contamination status of maize they were themselves consuming appeared to help translate knowledge into action.

In the following section, we review related literature on the impact of information on health behavior and demand for safe food in low and middle-income countries. We then describe the study context, the study design, the empirical strategy, and the findings. The final section concludes.

\subsection{Related literature}

Our study relates to an extensive literature on the role of information in preventive health behavior. A substantial body of work, summarized by Dupas and Miguel (2017), demonstrates that information can lead to health-improving changes in behavior, including the selection of safer water sources, treatment of drinking water, and reduced sexual risk-taking. Providing specific information on relative risk or personal risk exposure tends to be more effective than general recommendations. For example, informing Kenyan schoolgirls about the age-disaggregated HIV rates of potential male partners reduced the overall incidence of childbearing, a proxy for unprotected sex, with the effect driven by a reduction in unprotected sex with older, higher-risk, men (Dupas 2011). In contrast, a program conducted within the same schools a year earlier that provided information only on average risk and encouraged abstinence had no impact on this outcome. An earlier systematic review of the effectiveness of risk communication interventions in health care settings primarily within the context of high-income countries found that providing individualized risk estimates generally had stronger effects than general risk information (Edwards et al. 2000). 
A group of papers closely related to the present study in terms of methodology measure the impact of providing households with the results of water safety tests. Four experiments in which participants were given the results of fecal contamination tests all found that this intervention increased water treatment behavior (Jalan and Somanathan 2008; Luoto, Levine and Albert 2011; Brown 2017; Trent et al. 2018), either compared to no information or general recommendations about water treatment. The three of these papers that reported the impact of providing test results to households whose water was safe did not find a significant change in treatment behavior for this sub-group, indicating no downside to providing this information.

Also in the context of water safety, Bennear et al. (2013) tested the effectiveness of different messages communicating the arsenic contamination status of well water. The authors find that providing continuous information on arsenic levels does not increase the probability of switching to a safer source relative to binary safety information, and may even reduce switching behavior.

We contribute directly to the smaller body of research on consumer demand for safe food. Hoffmann, Moser, and Saak (2019), reviewing the literature in this field, find that while studies eliciting willingness to pay (WTP) for certified safe food often show that consumers are willing to pay a large premium for safety, WTP is almost always measured immediately after focusing participants' attention on this attribute. One exception is a recent study that evaluated the impact of a randomized marketing intervention emphasizing food safety on sales of safety-labeled maize flour (Hoffmann, Moser, et al. 2020). While the marketing intervention initially had a positive impact on sales of the target flour brand, this was not sustained beyond six weeks. Unlike most of the existing studies that measure the effect of food safety claims immediately after focusing consumers' attention to food safety, this chapter measures the effect of information nine weeks after the information was delivered. 
In contrast to the study by Hoffmann, Moser, and Herrman, which evaluated the effect of a marketing campaign that drew consumers' attention to a firm's aflatoxin testing claim, we consider the impact of information on the relative safety of particular brands provided by a third party. This information was based on results from previously published research and was not associated with any firm's marketing efforts. Further, we test the impact of consumer-specific information: the results of a rapid aflatoxin test conducted on the maize flour currently stocked by the household. Further, our design allows us to evaluate the effect of information on individual consumer behavior, which implies greater statistical power compared to the study by Hoffmann, Moser, and Herrman that measure the effect at the shop level.

Previous work in Kenya indicates that consumers may be willing to pay for aflatoxin-safe foods. Two framed field experiments show a high willingness to pay for safe maize among rural consumers in disparate regions of the country (Hoffmann and Gatobu 2014; De Groote et al. 2016). However, in both of these studies, the context surrounding consumers' choices were highly artificial: cash and information about food safety were provided immediately before the elicitation of bids for aflatoxin-safe and unlabeled maize. The current study examines the impact of food safety information on consumer choice in a natural setting, nine weeks after the information was provided. Also, our study is the first to our knowledge that estimates the effect of information on households' hazard exposure on food choice.

\subsection{Study context}

\subsubsection{Aflatoxin in Kenya}

The food safety hazard on which we provided information is contamination with the fungal toxin aflatoxin. Aflatoxin contaminates a variety of agricultural products and is most prevalent in maize 
and groundnut. Consumption of foods with very high levels of aflatoxin can result in acute and sometimes fatal poisoning, multiple outbreaks of which have occurred in the study region (Lewis et al. 2005). Chronic exposure is known to cause liver cancer (Wu et al. 2013) and is suspected of inhibiting immune system function (Wild \& Gong 2009). Further, exposure to aflatoxin in utero and during early childhood has been associated with low birth weight (Shuaib et al. 2010) and childhood stunting (Turner et al. 2007; Shirima et al. 2015; Hoffmann et al. 2018).

Like many food safety hazards, aflatoxin contamination can only be detected through a specialized test. The Government of Kenya has set a regulatory limit for aflatoxin of 10 parts per billion (ppb) in grains. A study based on data collected in 2013 found that $26 \%$ of branded maize flour samples collected in Eastern Kenya had aflatoxin levels higher than this limit (Hoffmann \& Moser 2017). The proportion of samples testing above $10 \mathrm{ppb}$ varied by brand and was significantly negatively associated with the mean price of the brand, with the lowest-priced brand 25 percentage points more likely to contain aflatoxin above the limit than the highest priced brand in the sample. In a separate study for which data was collected in the same region in $2010,37 \%$ of samples of flour from local hammer mills (to which consumers typically bring maize grain they have grown themselves or purchased) were found to contain levels above the regulatory limit (Mutiga et al. 2014).

\subsubsection{The Kenyan maize flour market}

Maize is the primary staple food in Kenya, accounting for $42 \%$ of dietary energy intake (Kilimo Trust 2017), and is consumed either as grain or flour. Grain may be produced by consumers or purchased from the informal market and is especially popular among rural consumers. Flour is of 
two types: more refined sifted flour processed in larger-scale roller mills, and less refined or wholegrain flour processed from whole grain in micro-scale hammer mills.

There are over 100 large-scale roller millers in Kenya; relatively few of these dominate the Nairobi market, and as of 2011 four firms accounted for $80 \%$ of sifted flour sales there (Kirimi et al. 2011). However, market concentration tends to be lower in rural areas, where regional millers offering maize at relatively low price points command significant market share. Prices vary widely across brands: in 2013 the difference between the highest and the lowest priced brand in various towns of Central and Eastern Kenya was 27 KES per kg, slightly more than half the price of the lowest-priced brand (Hoffmann \& Moser 2017).

Hammer mills ("posho mills") produce two types of flour, semi-refined (de-hulled) flour and whole-grain (non-refined) flour. Most of these mills only provide the milling service and therefore do not purchase any grain. Consumers take maize they have produced or purchased as grain from the informal grain market to be milled. This flour is unbranded, and the source of maize may not be easy to trace, except for the case of own produced maize. As a result, this type of flour is much cheaper than the sifted flour and is popular among rural consumers and the urban poor (Muyanga et al. 2005).

\subsection{Study design}

\subsubsection{Population and sample}

The study was carried out in Meru town, a county capital located in eastern Kenya, a global hotspot of aflatoxin contamination. A list of all adjoining urban locations, sublocations, and villages - the lowest administrative unit in Kenya - was generated with the help of an officer from the Kenya 
National Bureau of Statistics based in Meru County. ${ }^{4}$ Four locations, with a total of 10 sublocations and 64 villages (neighborhoods within the town), were identified. Villages are divided into clusters of houses or apartment buildings, from which a maximum of one household was randomly selected. In this way, a total of 1,000 households were selected to form the study sample.

\subsubsection{Experimental design}

Study participants were recruited during household visits conducted in August and September 2018. Assignment to one of three possible treatment groups, general information $(\mathrm{C}, 16.7 \%$ of those approached), safer brands (T1, 16.7\%), or safer brands plus testing (T2, 66\%), was determined using the Stata software package prior to recruitment. A larger number of households were included in the final group as testing was only expected to have an impact when the result showed contamination above the regulatory limit. Based on a previous study of branded maize flour in the region, a quarter of samples were expected to exceed the limit, implying that $16.7 \%$ of households were expected to receive information that would affect their behavior.

To ensure that, if indicated by treatment assignment, it would be possible to test households' flour, only those with maize flour in the home at the time of the baseline interview are included in the sample analyzed below.

The baseline interview was conducted during the recruitment visit, and covered household characteristics, maize flour consumption, and aflatoxin knowledge and risk awareness. After the survey was completed, a script containing general information about aflatoxin and the negative

\footnotetext{
${ }^{4}$ A location is the third-level administrative unit in Kenya, below the county and sub county. Locations are subdivided into sublocations, which are in turn subdivided into villages.
} 
health consequences of dietary exposure was read to all participants. In addition to this general information, households assigned to the safer brands information treatment (T1) were told about two brands previously found to be relatively unlikely to exceed the Kenyan limit for allowable aflatoxin contamination, and about the negative correlation between price and contamination (Hoffmann and Moser 2017). Scripts for both treatments are included in Appendix 2.1. To avoid affecting consent or survey responses, recruitment and survey protocols were identical across groups until the end of the interview.

For those households further assigned to be offered aflatoxin testing of the maize flour they had in their home (T2), a binary test, the Romer AgraStrip Total Aflatoxin Test, was used to test for aflatoxin. This test takes 10-15 minutes, and the results can easily be read visually. Study participants were invited to observe as the test was conducted, and its result and interpretation were shared immediately upon completion. In case the test showed a positive result, the participant was advised to bury the contaminated flour and cover it in lime or dispose of it in a pit latrine. The participant was further given KES $150^{5}$ (approximately USD 1.40) to replace the contaminated flour.

Follow up data was collected in November 2018, nine weeks after baseline data collection and the information intervention. The primary outcomes analyzed are the consumption of one of the safer brands mentioned in the scripts read to participants assigned to $\mathrm{T} 1$ and $\mathrm{T} 2$, and the price of maize flour consumed.

${ }^{5}$ This is worth $2 \mathrm{~kg}$ of the premium brand (one of the expensive safer brands). 


\subsubsection{Data}

Of 1,000 households approached to participate in the study, 21 declined, and of the remaining 979, 819 currently had maize flour in their homes which could be tested. We restrict our analysis to

this group, for whom testing was feasible in case this was required based on the experimental treatment assignment. Of the 819 households in the sample, 132 were randomly assigned to the comparison group, 137 to T1 (safer brands information), and 550 to T2 (safer brands plus testing information).

All of the households assigned to the comparison and safe brands information treatment group (T1) were included in the sample for follow-up. However, only a subset of households in the safer brands plus testing group (T2) were followed up. This included all of the households whose flour had tested above the regulatory threshold for aflatoxin contamination (54 households) and a randomly selected subsample of the households whose flour had tested below this (215 households). The latter accounted for $44 \%$ of the 484 households that received a negative test result. Other households with a negative test result were excluded from the follow-up sample due to budgetary constraints, and because adding households with a negative test result did not offer significant benefits in terms of power. To account for this sampling design, we weight observations by the inverse probability of assignment to being followed up in the analysis below (1/0.44 for T2 households with a negative test result and 1 for all other households). Twelve households who refused to have their flour tested at baseline were not followed up for a second interview. We test for the robustness of our results to any bias arising from this oversight through a Manski bounds approach (Horowitz and Manski 2000). The number of observations by treatment group and test result is shown in Table 2.1. 


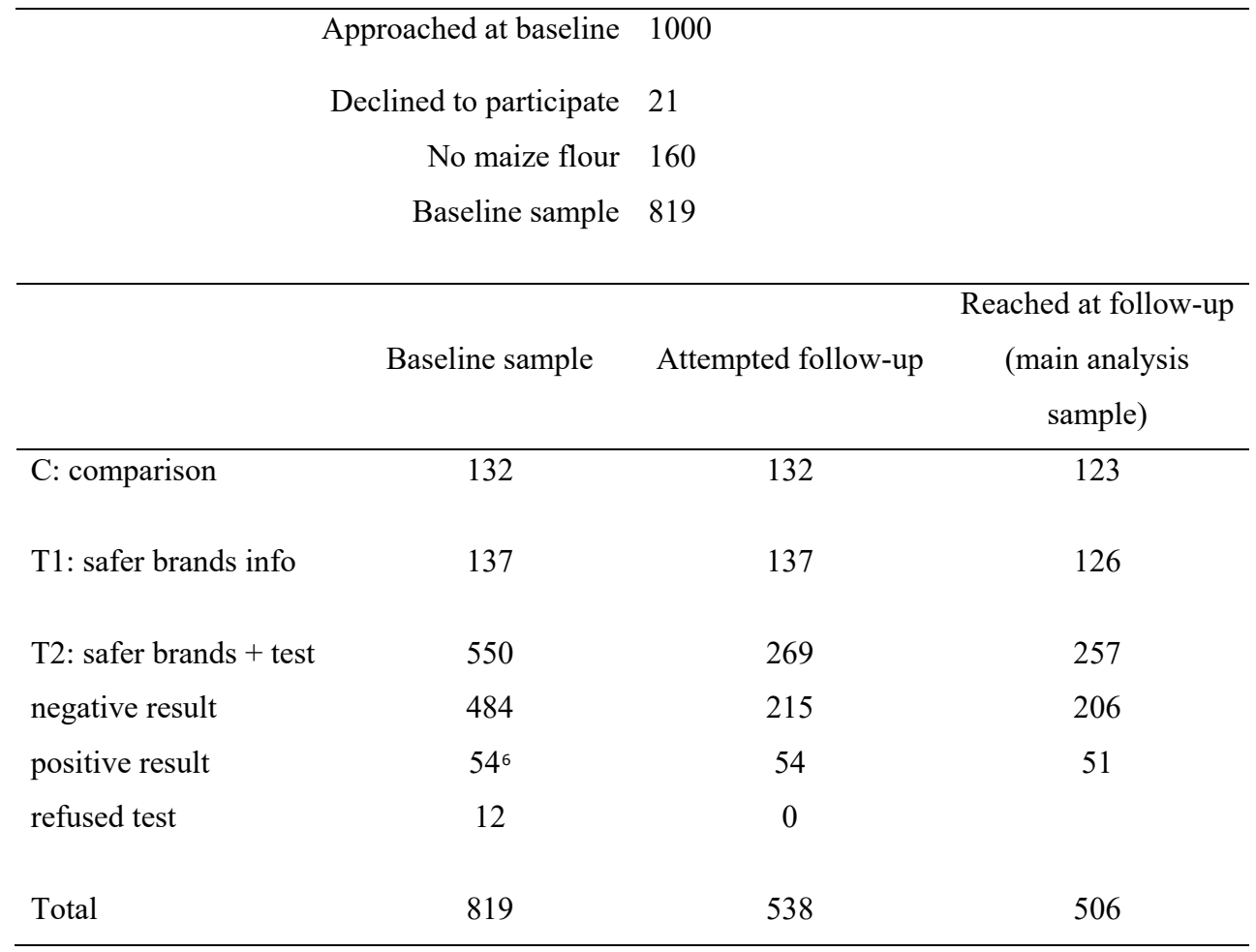

\subsubsection{Descriptive statistics and balance checks}

In this section, we briefly describe key features of the choice environment and sample, and test for balance on baseline characteristics across treatment groups.

Table 2.2 presents descriptive statistics on the proportion of study households consuming each type of flour at baseline, median prices per $\mathrm{KG}$, and the proportion of samples of each type found

\footnotetext{
${ }^{6}$ The proportion that tested above the limit (positive result) is less than what was expected (25\% as reported in Hoffmann and Moser study). This discrepancy could be explained by the fact that aflatoxin contamination varies by season.
} 
to contain aflatoxin above the regulatory limit of $10 \mathrm{ppb}$. As shown in column 1 of the table, most households (83\%) were consuming sifted (packaged) flour at baseline. Of these, only 9\% were consuming either of the two safer brands. Six percent consumed Brand 1, for which the median price of $52 \mathrm{KSh}$ was close to the overall median price of sifted flour (51 KSh) (column 3), while $3 \%$ consumed Brand 2, a premium brand with a median price of $73 \mathrm{KSh}$ per KG.

Nineteen percent of study households were consuming flour processed by small-scale hammer ("posho") mills. This included maize the consumers had produced themselves (15\%) or purchased as whole grains and brought to the mill (3.8\%), and that which had been pre-milled at the posho mill and then purchased (0.4\%). Posho-milled flour made from purchased grain was far less expensive than sifted flour, at a median price of $31 \mathrm{KES}$ per kg including the cost of milling. We do not report prices for own-produced posho-milled since we do not have data on maize sales prices or production costs.

Column 5 of Table 2.2 shows the proportion of samples of each type of flour tested that were found to contain aflatoxin above the $10 \mathrm{ppb}$ Kenyan regulatory limit. None of the samples of either safer brands had aflatoxin levels higher than $10 \mathrm{ppb}$, and $7 \%$ of other packaged brands had levels higher than $10 \mathrm{ppb}$. Among flour samples that had been ground at a posho mill, 28\% tested above the aflatoxin standard, with the rate equal between home-produced and purchased maize. The higher level of contamination in posho flour may be due to the fact that the study was conducted in one of the highest aflatoxin risk counties in Kenya, whereas much of commercially milled maize is grown elsewhere in the country where maize yields are higher and aflatoxin is lower. Further, as aflatoxin tends to be concentrated in the hull of the grain, sifted flour is partially decontaminated through the removal of the maize hull. 
Table 2.2. Baseline Consumption, Median Price, and Aflatoxin Contamination, by Flour Type

\begin{tabular}{|c|c|c|c|c|c|}
\hline & 1 & 2 & 3 & 4 & 5 \\
\hline Type of flour & $\begin{array}{c}\text { Proportion } \\
\text { of initial } \\
\text { sample } \\
\text { observed to } \\
\text { consume } \\
\text { flour type }\end{array}$ & $\mathrm{N}$ & $\begin{array}{c}\text { Median } \\
\text { price per } \\
\text { flour } \\
\text { type/brand } \\
\text { (KES per } \\
\text { kg) }\end{array}$ & $\begin{array}{c}\text { Number } \\
\text { of } \\
\text { samples } \\
\text { tested }\end{array}$ & $\begin{array}{l}\text { Proportion } \\
\text { with } \\
\text { aflatoxin } \\
\text { level higher } \\
\text { than } 10 \mathrm{ppb}\end{array}$ \\
\hline Safer brand 1 & 0.06 & 52 & 52 & 27 & 0.00 \\
\hline Safer brand 2 & 0.03 & 26 & 73 & 17 & 0.00 \\
\hline Other sifted brands & 0.74 & 604 & 51 & 394 & 0.07 \\
\hline Own produced grain, posho-milled & 0.15 & 125 & $\mathrm{n} / \mathrm{a}$ & 71 & 0.28 \\
\hline Purchased, posho-milled & 0.04 & 34 & 31 & 29 & 0.28 \\
\hline Total & & 841 & & 538 & 0.10 \\
\hline
\end{tabular}

Notes: Some households had more than one brand hence the total value in column 2 exceeds the number of households (819). The price of own produced maize is omitted since we do not have sufficient data to calculate the value of own produced maize.

Next, we present descriptive statistics for the households in the sample. Column 1 of Table 2.3 presents means for the entire sample for which follow-up was attempted plus the 12 households that refused to have the test and were not followed up ${ }^{7}$. Means for each treatment group are presented in columns 2, 3, and 4. Variable definitions are included in Appendix 2.2.

Responses to two statements are used to assess participants' awareness about variation in aflatoxin safety across brands at baseline: (a) any packaged maize flour available at the shop must be safe (which is false), and (b) some brands of packaged flour have higher levels of aflatoxin

\footnotetext{
${ }^{7}$ We address the issue of the 12 households that were not followed up in the attrition section
} 
contamination than others (which is true). Thirty-nine percent of participants stated that any packaged maize flour is safe, while just over half (54\%) knew that some brands are safer than others. The knowledge that the two brands mentioned in the script are relatively low in aflatoxin was also tested; $14 \%$ of respondents identified one of these brands as less likely than other brands to be contaminated.

The average age of participants was 43 years, with an average of 10 years of formal education. In just under half of the cases, the study participant was the head of the household.

Indices of aflatoxin knowledge, household wealth level, respondents' general and institutional trust, and impatience were constructed; details of these are provided in Appendix 2.2. The aflatoxin knowledge index was constructed based on a set of questions about the definition of the contaminant and the health effects associated with it. Awareness of aflatoxin was high: $70 \%$ of participants said they had previously heard of aflatoxin, 59\% were able to define it correctly, and $75 \%$, including those who initially said they had not heard of the toxin, could name at least one health effect of exposure. ${ }^{8}$

Respondents had low levels of both general trust, with an average of 0.32 out of a maximum score of 2 based on their assessment of the statement "most people can be trusted". Institutional trust related to food safety practices by food processors and enforcement by the government was an average of 1.65 out of a maximum of 4 .

We report p-values of tests of equality of means for each treatment group versus the comparison group and between the two treatment groups. Three out of 45 tests ( 3 comparisons for

\footnotetext{
${ }^{8}$ Respondents who had not heard of aflatoxin were read the following statement before being asked to describe the health effects of exposure: "Aflatoxin is a poison that is produced by mold on maize and other crops".
} 
each of 15 respondent and household characteristics) show a difference significant at the $\mathrm{p}<0.05$ level. In addition to the tests of each baseline covariate, we test for the joint significance of all the covariates. We follow a non-parametric approach described in (Hansen and Bowers 2008), which assesses balance on all the covariates jointly including all linear combinations of the covariates. The result is a single test statistic with a chi-square distribution. The comparison between each of the treatment groups (T1 and T2) with the comparison group, and with each other, yield p-values of $0.324,0.206$, and 0.459 respectively. Both approaches indicate that randomization was effective.

Households assigned to T2 can further be divided into two groups depending on the test result. While the test result is not random, and we do not expect balance on baseline variables for these two subgroups, we find it interesting to compare each of these groups with one another and with the comparison group. Results are shown in the Appendix Table A2.1 and show that households with a negative test result were on average wealthier, more educated, had higher levels of aflatoxin knowledge, and were less likely to be represented in the survey by the household head, compared to those whose maize was found to be contaminated. Relative to comparison group households, those with maize above the allowable aflatoxin level differed in terms of the type of maize consumed, while heads of households with negative test results were less likely to have been interviewed.

In addition to the respondent and household characteristics discussed above, Table 2.3 includes balance tests for the proportion of households that were randomly selected to be administered an additional qualitative interview to assess the respondents' perceptions of the attributes of flour they normally consume. Previous work has shown that baseline interviews may 
influence subsequent behavior (Zwane et al. 2014). As all participants were interviewed at baseline, we are only able to control for the effect of this additional qualitative interview 


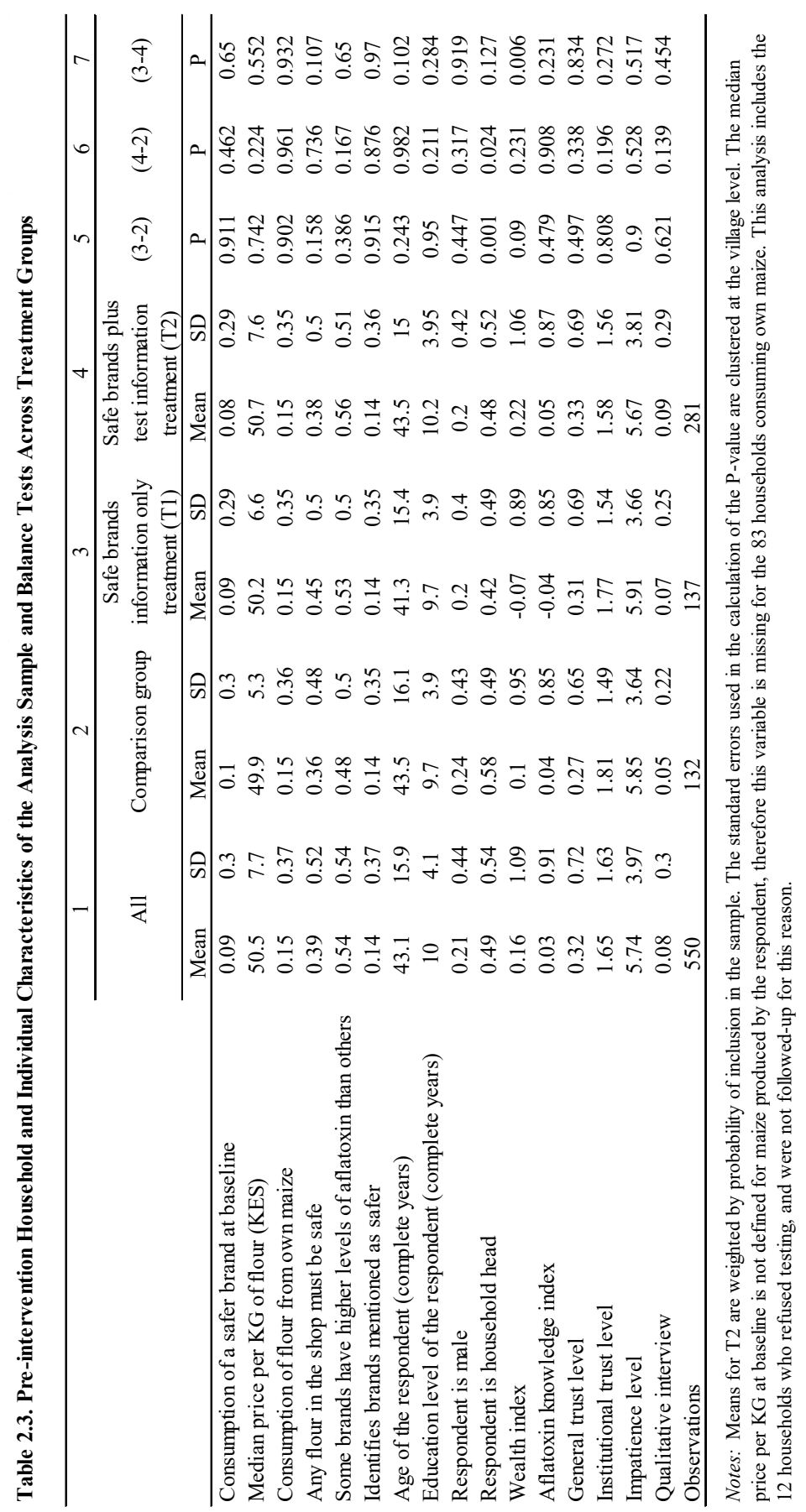




\subsubsection{Attrition}

The overall attrition rate between enrollment and follow-up two months later was $8 \%$. This is driven primarily by the survey team failing to find respondents in their homes during the followup survey. Attrition was lowest in the safer brands plus test information group at $6.4 \%$, and highest in the safer brands information only group (T1), at 8.0\%. As shown in Appendix Table A2.2, differences in attrition across treatment groups are not statistically significant. However, exclusion of the 12 respondents who refused to have their maize tested at baseline from follow-up data collection implies that attrition within T2 was non-random. Further, attritors differ from nonattritors on other observables characteristics, namely age, aflatoxin knowledge, and beliefs regarding the heterogeneity of aflatoxin contamination in branded flour. We include in the appendix Manski bounds on the experimental treatment effects to account for the excluded participants. In the estimated bounds, we address other aspects of non-random attrition by weighting observations by the inverse probability of being observed at follow-up.

\subsection{Empirical strategy}

\subsubsection{Main outcomes}

Data collected during the follow-up survey was used to generate the two primary outcome variables: consumption of a safer ${ }^{9}$ brand at follow-up and the price of flour consumed at followup. Consumption of a safer brand is measured as a binary variable indicating whether the flour consumed by the household at follow-up was one of the two brands described as relatively safer in the information script. This is based on direct observation of the flour held by the household if possible, but if there was no flour in the house, as was the case for $23 \%$ of households, respondents

\footnotetext{
${ }^{9}$ We refer to the two brands as "safer" to denote that they are safer relative to other brands
} 
were asked about the type of flour they had purchased most recently. We include in our analysis a specification in which the sample is restricted to those who had flour in their homes at follow-up, and whose flour choice was thus directly observed.

For the price of flour consumed at follow-up, we use the median price per kg of that brand or type as reported by households in the follow-up sample due to significant measurement error observed in the price data. The accuracy of the reported price may depend on whether the respondent is normally the one responsible for maize flour purchases.

To estimate treatment effects on each outcome of interest, we estimate Equation (2.1),

$$
y_{i 1}=\alpha_{1}+\beta_{2} \cdot T 1_{i}+\beta_{3} \cdot T 2_{i}+\beta_{4} \cdot y_{i 0}+\beta_{5} \cdot Q_{i}+\beta_{6} \cdot X_{i}+\varepsilon_{1 i}
$$

where $y_{i 1}$ is the outcome variable for household $i$ at follow-up, $T 1_{i}$ is an indicator of assignment to the safer brands information treatment, $T 2_{i}$ is an indicator of assignment to the safer brands information plus test treatment, $y_{i 0}$ is the outcome variable at baseline, $Q_{i}$ indicates that the respondent participated in the qualitative interview, $X_{i}$ is the set of baseline controls for household $i$, and $\varepsilon_{1 i}$ is the error term. Standard errors are clustered at the village level to account for potential spatial correlation in outcomes.

As randomization was successful, we present as our primary specification the version of Equation (2.1) that omits baseline respondent household characteristics. Treatment effects from equations in the variables shown in Table 2.3 are included are shown in Appendix Table A2.3. ${ }^{10}$

Additionally, we provide descriptive results on how outcomes differ depending on the result of the aflatoxin test result. These differences are estimated using Equation (2.2),

\footnotetext{
${ }^{10}$ For the baseline price control, we replace the missing observations (for those consuming flour from own maize) with the median price and add a dummy equal to 1 for the missing observations.
} 


$$
y_{i}=\alpha_{2}+\beta_{7} \cdot T 1_{i}+\beta_{8} \cdot T 2 P_{i}+\beta_{9} \cdot T 2 N_{i}+\beta_{10} \cdot y_{i 0}+\beta_{11} \cdot Q_{i}+\beta_{12} \cdot X_{i}+\varepsilon_{2 i}
$$

in which $T 2 P_{i}$ indicates that the household's flour tested above the Kenyan aflatoxin standard, $T 2 N_{i}$ indicates a test result showing contamination below this threshold, and other variables are as defined above. Test results are not random, and as noted above, the households that received a positive test result differed significantly at baseline both from control households and from those who received a negative test result. Therefore, we only estimate Equation (2.2) with the full set of baseline controls included, and caution that $\beta_{8}$ and $\beta_{9}$ capture the influence of any unobserved differences across sub-groups in addition to the impact of receiving a positive or negative test result, respectively.

\subsubsection{Mechanisms}

Information on the safest brands and on personal exposure to risk is expected to affect consumers' choice of maize flour and spending per unit of flour through two complementary mechanisms: first, awareness that aflatoxin safety systematically varies across brands and knowledge of which brands are safer than others, and second, the importance assigned to aflatoxin safety when choosing among alternative flours.

To test whether our information treatments affect consumer behavior through these mechanisms, we estimate Equations (2.1) and (2.2) using three outcomes: awareness regarding the variation of safety across brands (which we refer to as risk awareness), a dummy variable indicating whether the respondent can identify either of the two safer brands mentioned in the information script and an indicator of whether aflatoxin safety is considered in the choice of flour consumed at follow-up. 
The risk awareness index is constructed from respondents' reactions to the following three statements: (a) any packaged maize flour available at the shop must be safe (false), (b) some brands of packaged flour have higher levels of aflatoxin contamination than others (true), and (c) more expensive brands have a lower chance of being contaminated with aflatoxin compared to cheaper brands. Each answer is assigned a value ranging from 0 to 4 , based on a five-point Likert response ranging from strongly agree to strongly disagree. A response of strongly agree in the accurate answer is assigned a value of 4 , while the same response in the incorrect answer is assigned a value of 0 . The index, therefore, ranges from 0 to 12 , where 12 indicates the highest awareness level and 0 indicates the lowest awareness level.

Lastly, we note that the safer brands plus testing treatment can also influence consumers' behavior (flour choice and expenditure) through the extra salience due to the act of carrying out the test at the consumer's house and not through the additional information provided by the test. While our design ${ }^{11}$ does not allow us to explicitly test the channel through which this treatment affects consumer behavior, our results on these mechanism variables may shed some light on this issue.

\subsection{Results}

\subsubsection{Flour type consumed by treatment group and test result}

We begin the presentation of results with a graphical depiction of flour consumption at baseline and follow-up. As shown in figure 2.1, we do not observe any apparent changes among households

\footnotetext{
${ }^{11}$ To test this, we needed to conduct aflatoxin test to all the households in the treatments but share the results of the test during follow-up. Doing so may raise ethical concerns especially for households whose flour test positive.
} 
in the comparison group relative to their baseline levels. Similarly, we note only a slight increase (not statistically significant) in the proportion consuming a safer brand among households assigned to the safer brands information treatment (T1). A larger increase in the proportion consuming a safer brand is apparent for households in the safer brands plus testing treatment (T2).
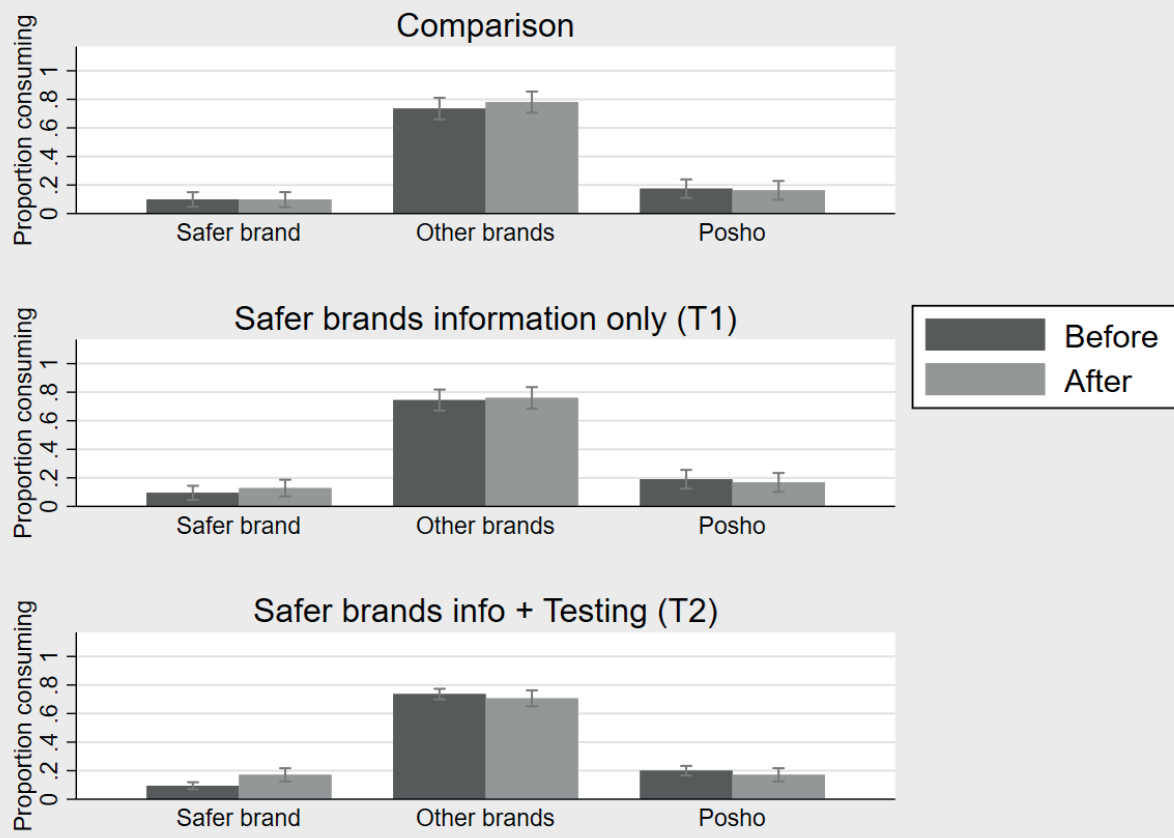

Figure 2.1. The proportion of households consuming each type of flour before and after the intervention, by treatment group (weighted by the probability of inclusion)

Disaggregating households in the testing group by test result, we see in figure 2.2 that the increase in consumption of a safer brand between baseline and follow-up is greater for households that received a positive test result (above $10 \mathrm{ppb}$ ) compared to those that received a negative result (10 ppb or below). This increase corresponds to a dramatic decline in the proportion of households 
who consumed posho flour, the category most likely to be contaminated above the regulatory limit, after receiving a positive result.
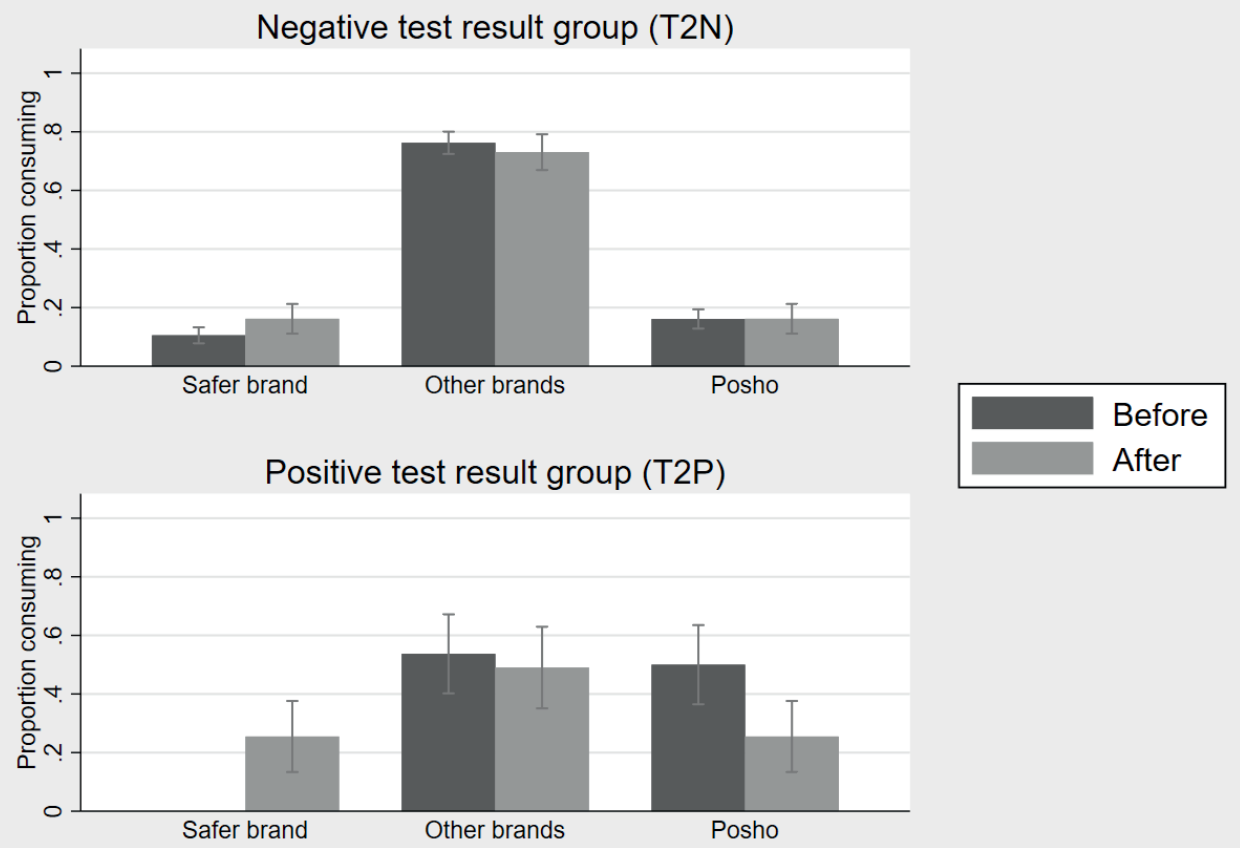

Figure 2.2. The proportion of households consuming each type of flour before and after the intervention, by test result

\subsubsection{Impact of information on product choice}

Turning to the formal analysis of treatment effects on flour choice, Table 2.4 shows the impact of information on the two primary outcomes: consumption of a safer brand and the price of the brand consumed at follow-up. In panel A, we show treatment effects as estimated through Equation (2.1). 
Panel B shows results of Equation (2.2), in which outcomes for T2 households are split by the test result.

Columns 1 and 2 within Panel A show treatment effects on the likelihood of consuming a safer brand at follow-up. The safer brands information only treatment, T1 on the likelihood of consuming a safer brand is not statistically distinguishable from zero. However, households whose flour was tested (T2) were 8.5 percentage points more likely than comparison group households to be consuming a safer brand at follow-up, an $87 \%$ increase relative to the comparison mean. The estimated effect is similar in the sample restricted to households whose flour could be observed. For this sub-group, which avoids potential reporting bias introduced through the implicit recommendation to consume a safer brand, the difference between $\mathrm{T} 1$ and $\mathrm{T} 2$ treatment effects is marginally significant at $\mathrm{p}=0.075$.

Households that received a positive test result were especially likely to be consuming a safer brand at follow-up, at 22 percentage points, or over three times, above comparison households (columns 1 and 2, Table 2.4, Panel B). Consumption of safer flour at follow-up among these households is also significantly higher than both those assigned to receive only safer brands information (T1), and those who received a negative test result. While these differences cannot be interpreted as experimental effects, it is worth noting that at baseline, households with positive test results were far less likely to be consuming one of the safer brands. Consumption of a safer flour brand is also slightly higher than comparison households (at $\mathrm{p}<0.1)$ among those who received a negative test result, though this may be a result of pre-existing differences across these groups.

Treatment effects on the median price of the brand consumed at follow-up are shown in Panel A of column 3 in Table 2.4. For households given information alone (T1) this is positive but not statistically different from 0 . The effect on those provided information plus testing (T2) is positive 
and weakly statistically significant $(\mathrm{p}=0.070)$ : households in this treatment group were consuming maize flour that cost an average of $1.23 \mathrm{KSh}(2.5 \%)$ more per $\mathrm{KG}$ than those in the comparison group. Treatment effects on the median price paid for maize flour are not statistically distinguishable between $\mathrm{T} 1$ and $\mathrm{T} 2$.

Disaggregating T2 by test result, the greatest difference in expenditure on maize flour per KG is between comparison households and those with a positive test result, though this is imprecisely estimated due to the smaller number of households in this group. The difference against comparison households is smaller, but still statistically significant at $\mathrm{p}<0.1$, for the larger group of households whose flour tested below the aflatoxin standard at baseline. Similar to the difference in consumption of safer flour discussed above, this could be a result of pre-existing preferences for higher-priced flour among those whose flour tested negative.

Treatment effects from specifications in which all baseline controls described in Table 2.3 are included are presented in Appendix Table A2.3; these are very similar to those shown here. 
Table 2.4. Impact of Information Treatment on the Consumption of a Safer Brand and the Price per KG of Maize Flour

\begin{tabular}{|c|c|c|c|}
\hline & 1 & 2 & 3 \\
\hline & $\begin{array}{l}\text { Consumes a } \\
\text { safer brand }\end{array}$ & $\begin{array}{l}\text { Consumes a safer } \\
\text { brand }\end{array}$ & $\begin{array}{l}\text { Median price per kg } \\
\text { of flour consumed }\end{array}$ \\
\hline \multicolumn{4}{|l|}{ Panel $A$} \\
\hline $\begin{array}{l}\text { Safe brands information only } \\
\text { (T1) }\end{array}$ & $\begin{array}{c}0.036 \\
(0.036)\end{array}$ & $\begin{array}{c}0.033 \\
(0.041)\end{array}$ & $\begin{array}{c}0.925 \\
(0.745)\end{array}$ \\
\hline $\begin{array}{l}\text { Safe brands info plus testing } \\
\text { (T2) }\end{array}$ & $\begin{array}{l}0.085 * * \\
(0.035)\end{array}$ & $\begin{array}{l}0.101 * * \\
(0.045)\end{array}$ & $\begin{array}{l}1.228 * \\
(0.665)\end{array}$ \\
\hline $\mathrm{T} 1=\mathrm{T} 2: \mathrm{P}$-value & 0.114 & 0.075 & 0.654 \\
\hline Observations & 503 & 389 & 432 \\
\hline \multicolumn{4}{|l|}{ Panel B } \\
\hline Negative test result group (T2N) & $\begin{array}{l}0.056^{*} \\
(0.033)\end{array}$ & $\begin{array}{l}0.072 * \\
(0.042)\end{array}$ & $\begin{array}{l}1.148 * \\
(0.659)\end{array}$ \\
\hline Positive test result group (T2P) & $\begin{array}{l}0.216 * * * \\
(0.065)\end{array}$ & $\begin{array}{l}0.218 * * \\
(0.090)\end{array}$ & $\begin{array}{c}2.124 \\
(1.455)\end{array}$ \\
\hline $\mathrm{T} 1=\mathrm{T} 2 \mathrm{~N}: \mathrm{P}$-value & 0.690 & 0.548 & 0.993 \\
\hline $\mathrm{T} 1=\mathrm{T} 2 \mathrm{P}: \mathrm{P}$-value & 0.005 & 0.038 & 0.452 \\
\hline $\mathrm{T} 2 \mathrm{~N}=\mathrm{T} 2 \mathrm{P}: \mathrm{P}$-value & 0.014 & 0.114 & 0.473 \\
\hline Observations & 503 & 389 & 432 \\
\hline Additional sample restrictions & & $\begin{array}{l}\text { Had flour at } \\
\text { follow-up }\end{array}$ & \\
\hline Comparison group mean & 0.098 & 0.117 & 48.24 \\
\hline $\begin{array}{l}\text { Notes: Standard errors cluster } \\
\text { p }<0.01 \text {. Panel A shows results fron } \\
\text { assignment to the two experimenta } \\
\text { on the test result, a negative test re } \\
\text { result group for the households wl } \\
\text { the inverse probability of rand } \\
\text { specifications include the outcome } \\
\text { baseline respondent participated } \\
\text { include respondent and household } \\
\text { indicator. }\end{array}$ & $\begin{array}{l}\text { at the village } \\
\text { a regression of } \\
\text { treatments. In } \\
\text { lt group whos } \\
\text { se flour testec } \\
\text { nly determine } \\
\text { ariable measu } \\
\text { a qualitative } \\
\text { haracteristics }\end{array}$ & $\begin{array}{l}\text { vel in parentheses. * } \\
\text { ch of the outcome } v \\
\text { anel } \mathrm{B}, \mathrm{T} 2 \text { is divide } \\
\text { lour tested below } 10 \\
\text { bove } 10 \mathrm{ppb} \text {. Obser } \\
\text { inclusion in the } \\
\text { at baseline and an i } \\
\text { erview. Estimations } \\
\text { scribed in Table } 2 .\end{array}$ & $\begin{array}{l}<0.10, * * \mathrm{p}<0.05, * * * \\
\text { iables on indicators of } \\
\text { into two groups based } \\
\mathrm{pb} \text {, and a positive test } \\
\text { tions are weighted by } \\
\text { llow-up sample. All } \\
\text { licator for whether the } \\
\text { hown in Panel B also } \\
\text { and the T1 treatment }\end{array}$ \\
\hline
\end{tabular}




\subsubsection{Mechanisms}

To shed light on the mechanisms behind the treatment effects on product choice described in the previous section, we next turn to three intermediate outcomes. These are the risk awareness index, identification of either of the two brands described in the experimental scripts as relatively safe, and whether aflatoxin safety is among the reasons for selecting the most commonly consumed brand.

Results in column 1 of Table 2.5 show that information has a significant effect on people's awareness of the heterogeneity of aflatoxin safety across maize flour brands. Households assigned to both $\mathrm{T} 1$ and $\mathrm{T} 2$ showed a higher level of awareness than those in the comparison group (Table 2.5, Panel A, column 1). The difference in the effect size of the two treatments on this outcome is small and not statistically significant.

Results in Panel B show that risk awareness was higher among households that received a positive test result (T2P) relative to those in the comparison group, those who had received information on safer brands without a test (T1), and those who had received a negative test result (T2N). While this result cannot be interpreted as strictly causal, it stands to reason that information about the relative aflatoxin safety of different maize flour brands would be more salient to households who were at the same time told the flour they are consuming is contaminated. It also suggests that the effects of $\mathrm{T} 2$ could be driven by the information on risk and not the extra salience due to the 'act of carrying out a test at the household'.

Households assigned to both T1 and T2 were more likely than comparison group households to correctly identify one of the two brands described as safer in the information script as less risky (Table 2.5, Panel A, column 2). As for the treatment effects on risk awareness, effects of T1 and $\mathrm{T} 2$ are statistically indistinguishable. 
Also similar to the awareness index, the proportion of households able to name one of these brands was higher among those who received positive test result (Table 2.5, Panel B, column 2), relative to both those with a negative test result, or assigned to either of the other experimental groups.

Finally, we see no impact of the safer brands information alone (T1) on the likelihood that aflatoxin safety was stated as a reason for selecting the brand most commonly consumed at followup. The testing treatment, however, had a significant impact on this outcome, and the effect is statistically distinguishable from that of $\mathrm{T} 1$ at $\mathrm{p}=0.055$. This result appears to be driven by the effect on those who received a positive test result, who are more likely than those in the comparison group, $\mathrm{T} 1$, or $\mathrm{T} 2 \mathrm{~N}$, to cite aflatoxin safety as a reason for their choice of flour.

Overall, these results indicate that while information alone is effective at increasing awareness about food safety risks and increasing knowledge of safer options, providing specific information on hazard exposure is critical for turning awareness and knowledge into action. 
Table 2.5. Impact of Information on Risk Awareness and Stated Reasons for the Preferred Flour Type at Follow-up

\begin{tabular}{|c|c|c|c|}
\hline & 1 & 2 & 3 \\
\hline & $\begin{array}{c}\text { Risk } \\
\text { Awareness }\end{array}$ & $\begin{array}{c}\text { Correctly names a } \\
\text { safer brand }\end{array}$ & $\begin{array}{l}\text { Aflatoxin saf } \\
\text { considered i } \\
\text { flour choic }\end{array}$ \\
\hline \multicolumn{4}{|l|}{ Panel $A$} \\
\hline \multirow[t]{2}{*}{ Safe brands information only (T1) } & $0.488^{*}$ & $0.195 * * *$ & 0.032 \\
\hline & $(0.254)$ & $(0.052)$ & $(0.025)$ \\
\hline \multirow[t]{2}{*}{ Safe brands info plus testing (T2) } & $0.588 * * *$ & $0.266 * * *$ & $0.097 * * *$ \\
\hline & $(0.188)$ & $(0.045)$ & $(0.026)$ \\
\hline $\mathrm{T} 1=\mathrm{T} 2: \mathrm{P}-$ value & 0.927 & 0.232 & 0.055 \\
\hline Observations & 506 & 506 & 506 \\
\hline \multicolumn{4}{|l|}{ Panel B } \\
\hline \multirow[t]{2}{*}{ Negative test result group (T2N) } & $0.493 * *$ & $0.243 * * *$ & $0.068 * * *$ \\
\hline & $(0.189)$ & $(0.045)$ & $(0.024)$ \\
\hline \multirow[t]{2}{*}{ Positive test result group (T2P) } & $1.179 * * *$ & $0.486 * * *$ & $0.224 * * *$ \\
\hline & $(0.330)$ & $(0.086)$ & $(0.059)$ \\
\hline $\mathrm{T} 1=\mathrm{T} 2 \mathrm{~N}: \mathrm{P}-\mathrm{value}$ & 0.773 & 0.485 & 0.161 \\
\hline $\mathrm{T} 1=\mathrm{T} 2 \mathrm{P}: \mathrm{P}$-value & 0.054 & 0.003 & 0.001 \\
\hline T2N=T2P: P-value & 0.023 & 0.006 & 0.009 \\
\hline Observations & 506 & 506 & 506 \\
\hline Mean of the comparison group & 7.374 & 0.171 & 0.024 \\
\hline
\end{tabular}

Notes: Standard errors clustered at the village level in parentheses. ${ }^{*} \mathrm{p}<0.10,{ }^{* *} \mathrm{p}<0.05,{ }^{* * *}$ $\mathrm{p}<0.01$. Panel A shows results from a regression of each of the intermediate outcome variables on indicators of assignment to the two experimental treatments. In Panel B, T2 is divided into two groups based on the test result, a negative test result group whose flour tested below $10 \mathrm{ppb}$ and a positive test result group for the households whose flour tested above $10 \mathrm{ppb}$. Observations are weighted by the inverse probability of randomly determined inclusion in the follow-up sample. All specifications include the outcome variable measured at baseline, and an indicator for whether the baseline respondent participated in a qualitative interview. Estimations shown in Panel B in addition include respondent and household characteristics described in Table 2.3 and the T1 treatment indicator. 


\subsubsection{Robustness to attrition}

In Appendix Table A2.4, we present Manski bounds on the effect of T2 to account for the 12 participants excluded from follow-up. These estimated bounds, as well as the T1 treatment effects shown in the same table, are estimated through regressions in which we weight the observations by the inverse probability of being observed at follow-up to account for other non-random drivers of attrition. Except for the effect on the amount spent per KG of maize flour, bounds on the T2 treatment effects are close to the point estimates shown above, and lower bounds remain statistically different from zero at $\mathrm{p}<0.05$. $\mathrm{T} 1$ treatment effects using the inverse probability weights are likewise similar to those reported above.

\subsubsection{Multiple hypotheses testing}

We test the role of two experimental treatments, $\mathrm{T} 1$ and $\mathrm{T} 2$, on five outcomes and test for the equality of effects of these two treatments. This implies a total of 15 hypothesis tests (considering only the specifications reported in Tables $2.4 \&$ Table 2.5 for all observations). Following Omotilewa et al. (2018) and Ksoll et al. (2016), we control for False Discovery Rate (FDR) using the two-step procedure proposed by Benjamini, Krieger, and Yekutieli (2006). Anderson (2008) describes an empirical application of the procedure and provides a Stata code, which we utilize. This method controls for the expected proportion of all rejections that are due to chance and provides q-values that are used to determine which tests remain significant after adjusting for multiple hypothesis tests. Results, presented in Appendix Table A2.5, indicate that the results remain significant at the same thresholds reported above after adjusting for the number of hypotheses tested. 


\subsubsection{Spillover effects}

Since randomization was conducted at the household level, it is possible that information was shared between households in different treatment groups, potentially leading to underestimation of treatment effects. To minimize such spillovers, only one household per cluster of houses (plot) or apartment building was selected. However, in the urban setting of our sample, plots and apartment buildings are quite close to one another. The average minimum distance between a comparison household and a treated household was $0.076 \mathrm{~km}$.

To determine the extent of spillover effects, we re-estimate Equation (2.1) for each outcome, but include a variable indicating the proportion of study households within a distance radius $d$ of 50,75 , or 100 meters, which were assigned to either T1 or T2. ${ }^{12}$ For cases in which there were no study households within this range, we include a dummy indicating this, and set the variable to zero otherwise. This proportion is interacted with an indicator of assignment to either T1 or T2. This enables estimation of spillover effects on control households specifically, while also allowing for directly treated households to be affected by the treatment of their neighbors.

As shown in Table 2.6., we do not find evidence of spillover effects on either of the primary outcomes. Including additional controls to account for potential spillovers results in a smaller estimated treatment effect of $\mathrm{T} 2$ on the median flour price, which is no longer significant for two of the three distance radii, but the effect size and significance of this treatment on the consumption of a safer brand is generally unaffected aside from a slight reduction in precision for $d=75 \mathrm{~m}$.

\footnotetext{
12 These distances are close to the $25^{\text {th }}$ percentile $(43 \mathrm{~m})$, mean $(76 \mathrm{~m})$ and $75^{\text {th }}$ percentile $(92 \mathrm{~m})$ of the minimum distance between comparison households and the nearest treated household.
} 
Table 2.6. Test for Potential Information Spillover Effects

\begin{tabular}{|c|c|c|c|c|c|c|}
\hline \multirow{7}{*}{ Distance radius $(d)$} & 1 & 2 & 3 & 4 & 5 & 6 \\
\hline & \multicolumn{2}{|c|}{50 Meters } & \multicolumn{2}{|c|}{75 Meters } & \multicolumn{2}{|c|}{100 Meters } \\
\hline & & & & Median & & Median \\
\hline & & Median & & price per & & price per \\
\hline & Consumes & price per & Consumes & $\mathrm{kg}$ of & Consumes & $\mathrm{kg}$ of \\
\hline & a safer & $\mathrm{kg}$ of flour & a safer & flour & a safer & flour \\
\hline & brand & consumed & brand & consumed & brand & consumed \\
\hline \multicolumn{7}{|l|}{ Safe brands } \\
\hline \multicolumn{7}{|l|}{ information only } \\
\hline \multirow[t]{2}{*}{ (T1) } & 0.030 & 0.351 & 0.020 & 0.444 & 0.033 & 0.634 \\
\hline & $(0.035)$ & $(0.768)$ & $(0.037)$ & $(0.747)$ & $(0.036)$ & $(0.711)$ \\
\hline \multicolumn{7}{|l|}{ Safe brands info } \\
\hline \multirow[t]{2}{*}{ plus testing (T2) } & $0.075 * *$ & 0.490 & $0.067 *$ & 0.718 & $0.084 * *$ & $0.995^{*}$ \\
\hline & $(0.031)$ & $(0.696)$ & $(0.035)$ & $(0.608)$ & $(0.036)$ & $(0.591)$ \\
\hline \multicolumn{7}{|l|}{ Proportion of $\mathrm{HH}$} \\
\hline \multicolumn{7}{|l|}{ within $d$ assigned } \\
\hline \multicolumn{7}{|l|}{ to either $\mathrm{T} 1$ or $\mathrm{T} 2$, } \\
\hline \multirow[t]{2}{*}{ PT } & 0.017 & 0.233 & 0.095 & -0.103 & 0.088 & -0.039 \\
\hline & $(0.102)$ & (1.293) & $(0.090)$ & $(1.021)$ & $(0.120)$ & $(1.125)$ \\
\hline \multicolumn{7}{|l|}{ Proportion PT $\mathrm{x}$} \\
\hline \multirow[t]{2}{*}{ Treatment } & 0.030 & 1.894 & 0.078 & 2.419 & 0.034 & 2.086 \\
\hline & $(0.077)$ & (1.171) & $(0.108)$ & $(1.792)$ & $(0.147)$ & $(2.117)$ \\
\hline $\mathrm{T} 1=\mathrm{T} 2: \mathrm{P}$-value & 0.152 & 0.829 & 0.138 & 0.665 & 0.109 & 0.573 \\
\hline Observations & 503 & 432 & 503 & 432 & 503 & 432 \\
\hline
\end{tabular}

Notes: Standard errors in parentheses clustered at the village level. $* \mathrm{p}<0.10, * * \mathrm{p}<0.05, * * *$ $\mathrm{p}<0.01$. Observations are weighted by the inverse probability of inclusion in the follow-up sample. All specifications include the outcome variable measured at baseline, and an indicator for whether the baseline respondent participated in a qualitative interview. 
While we do not find significant geographical spillovers for the primary outcomes, it is possible for spillovers to occur through social connections that may not be correlated with the geographical spillovers. Unfortunately, we do not have data to test for these. Existence of such social spillovers biases our results toward zero. However, given that we do not see evidence of geographical spillovers, the likelihood of other social spillovers does not seem high.

\subsection{Discussions and conclusions}

This chapter tests the role of information in stimulating demand for maize flour products less likely to contain unsafe levels of the common fungal contaminant, aflatoxin. Maize consumers in a county capital in Eastern Kenya were visited in their homes and given general information about aflatoxin, and the names of the two brands with the highest probability of meeting the Kenyan regulatory limit for aflatoxin in a previous study. A rapid test of maize flour stored in the home during this visit was conducted for a subset of households.

Providing information about the identity of safer brands led to an increase in both the awareness of the differences in aflatoxin safety across maize flour brands and in the proportion of consumers who identified these brands as safe. However, only households that were also provided with a test result showing the contamination of their flour were more likely to be consuming one of these brands, or spending more per KG on maize flour, relative to comparison households nine weeks later. We interpret these results as arising due to the greater significance of information about how to avoid a food safety hazard when one's exposure to the hazard is known.

Our results suggest that simply providing consumers information about which foods are safest is insufficient to substantially shift the demand for safer maize in Kenya. Providing additional information on an individual's personal exposure to risk appears to result in a behavioral change 
for a subset of consumers, approximately doubling the proportion who select a safer brand two months later. While this study provided individualized test results, providing brand- or vendorspecific information on the relative levels of contamination would be far less costly than the individual testing. However, whether the brand or vendor-specific risk information will have a similar effect with the individualized risk information studied in this Chapter is an open question that warrants further attention. However, evidence on the effect of providing household vs. sourcelevel information on water quality suggests that the effects of the two may be similar (Luoto, Levine and Albert 2011).

One potential challenge to giving consumers information about the relative riskiness of different products is that governments may be reluctant to communicate the true rate of noncompliance with food safety standards, as this exposes their failure to enforce these standards. A recent recall of several brands of maize flour elicited outrage among Kenyan consumers that the government had failed to ensure the safety of marketed (BBC News 2019). However, in the study context, the rate of non-compliance with Kenya's aflatoxin standard is far higher in unregulated, informally marketed flour than among the various brands of sifted flour produced by formal sector millers. Thus, the most important difference in contamination rates does not implicate the regulator. The government could also limit its communication about high-risk products to those for which the rate of non-compliance, or for which the level of a hazard observed is higher than the regulatory standard by a large margin. Mandatory product recalls could accompany the provision of information about high-risk brands.

We also note two risks inherent in this approach. The first is that consumers over-interpret the seriousness of the problem, and that this leads to widespread psychological stress. To mitigate undue alarm among consumers, it would be important to put the hazards observed into context. 
Due to the high share of maize in the diet, Kenya's aflatoxin standard is relatively strict, by global standards. Pointing out that much of the noncompliant maize would be acceptable for consumption in many developed countries, including the United States, Canada, and Australia, could ease consumer concerns, as could drawing attention to the relative impact of aflatoxin exposure on health compared to other commonly experienced health hazards such as diarrheal pathogens, malaria, and air pollution. This concern could also be mitigated by the strategy noted above, of limiting the declaration of 'high risk' to products that are well outside the compliant range.

A second risk of providing information on food safety in this market is distributional. Even without access to information on relative contamination levels, price is inversely correlated with aflatoxin contamination (Hoffmann and Moser 2017), and Kenyans of lower socio-economic status have higher dietary exposure to aflatoxin (Leroy, Wang, and Jones 2015). Providing information on which types of flour are most and least safe could strengthen the relationship between price and aflatoxin contamination, pushing safer food further out of reach of the most vulnerable. For this reason, any intervention to make food safety information available should be accompanied by efforts to improve food safety overall. 


\section{Appendices}

\section{Appendix 2.1. Information script}

\section{Instructions:}

This script shall be read to the different groups as follows:

1. Comparison: Section $A$ and $B$

2. Treatment 1: Section $A, B, \& C$

3. Treatment 2: Section $A, B, C \& D$ (ALL the sections)

\section{A. Introduction (read to ALL households)}

Hello, my name is $\{\quad\}$. I am here on behalf of a project that is being implemented by Wageningen University (in Netherlands) and International Food Policy and Research Institute (a research Organization based in the US). This is a research project, and its aim is to understand people's knowledge and perception of the issue of Aflatoxin contamination and help us understand how consumers can reduce their exposure to contaminated foods. So, I am going to explain to you what aflatoxin contamination is and the possible effects of consuming contaminated foods. Please feel free to ask a question at any point if you do not understand.

[Please pause and ask if there is a question]

B. Information on aflatoxin and its prevention (read to ALL households)

Aflatoxin is a poison produced by certain types of fungus that live in the soil and on dead decaying matter. It affects many crops, especially maize and groundnut. This includes maize products like maize flour, the grain itself, muthokoi etc. It is not possible to see from the outside whether a crop or a product is contaminated. Aflatoxin is harmful and affects human health when consumed. Some of the health effects associated with consumption of contaminated foods are:

i. It increases the risk of liver cancer 
ii. It may suppress the immune system, making you more vulnerable to infectious diseases

iii. Is suspected of causing stunting in young children

iv. It may also affect an unborn baby through the pregnant mother. This may result in low birth weight or poor growth of the child during the early years of life

v. It can result in death if taken in high concentrations.

[Please pause and ask if there is a question]

\section{Information on safer brands (read to TREATMENT 1 and TREATMENT 2 only)}

Maize products made from aflatoxin contaminated maize will also be contaminated. Therefore, maize flour from contaminated maize will be contaminated and consumption of such flours might lead to the effects described previously. Scientific research has shown that maize grown from this region is contaminated. In addition, some of the brands available in the market are also contaminated. Further research has shown that the level of contamination is correlated with the price of the brand; the more expensive the brand is, the lower the chance that the flour is contaminated. This research has also shown that Hostess and Jogoo flour is relatively safe in terms of Aflatoxin contamination. This could be attributed to the fact that the millers who produce these brands are keen on the maize they buy, and they test the maze for aflatoxin contamination and the level of moisture before buying the maize

[Please pause and ask if there is a question]

\section{Test of maize flour samples and sharing of the results (read to TREATMENT 2 ONLY)}

As stated earlier, aflatoxin contamination can only be detected by a test (cannot be seen by the naked eye). Now, we are going to collect a sample from the flour that you are currently consuming in the household and test it for the contamination levels. 
In case more than one brand is available, ask for the most important brand for the household in terms of the amount consumed and the frequency of consumption/purchase relative to other brands.

We are going to use a rapid test designed for quick and simple tests in the field. The test will only take a few minutes (approximately 10-15 minutes). The results of the test will be shared with you and you will be present during the whole procedure. The test will show us whether the maize flour you are consuming is below or above $10 \mathrm{ppb}$. 10ppb is the maximum level of aflatoxin allowed in maize and maize products meant for human consumption in Kenya. Any sample below $10 \mathrm{ppb}$ is considered aflatoxin safe while any sample above $10 \mathrm{ppb}$ is considered unsafe for consumption. I am going to use a strip for the test. We are going to assess the results by looking at this strip (show a sample of the test strip and explain the next two points).

How to interpret the results

For test results less than 10ppb: 2 red lines will appear on the test strip. This indicates the flour sample contains total aflatoxin less than $10 \mathrm{ppb}$ (negative sample). For test results greater than $10 \mathrm{ppb}$ or equal to $10 \mathrm{ppb}$ : only 1 red line will be visible. This indicates the sample contains total aflatoxin greater than or equal to 10ppb (Positive sample). Now we are going to proceed with the test. I am going to take 10 grams of flour from the packet or batch (in case of flour from posho mill) that is being consumed by the household now. If the flour turns out to have contamination levels above $10 \mathrm{ppb}$ (positive test result), you should avoid consuming the floor as it is harmful to your health (remember the effects of consuming contaminated foods?). In this case, you should burry the contaminated flour and cover it in lime or dispose it in a pit latrine. Please do not feed the contaminated flour to any domestic animals. I am going to give you $150 \mathrm{KES}$ which is worth one packet $(2 \mathrm{KG})$ of hostess flour as a compensation for the contaminated flour. Please also note that exposure to aflatoxin at the levels typically observed in Kenya does not constitute an immediate 
risk to health. While consuming contaminated maize over many years does increase the risk of cancer, eating a few packets of maize flour over the standard will not give you cancer now. Acute aflatoxin poisoning (resulting in immediate sickness) generally only occurs when people eat maize that they know is not good.

NOTE: If the household does not have flour at the time of visit, please ask them to give you an appointment to come back after they have purchased the flour. Advise them to purchase the flour they normally purchase.

[Please pause and ask if there is a question] 


\section{Appendix 2.2. Definition of Baseline Covariates}

\begin{tabular}{|c|c|}
\hline Baseline beliefs & $\begin{array}{l}\text { Constructed from } 2 \text { questions: a) any packaged maize flour available at the } \\
\text { shop must be safe and (b) some brands of packaged flour have higher levels of } \\
\text { aflatoxin contamination than others. } \\
\text { In both cases, a response of agree is assigned } 1 \text {, while the rest (neither agree } \\
\text { nor disagree and disagree) a value of } 2 \text {. }\end{array}$ \\
\hline $\begin{array}{l}\text { Consumption of } \\
\text { a safer brand at } \\
\text { baseline }\end{array}$ & $\begin{array}{l}\text { Dummy variable with a value of } 1 \text { if the most recently purchased flour is one } \\
\text { of the brands described as relatively safe in the intervention script. }\end{array}$ \\
\hline $\begin{array}{l}\text { Price per KG at } \\
\text { baseline (KES) }\end{array}$ & Price per KG of the most recently purchased flour \\
\hline $\begin{array}{l}\text { Consumption of } \\
\text { flour from own } \\
\text { produced maize }\end{array}$ & $\begin{array}{l}\text { Dummy variable with a value of } 1 \text { if the most recently purchased flour is from } \\
\text { own produced maize }\end{array}$ \\
\hline $\begin{array}{l}\text { Age of the } \\
\text { respondent } \\
\text { (complete years) }\end{array}$ & Age of the respondents in years \\
\hline $\begin{array}{l}\text { Education level } \\
\text { of the } \\
\text { respondent } \\
\text { (complete years) }\end{array}$ & Number of years of formal education \\
\hline $\begin{array}{l}\text { Respondent is } \\
\text { household head }\end{array}$ & Dummy variable with a value of 1 if the respondent is the household head \\
\hline $\begin{array}{l}\text { Respondent is } \\
\text { female }\end{array}$ & Dummy variable with a value of 1 if the respondent is male \\
\hline $\begin{array}{l}\text { Flour available } \\
\text { at the time of } \\
\text { visit }\end{array}$ & $\begin{array}{l}\text { Dummy variable with a value of } 1 \text { if there was some flour available in the } \\
\text { house at the time of visit }\end{array}$ \\
\hline $\begin{array}{l}\text { Aflatoxin } \\
\text { knowledge } \\
\text { index }\end{array}$ & $\begin{array}{l}\text { An index constructed as follows: } \\
0.75 \text { times the z-score of the sum of dummy variables indicating correct or } \\
\text { affirmative answers to these three questions a) do you know of any }\end{array}$ \\
\hline
\end{tabular}




\begin{tabular}{|c|c|}
\hline & $\begin{array}{l}\text { problem/situation whereby eating maize or maize flour can make you sick? b) } \\
\text { Have you ever heard of aflatoxin before today? c) can you please tell me what } \\
\text { aflatoxin is? Plus } 0.25 \text { times the z-score of the number of correct responses to } \\
\text { this question e) do you know any health effects that come from eating aflatoxin } \\
\text { contaminated foods }\end{array}$ \\
\hline Wealth index & $\begin{array}{l}\text { created as } 0.9 \text { times the } \mathrm{z} \text { score of the sum of dummies indicating ownership } \\
\text { status of a list of household assets, a dummy indicating ownership status of the } \\
\text { house, ( } 1 \text { own, } 0 \text { otherwise) and the dummies indicating whether the bathroom, } \\
\text { kitchen, piped water and kitchen are within the house; plus } 0.1 \text { times the } \mathrm{z} \\
\text { score of a continuous variable indicating the number of independent bedrooms } \\
\text { owned by the household. }\end{array}$ \\
\hline $\begin{array}{l}\text { General trust } \\
\text { level }\end{array}$ & $\begin{array}{l}\text { A continuous variable created from the response to the question; 'Most people } \\
\text { can be trusted' where a response of disagree is assigned } 0 \text {, not sure or neither } \\
\text { agree/disagree assigned a value of } 1 \text { and agree a value of } 2 \text {. } \\
\text { The values range from } 0 \text { to } 2 \text {, with } 2 \text { indicating highest level of general trust. }\end{array}$ \\
\hline $\begin{array}{l}\text { Institutional } \\
\text { trust level }\end{array}$ & $\begin{array}{l}\text { A continuous variable created as the sum of the response to } 2 \text { questions: a) } \\
\text { food processors/ millers can be trusted to supply safe food to the consumers b) } \\
\text { the government can be trusted to protect the consumers; a response of disagree } \\
\text { is assigned } 0 \text {, not sure or neither agree/disagree assigned a value of } 1 \text { and agree } \\
\text { a value of } 2 \text {. } \\
\text { The values range from } 0 \text { to } 4 \text {, with } 4 \text { indicating highest level of institutional } \\
\text { trust. }\end{array}$ \\
\hline $\begin{array}{l}\text { Participated in } \\
\text { the qualitative } \\
\text { survey }\end{array}$ & $\begin{array}{l}\text { A dummy variable with a value of } 1 \text { if a respondent participated in additional } \\
\text { qualitative survey }\end{array}$ \\
\hline Impatience level & $\begin{array}{l}\text { A continuous variable measured by asking five questions that involve a choice } \\
\text { between a certain amount of maize flour today or a certain amount in one } \\
\text { month. The time preference of an individual is indicated by the question } \\
\text { number where an individual switch from preferring certain amount of flour in } \\
\text { one month to preferring a certain amount today }\end{array}$ \\
\hline
\end{tabular}


Appendix 2.3. Additional Tables

Appendix Table A.2.1 Comparison of the Means of the Pre-Intervention Household and Individual Characteristics for the Comparison Group, the Positive Test Results Group and the Negative Test Result Group

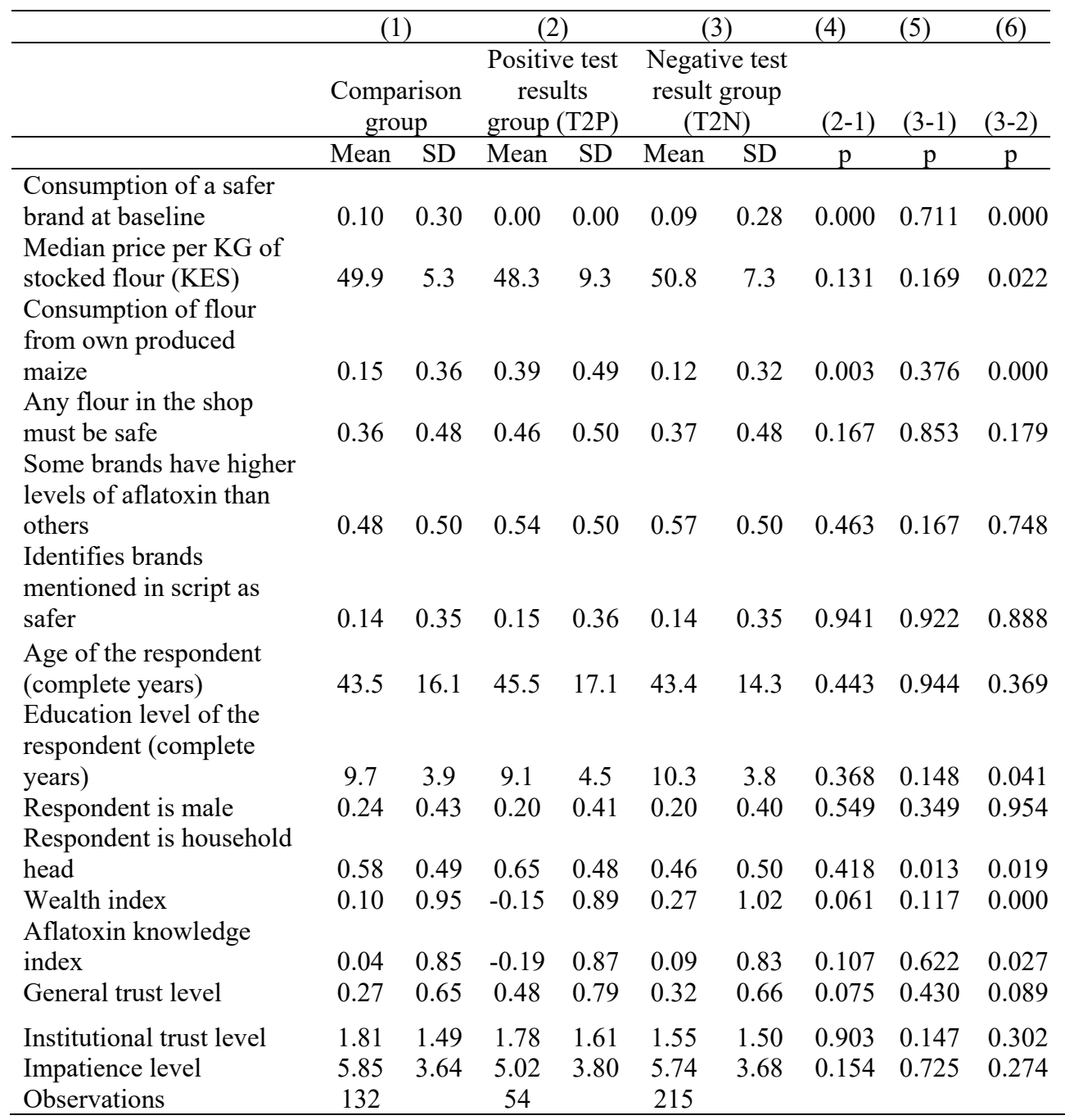

Notes: Means for T2 are weighted by probability of inclusion in the sample. The standard errors used in the calculation of the $\mathrm{P}$ value are clustered at the village level. 


\begin{tabular}{|c|c|c|c|c|}
\hline & 1 & 2 & 3 & 4 \\
\hline & \multicolumn{2}{|c|}{ Panel A } & \multicolumn{2}{|c|}{ Panel B } \\
\hline & Attrition & Attrition & Attrition & Attrition \\
\hline \multirow[t]{2}{*}{ Safe brands information only (T1) } & 0.012 & 0.012 & 0.012 & 0.011 \\
\hline & -0.032 & -0.035 & -0.033 & -0.034 \\
\hline \multirow[t]{2}{*}{ Safe brands plus testing info (T2) } & -0.004 & 0.002 & & \\
\hline & -0.03 & -0.03 & & \\
\hline \multirow[t]{2}{*}{ Positive test result group (T2P) } & & & -0.013 & -0.001 \\
\hline & & & -0.038 & -0.043 \\
\hline \multirow[t]{2}{*}{ Negative test result group $(\mathrm{T} 2 \mathrm{~N})$} & & & -0.026 & -0.023 \\
\hline & & & -0.029 & -0.029 \\
\hline \multirow[t]{2}{*}{ Safe brands plus no test category } & & & $0.932 * * *$ & $0.921 * * *$ \\
\hline & & & -0.026 & -0.033 \\
\hline \multirow[t]{2}{*}{ Consumption of a safer brand at baseline } & & 0.063 & & 0.064 \\
\hline & & -0.044 & & -0.042 \\
\hline \multirow[t]{2}{*}{ Median price per KG of stocked flour (KES) } & & 0.001 & & 0 \\
\hline & & -0.002 & & -0.002 \\
\hline \multirow[t]{2}{*}{ Consumption of flour from own produced maize } & & 0.026 & & -0.011 \\
\hline & & -0.026 & & -0.018 \\
\hline \multirow[t]{2}{*}{ Any flour in the shop must be safe } & & -0.013 & & -0.01 \\
\hline & & -0.019 & & -0.018 \\
\hline \multirow[t]{2}{*}{ Some brands have higher levels of aflatoxin } & & $-0.043 * *$ & & $-0.034 *$ \\
\hline & & -0.021 & & -0.019 \\
\hline \multirow[t]{2}{*}{ Identifies brands mentioned in script as safer } & & -0.015 & & 0 \\
\hline & & -0.025 & & -0.024 \\
\hline \multirow[t]{2}{*}{ Age of the respondent (complete years) } & & $-0.002 * * *$ & & $-0.002 * * *$ \\
\hline & & -0.001 & & -0.001 \\
\hline \multirow[t]{2}{*}{ Education level of the respondent (years) } & & 0.003 & & 0.002 \\
\hline & & -0.003 & & -0.003 \\
\hline \multirow[t]{2}{*}{ Respondent is male } & & 0.02 & & 0.026 \\
\hline & & -0.032 & & -0.03 \\
\hline \multirow[t]{2}{*}{ Household head } & & 0.019 & & 0.014 \\
\hline & & -0.027 & & -0.026 \\
\hline \multirow[t]{2}{*}{ Wealth index } & & 0.002 & & 0.004 \\
\hline & & -0.015 & & -0.014 \\
\hline \multirow[t]{2}{*}{ Aflatoxin knowledge index } & & $-0.034 * *$ & & $-0.026^{*}$ \\
\hline & & -0.015 & & -0.016 \\
\hline \multirow[t]{2}{*}{ General trust level } & & 0.01 & & 0.017 \\
\hline & & -0.02 & & -0.019 \\
\hline \multirow[t]{2}{*}{ Institutional trust level } & & -0.002 & & -0.004 \\
\hline & & -0.009 & & -0.009 \\
\hline \multirow[t]{2}{*}{ Impatience level } & & 0.004 & & 0.004 \\
\hline & & -0.003 & & -0.003 \\
\hline \multirow[t]{2}{*}{ Qualitative interview } & & -0.01 & & 0.004 \\
\hline & & -0.042 & & -0.043 \\
\hline Observations & 550 & 550 & 550 & 550 \\
\hline Attrition rate for the control group & 0.068 & 0.068 & 0.068 & 0.068 \\
\hline
\end{tabular}

Notes: ${ }^{*} \mathrm{p}<0.10, * * \mathrm{p}<0.05, * * * \mathrm{p}<0.01$. Standard errors in parentheses clustered at the village level. Observations are weighted by the inverse probability of inclusion in the followup sample. 


\section{Appendix Table A2.3 Treatment Effects Including All Baseline Controls}

\begin{tabular}{ccccccc}
\hline 1 & 2 & 3 & 4 & 5 & 6 \\
\hline Consumes & Consumes & price per & & Correctly & Aflatoxin \\
a safer & a safer & kg of & Risk & names a & safety \\
brand & brand & flour & & awareness & safer & considered \\
& & & consumed & brand & in flour \\
& & & & & choice
\end{tabular}

Panel A

Safe brands

$\begin{array}{lllllll}\text { information only } & 0.042 & 0.039 & 1.07 & 0.572 * * & 0.209 * * * & 0.026\end{array}$

(T1)
$(0.034)$
$(0.040)$
(0.809)
$(0.267) \quad(0.051)$
$(0.027)$

Safe brands info

plus testing (T2)

$0.091 * * * \quad 0.096^{* *} \quad 1.40^{* *} \quad 0.662 * * * \quad 0.296 * * * \quad 0.103 * * *$
$(0.032)$
$(0.040)$
$(0.676)$
$(0.193) \quad(0.044)$
$(0.027)$

$\mathrm{T} 1=\mathrm{T} 2: \mathrm{P}$-value

0.110

0.155

0.619

0.627

0.091

0.025

Observations

$$
503
$$

389

432

506

503

506

Notes: Standard errors clustered at the village level in parentheses. ${ }^{*} \mathrm{p}<0.10,{ }^{* *} \mathrm{p}<0.05,{ }^{* * *}$ $\mathrm{p}<0.01$. Observations are weighted by the inverse probability of randomly determined inclusion in the follow-up sample. All specifications include the outcome variable measured at baseline, an indicator for whether the baseline respondent participated in a qualitative interview, and other baseline respondent and household characteristics as shown in Table 2.3. 


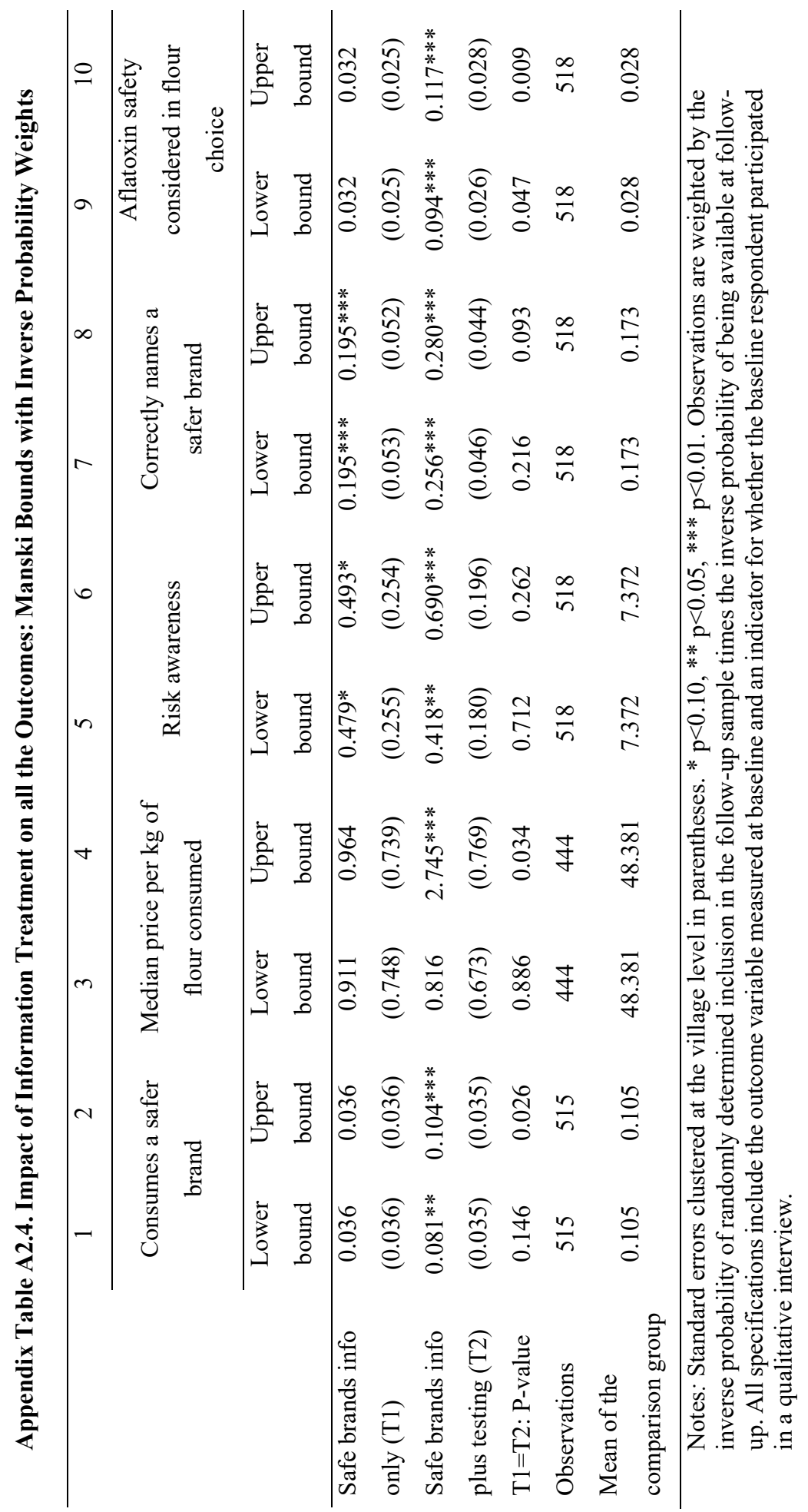


Appendix Table A2.5. Unadjusted P-Values and Q-Values Taking into Account the Number of Hypotheses Tested

\begin{tabular}{|c|c|c|c|c|c|c|}
\hline \multirow{5}{*}{ Outcome } & \multicolumn{6}{|c|}{ Safe brands info plus } \\
\hline & \multirow{2}{*}{\multicolumn{2}{|c|}{$\begin{array}{l}\text { Safe brands } \\
\text { information only (T1) }\end{array}$}} & \multicolumn{2}{|c|}{ testing information } & \multicolumn{2}{|c|}{$\mathrm{T} 1=\mathrm{T} 2$} \\
\hline & & & \multicolumn{2}{|c|}{ (T2) } & & \\
\hline & Unadjusted & q- & Unadjusted & q- & Unadjusted & q- \\
\hline & p-values & values & $\mathrm{p}$-values & values & $\mathrm{p}$-values & values \\
\hline Consumes a safer brand & 0.319 & 0.208 & 0.019 & 0.044 & 0.114 & 0.129 \\
\hline \multicolumn{7}{|c|}{ Median price per $\mathrm{kg}$ of flour } \\
\hline consumed & 0.219 & 0.152 & 0.070 & 0.096 & 0.654 & 0.306 \\
\hline Risk awareness & 0.060 & 0.094 & 0.003 & 0.010 & 0.550 & 0.306 \\
\hline \multicolumn{7}{|l|}{ Correctly names a safer } \\
\hline brand & 0.000 & 0.001 & 0.000 & 0.001 & 0.156 & 0.148 \\
\hline \multicolumn{7}{|l|}{ Aflatoxin safety considered } \\
\hline in flour choice & 0.207 & 0.152 & 0.001 & 0.005 & 0.041 & 0.074 \\
\hline
\end{tabular}

Note: FDR q-values can be less than the corresponding unadjusted p-values if many hypotheses are rejected. This typically occurs for relatively large p-values, for which the corresponding qvalues remain above significance thresholds. 


\section{Chapter 3}

\section{Safe Food For Me - and Maybe for You: Upside Risk, Premium Market Access, and Producer Demand for a Food Safety Technology}

\section{Vivian Hoffmann, Sarah Wairimu Kariuki, Janneke Pieters and Mark Treurniet}

Premium prices conditional on food safety attributes are often proposed as a way to increase food safety for marketed produce in developing countries where regulatory capacity is weak. However, domestic markets in these settings may not support premia of sufficient magnitude to affect farmer behavior. We examine how a quality premium affects the adoption of a food safety technology among subsistence farmers who value the safety of food they consume themselves. We present a simple model showing that a modest quality premium that is too low to affect adoption on the extensive margin can harness upside production risk by providing subsistence farmers a high-value market for their excess high-quality output. Through a randomized trial among maize farmers in Kenya, we find, in line with model predictions, that a modest quality premium for food safety increases subsistence farmers' adoption of an aflatoxin-reducing technology at the intensive margin, but not at the extensive margin. 


\subsection{Introduction}

Foodborne pathogens and toxins exact a significant health toll in developing countries (WHO 2015), particularly among the poorest (Leroy, Wang, and Jones 2015). Further, food safety is an increasingly important precondition for access to high value markets (Ashraf et al. 2009; Beuningen and Knorringa 2009). Improving the safety of food produced for subsistence typically relies on education and subsidies. Regulatory or voluntary standards, the latter combined with price premia or market access advantages, are employed in the case of marketed food. In this chapter, we examine how a market-based instrument - a price premium for food safety - affects the safety of food produced for home consumption in the context of production risk. We show that when production quantity is stochastic, access to a premium market for safe food reduces expected exposure to a common food safety hazard among subsistence producers.

We consider the case of aflatoxin, a common mycotoxin, in maize produced by Kenyan smallholder farmers. Dietary aflatoxin exposure accounts for a large share of the liver cancer burden in developing countries (Liu and $\mathrm{Wu} 2010$ ), and evidence is emerging that the toxin plays a role in childhood stunting (Gong et al. 2002; Hoffmann, Jones, and Leroy 2018; Turner et al. 2007). At high levels of exposure, aflatoxin can cause jaundice, permanent liver damage, and death. Dozens of cases of acute aflatoxin poisoning have been linked to the consumption of maize produced and stored by households in eastern Kenya, the setting of our study (Daniel et al. 2011). Likely because of these poisoning events, which have been covered extensively in Kenyan media, awareness of aflatoxin is high in the study region (Hoffmann et al., in press), and Kenyan consumers have demonstrated significant willingness to pay for aflatoxin-safe maize in experimental studies (De Groote et al. 2016; Hoffmann and Gatobu 2014). 
Beyond its impact on public health, widespread aflatoxin contamination of maize and groundnut limits opportunities for economic growth through agriculture. African nations' exports have often failed to meet the aflatoxin standards of important target markets (Munasib and Roy 2011b), and domestic food processors in Kenya avoid sourcing from aflatoxin-affected regions (Hoffmann and Moser, 2017). Some processors in Africa go so far as to import aflatoxinsusceptible ingredients from the Americas at considerable cost (personal communication, Carly Edwards, Project Peanut Butter, March 28, 2018).

Effective technologies to reduce aflatoxin contamination are available but face several barriers to adoption. First, food safety is a hidden trait, and its observation requires specialized tests that are costly relative to the value of farm produce. In the case of aflatoxin, a single test costs on the order of US $\$ 10$ - almost $20 \%$ the cost of the typical value of maize grains sold by smallholder farmers in a normal harvest season in aflatoxin-prone regions of Kenya. ${ }^{13}$ This information problem, exacerbated by the fact that Kenyan maize supply chains often include multiple intermediaries, has to date precluded the pass-through of premium prices offered by some formal sector maize processing companies to farmers (Hoffmann and Moser, 2017).

However, as consumer awareness and regulatory capacity to address food safety increase, incentives are growing for Kenyan maize processors to secure safer inputs by establishing direct procurement relationships with farmer groups. Several studies have shown that market incentives affect production and marketing decisions in general (Bernard et al. 2018; Burchardi et al. 2019; Casaburi and Macchiavello 2015), and for food quality and safety specifically (Bernard et al. 2017;

\footnotetext{
${ }^{13}$ The median sale volume in a normal harvest in our sample is $270 \mathrm{~kg}$. Beyond the cost of testing supplies, tests should be executed by an experienced technician and compared regularly against results using a reference material to obtain reliable results.
} 
Hoffmann, Magnan, et al. 2018; Hoffmann and Jones 2018; Saenger et al. 2013; Treurniet 2019b). However, previous studies of the adoption of food safety and quality technologies have either focused on marketed produce (Bernard et al. 2017; Saenger et al. 2013; Treurniet 2019b), considered technologies for which adoption is a binary decision (Hoffmann, Magnan, et al. 2018), or offered an unrealistically large price premium on a fixed amount of produce, enabling analysis of adoption only on the extensive margin (Hoffmann and Jones, 2018). In contrast, we study how a modest market premium affects the adoption of a divisible food safety technology among smallholder farmers.

Another barrier to adoption is production risk. Like many food safety technologies, one of the most effective tools for aflatoxin prevention, the biocontrol product Aflasafe $^{\mathrm{TM}}$, is applied during production, before the outcome of this process is observed. In a stochastic agricultural production function, any costly input increases the variability of farm profit (Just and Pope 1978). For low-income populations engaged in rainfed agriculture, who lack access to financial smoothing instruments, this implies increased consumption risk and thus constitutes an important impediment to technology adoption (Dercon and Christiaensen 2011; Emerick et al. 2016; Rosenzweig and Binswanger 2016).

While the literature on how downside risk affects adoption of agricultural technologies is vast, upside production risk has received far less attention. In our setting, upside production risk constitutes a potential driver of adoption intensity among farmers who value safer food for their own family's consumption. When weather conditions are favorable, farmers harvest more safe grain for a given cultivated area to which a food safety input is applied. If production exceeds household subsistence needs, and no market reward for quality exists, a portion of the value of the food safety investment is lost. Below, we present a simple model showing that a modest quality 
premium that is too low to affect adoption on the extensive margin can harness this upside risk by providing subsistence farmers a high-value market for their excess high-quality output.

We subsequently test the model's predictions by studying the impact of a market premium for food safety on subsistence farmers' adoption of an aflatoxin-reducing technology (Aflasafe $\mathrm{KE} 01^{\mathrm{TM}}$ ) through a randomized trial in which farmers in one of the most aflatoxin-affected regions in the world were given the opportunity to purchase Aflasafe ${ }^{\mathrm{TM}}$ under experimentally varied market conditions. Half of 152 pre-existing producer groups were assigned to a market linkage treatment and offered a premium price for the maize they aggregated if it conformed to the East African aflatoxin standard. ${ }^{14}$

We find that the price premium, which was set to a modest $5 \%$ of the value of maize, did not affect the extensive margin of adoption, suggesting that farmers who purchased the product used it first on maize produced for their own consumption. We do, however, see a strong positive impact of the premium on the intensive margin of adoption. Farmers who were offered the food safety premium purchased nearly twice as much Aflasafe $\mathrm{T}^{\mathrm{TM}}$ as those not given this opportunity.

${ }_{14}$ The market linkage treatment was cross-cut with a bundled insurance treatment, in which Aflasafe $^{\mathrm{TM}}$ could only be purchased together with an actuarially fair rainfall index insurance product designed to insure against maize losses due to unfavorable weather conditions during the growing period. Farmers not assigned to the bundled insurance treatment who purchased Aflasafe $^{\mathrm{TM}}$ were able to purchase the same insurance separately. The bundled insurance treatment is described in Hoffmann, Kariuki et al. (2018). As farmers not assigned to the bundled insurance treatment also had the option of buying insurance, and $75 \%$ did so, bundling Aflasafe ${ }^{\mathrm{TM}}$ with insurance had no impact on adoption. 
We begin by presenting a simple model of the food safety investment decision faced by a subsistence farmer in the context of production risk in Section 3.2. In Section 3.3, we describe the market context, technology offered, and study population. Section 3.4 describes the study design and data, and Section 3.5 outlines the empirical strategy. Results are presented in Section 3.6, and Section 3.7 offers concluding remarks.

\subsection{Model}

In this section we formally derive conditions under which a price premium increases adoption of food safety technology among subsistence farmers at the extensive and intensive margin. We start by defining farmers' utility as a function of food safety investments, and distinguish between farmers with a low versus high valuation of safe home consumption. We first discuss the baseline situation without a price premium, in which the low type will not and the high type will adopt the food safety technology. We then show that a high price premium increases adoption at both the extensive and intensive margin. We finally show how a modest price premium that is insufficient to induce low type farmers to adopt can increase the level of adoption by the high type. Intuitively, a modest price premium increases the value of safe maize produced in excess of home consumption needs. This causes a marginal increase in the expected benefit of investing in safe food, leading the high type to invest more.

\subsubsection{Set-up}

Assume that farmers maximize their utility:

$$
\max E[U]=E[V]+E[R]-C,
$$


where $V$ is the total value of home consumption, $R$ is total revenue of produce delivered to the market, and $C$ is the total cost of investment in food safety.

Let $I \in[0,1]$ denote the proportion of land to which the food safety technology is applied. Let $c>0$ denote the cost of investment to cover the entire cultivated area. Then, the cost of investment is:

$$
C=c I \text {, }
$$

So that the marginal cost of investment equals $c$. We assume (i) that investment in food safety directly results in safe produce $s=I$, where $s$ is the proportion of food produced that is safe, ${ }^{15}$ (ii) that the total harvest amount is stochastic and uniformly distributed $q \sim U\left(q_{L}, q_{H}\right)$, so that the mean harvest equals $\mu_{q}=\left(q_{L}+q_{H}\right) / 2$, (iii) that home consumption varies with harvest, but never exceeds a fixed amount $q_{\text {home }}=\min \left\{q, \widetilde{q_{\text {home }}}\right\}$, (iv) that $\widetilde{q_{\text {home }}} \leq q_{H}$ to generate upside risk, and (v) that the remainder $q_{\text {market }}=q-q_{\text {home }}$ is sold.

Safe food produced will either be consumed at home or delivered to the market:

$$
s_{\text {home }} q_{\text {home }}+s_{\text {market }} q_{\text {market }}=I q,
$$

where $s_{\text {home }} \in[0,1]$ is the proportion of produce consumed by the household that is safe, and $s_{\text {market }} \in[0,1]$ is the proportion of produce delivered to the market that is safe. The farmer first chooses the level of investment $I$, and then chooses both $s_{\text {home }}$ and $s_{\text {market }}$ after the realisation of $q$.

The total value of home consumption equals:

$$
V=\left(\alpha+\beta_{i} s_{\text {home }}\right) q_{\text {home }},
$$

\footnotetext{
${ }^{15}$ The remaining produce may still be safe, but can be unsafe, and this is not observable, so that there are food safety risks.
} 
where $\alpha$ is the value of consuming food of the quality produced by the farmer in the absence of any food safety investment, and $\beta_{i}$ is the value premium for consuming safe food.

Farmers vary in the additional value they derive from consumption of safe food:

$$
\beta_{i} \in\left\{\beta_{L}, \beta_{H}\right\}
$$

where, to make the model interesting, we assume that:

$$
\beta_{L}<\frac{c}{\mu_{q}}<\beta_{H}<\tilde{\beta} \equiv \frac{c}{\left.\frac{\partial E\left[s_{\text {home }} q_{\text {home }}\right]}{\partial I}\right|_{I=1}},
$$

The first inequality ensures that the low type will not adopt the technology, and the second inequality ensures that the high type will adopt in absence of a premium price. The third inequality ensures that the high type's motivation to produce safe food for home consumption is by itself insufficient for full adoption, so that some room is left for market incentives to increase adoption at the intensive margin. One can later easily see that $\tilde{\beta}=\infty$ if $q_{L} \geq \widetilde{q_{\text {home }}}$.

The total revenue of produce delivered to the market equals:

$$
R=\left(\gamma+\delta s_{\text {market }}\right) q_{\text {market }}
$$

where $\gamma$ is the standard commodity price, and $\delta$ is the price premium for safe produce delivered to the market.

The farmers' utility maximization problem then becomes:

$$
\begin{aligned}
\max _{I, S_{\text {home }} S_{\text {market }}} E[U] \\
\quad=\alpha E\left[q_{\text {home }}\right]+\beta_{i} E\left[s_{\text {home }} q_{\text {home }}\right]+\gamma E\left[q_{\text {market }}\right]+\delta E\left[s_{\text {market }} q_{\text {market }}\right]-c I,
\end{aligned}
$$

subject to (3.3), and $s_{\text {home }}, s_{\text {market }}, I \in[0,1]$. 


\subsubsection{Solution}

First consider $\delta=0$, so that the only incentive to invest in food safety comes from $\beta_{i}$. The farmer will select her safe produce for home consumption and deliver the remainder to the market, so that:

$$
s_{\text {home }} q_{\text {home }}=\min \left\{I q, q_{\text {home }}\right\}=\min \left\{\text { Iq }, \widetilde{q_{\text {home }}}\right\}=\left\{\begin{array}{cl}
\text { Iq } & \text { if } q \leq \frac{\widetilde{q_{\text {home }}}}{I} \\
\widetilde{q_{\text {home }}} & \text { if } q>\frac{\widetilde{q_{\text {home }}}}{I}
\end{array}\right.
$$

which in expectation equals:

$$
E\left[s_{\text {home }} q_{\text {home }}\right]=\left\{\begin{array}{lc}
\text { I } \mu_{q} & \text { if } I \leq \frac{\widetilde{q_{\text {home }}}}{q_{H}} \\
f(I) & \text { if } \frac{\widetilde{q_{\text {home }}}}{q_{H}}<I \leq \frac{\widetilde{q_{\text {home }}}}{q_{L}}, \\
\widetilde{q_{\text {home }}} & \text { if } I>\frac{\widetilde{q_{\text {home }}}}{q_{L}}
\end{array}\right.
$$

where:

$$
f(I)=\int_{q_{L}}^{q_{\text {home }} / I} I q \frac{1}{q_{H}-q_{L}} d q+\int_{\widetilde{q_{\text {home }} / I}}^{q_{H}} \widetilde{q_{\text {home }}} \frac{1}{q_{H}-q_{L}} d q,
$$

Equation (3.10) is differentiable and monotonically increasing in $I$, and its first derivative with respect to $I$ equals:

$$
\frac{\partial E\left[s_{\text {home }} q_{\text {home }}\right]}{\partial I}=\left\{\begin{array}{cc}
\mu_{q} & \text { if } I \leq \frac{\widetilde{q_{\text {home }}}}{q_{H}} \\
\frac{1}{2} \frac{\left.\widetilde{\left(q_{\text {home }}\right.} / I-q_{L}\right)\left(\widetilde{q_{\text {home }}} / I+q_{L}\right)}{q_{H}-q_{L}} & \text { if } \frac{\widetilde{q_{\text {home }}}}{q_{H}}<I \leq \frac{\widetilde{q_{\text {home }}}}{q_{L}} \\
0 & \text { if } I>\frac{\widetilde{q_{\text {home }}}}{q_{L}}
\end{array}\right.
$$

which is continuous and monotonically decreasing in $I .{ }^{16}$

Intuitively, Equation (3.10) says that when investment in food safety is so low that there is not sufficient safe produce to satisfy home consumption needs even in the case of the best

${ }^{16}$ See Appendix 3.1 for mathematical details. 
possible harvest, all safe food is consumed by the household. Beyond this level of investment, the expected quantity of safe home consumption is increasing with investment in food safety, but at a decreasing rate, since the greater the share of land to which the technology is applied, the higher the chance of producing more than is needed for household consumption. Eventually, investment in the food safety technology reaches a point at which there will always be sufficient safe produce for home consumption even when the worst possible harvest, $q_{L}$, is realized. However, this last point will never be reached if $\widetilde{q_{\text {home }}}>q_{L}$.

For farmers who place a low value, $\beta_{L}$, on the safety of home consumption, we have that:

$$
\beta_{L} \frac{\partial E\left[s_{\text {home }} q_{\text {home }}\right]}{\partial I} \leq \beta_{L} \mu_{q}<c,
$$

which implies that the marginal benefits of investment in food safety are strictly smaller than the marginal costs of investment. These farmers will not invest in food safety in the absence of a price premium.

For farmers who place a high value, $\beta_{H}$, on the safety of home consumption, we have $\beta_{H} \mu_{q}>c>0$ and:

$$
\left.\beta \frac{\partial E\left[s_{\text {home }} q_{\text {home }}\right]}{\partial I}\right|_{I=1}<c,
$$

so that the optimal investment $I^{*}$ is uniquely defined by:

$$
\left.\beta_{H} \frac{\partial E\left[s_{\text {home }} q_{\text {home }}\right]}{\partial I}\right|_{I=I^{*}}=c,
$$

Intuitively, farmers with a high value of safe home consumption invest in food safety until the probability that additional safe harvest will be consumed at home becomes too low to justify the cost of investment. 
Now consider the case of a high price premium $\delta>c / \mu_{q}$. Since the high premium outweighs the expected unit-cost of producing safe food, all farmers may now adopt the food safety technology, so that the market premium increases investment in the food safety technology at the extensive margin. Farmers with a low valuation for safe home consumption $\beta_{L}$ will not apply the food safety to their full land, first consume potentially unsafe maize at home, and deliver primarily safe maize to the market. Farmers with a high valuation for safe home consumption $\beta_{H}$, will increase adoption and apply the food safety technology to their full land, so that all their produce will be safe. This leads to Proposition 1:

Proposition 1: A high price premium increases adoption of food safety technology at both the extensive and intensive margin.

Now consider $c / \mu_{q}>\delta>0$. As the price premium is insufficient to produce safe food solely for marketing purposes in expectation, it will not induce farmers who place a low value on the safety of home consumption $\beta_{L}$ to start investing. This implies that the price premium has no effect at the extensive margin of investment. This leads to Proposition 2:

Proposition 2: A modest price premium does not increase adoption of food safety technology at the extensive margin.

Since $\beta_{H}>c / \mu_{q}>\delta$, farmers with high valuation of safety of home consumption $\beta_{H}$ will still select their safe produce for home consumption and deliver the remainder to the market, so that Equations (3.9) to (3.12) still hold, and:

$$
s_{\text {market }} q_{\text {market }}=\max \left\{0, I q-\widetilde{q_{\text {home }}}\right\}=\left\{\begin{array}{cl}
0 & \text { if } q \leq \frac{\widetilde{q_{\text {home }}}}{I} \\
\text { Iq- } \widetilde{q_{\text {home }}} & \text { if } q>\frac{\widetilde{q_{\text {home }}}}{I}
\end{array}\right.
$$

which in expectation equals: 


$$
E\left[s_{\text {market }} q_{\text {market }}\right]=\left\{\begin{array}{crl}
0 & \text { if } I \leq \frac{\widetilde{q_{\text {home }}}}{q_{H}} \\
g(I) & \text { if } \frac{\widetilde{q_{\text {home }}}}{q_{H}}<I \leq \frac{\widetilde{q_{\text {home }}}}{q_{L}} \\
\text { I } \mu_{q}-\widetilde{q_{\text {home }}} & \text { if } I>\frac{\widetilde{q_{\text {home }}}}{q_{L}}
\end{array}\right.
$$

where:

$$
g(I)=\int_{\widetilde{q_{\text {home }} / I}}^{q_{H}}\left(I q-\widetilde{q_{\text {home }}}\right) \frac{1}{q_{H}-q_{L}} d q
$$

Equation (3.17) is differentiable and monotonically increasing in in $I$, and its first derivative with respect to $I$ equals:

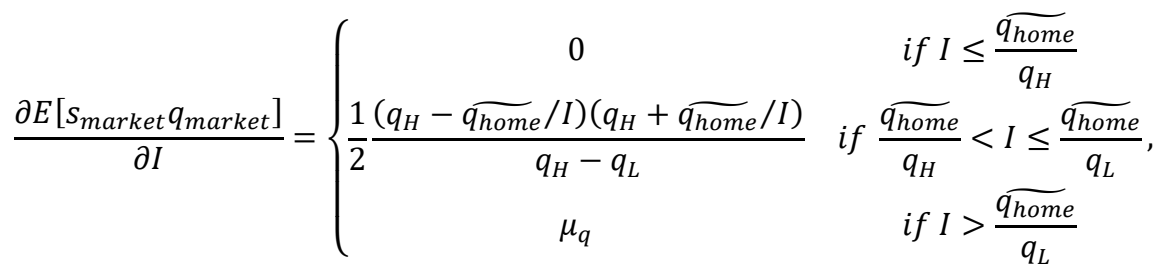

and is continuous and monotonically increasing in $I$. Note again that the last condition will never be satisfied if $\widetilde{q_{\text {home }}}>q_{L}$.

For farmers with a high valuation of safe home consumption $\beta_{H}$, we have $\beta_{H} \mu_{q}>c>0$, so that the optimal investment $I^{* *}$ is uniquely defined by:

$$
\left.\beta_{H} \frac{\partial E\left[s_{\text {home }} q_{\text {home }}\right]}{\partial I}\right|_{I=I^{* *}}+\left.\delta \frac{\partial E\left[s_{\text {market }} q_{\text {market }}\right]}{\partial I}\right|_{I=I^{* *}}=c,
$$

which has a solution for $I \leq 1$, or otherwise $I=1>I^{*}$.

Equation (3.20) can be reduced to:

$$
\left.\left(\beta_{H}-\delta\right) \frac{\partial E\left[s_{\text {home }} q_{\text {home }}\right]}{\partial I}\right|_{I=I^{* *}}+\delta \mu_{q}=c,
$$


The LHS of Equation (3.21) is decreasing in $I^{* *}$ and, by Equations (3.15) and (3.20), this exceeds $c$ for $I^{* *} \leq I^{*}$. We therefore conclude that $I^{* *}>I^{*}$, meaning that the modest price premium has a positive effect at the intensive margin of investment. Intuitively, the value of safe harvest in excess of home consumption increases, which causes a marginal increase in the benefits of investments in safe food, leading the farmer to invest more. In this way, the introduction of a modest market premium can increase the investment in food safety and the safety of food consumed by subsistence farmers. This leads to Proposition 3:

Proposition 3: A modest price premium increases adoption of food safety technology at the intensive margin.

\subsection{Study setting}

\subsubsection{The market for safe maize}

The informal markets to which most maize farmers in Kenya sell do not reward unobservable quality (Hoffmann, Mutiga, et al. 2020). However, a growing number of maize millers in the formal sector do test for aflatoxin at purchase (typically from intermediaries who aggregate from a large number of farmers) and reject maize that does not conform to the regulatory standard. These millers offer a significant premium above the spot market price of maize in the informal market. ${ }^{17}$ To obtain a premium price, several quality characteristics must typically be met: maize must be at or below $13.5 \%$ moisture content; it must conform to grading standards for the proportion of foreign matter, broken, damaged, and discolored kernels; and it must contain total aflatoxins below

17 On the same day in February 2015, Unga Ltd.'s Eldoret plant was paying 2200 Kenyan Shillings (KSH) - approximately \$22 US - for a $90 \mathrm{~kg}$ bag of maize, while the price at the openair market in Eldoret was $1700 \mathrm{KSH}$. 
the regulatory standard. Farmers can meet most of these criteria through adequate drying and removal of sub-standard grains and other particles. The exception is aflatoxin, which may be present without any visible sign of contamination.

The cost of transporting maize from the study region to the Nairobi market, where premium prices can be obtained, is prohibitive in most years. Local millers within the study counties did not screen for aflatoxin at the time of the experiment, though one maize wholesaler did report testing in response to demands by particular buyers, and recently launched a maize flour product. ${ }^{18}$ As disposable incomes and concern over food safety grow, and government enforcement of existing regulations strengthens, it is reasonable to expect that that a local premium market will emerge. However, the premium paid by regional millers is likely to be lower than that offered by the miller referenced above, which produces two of the best-known brands in the country, including the most expensive. Nairobi-based millers in the next quality tier offer a premium of between 200-250 KSH per $90 \mathrm{~kg}$ bag over the informal market. We propose that a conservative estimate of the premium farmers in the study region could expect to receive from a regional miller for aflatoxin-safe maize, accounting for the lower spending power of consumers in this market, and the additional sourcing and quality control costs to the miller, is $100 \mathrm{KSH}$ per bag. This is the aflatoxin safety premium we offer to farmers in the market linkage treatment.

Because the cost of testing for aflatoxin (and other food safety hazards) is high relative to the value of produce sold by the typical smallholder farmer, access to a food safety premium requires that maize is aggregated prior to testing. This can be done through producer groups, which

\footnotetext{
${ }_{18}$ This product was launched after the conclusion of data collection for the experiment described here, and the research team was unable to identify local buyers for aflatoxin-safe maize produced by study farmers.
} 
are common in Kenya and throughout sub-Saharan Africa. Such groups are sometimes formed by NGOs or other external actors as a platform for providing agricultural training and extension, or by farmers themselves to aggregate their demand for inputs or their produce and reduce transaction costs or obtain better prices. Farmers in such groups who sell to markets with food safety requirements have a strong incentive to ensure that others in the group treat their fields, analogous to a joint liability lending model.

\subsubsection{The technology}

Aflasafe $^{\mathrm{TM}}$ is a biocontrol product that uses native strains of the Aspergillus fungus that do not produce toxins to outcompete toxigenic strains. Aflasafe ${ }^{\mathrm{TM}}$ has been shown in farmer field trials to reduce aflatoxin contamination by between $80 \%$ and $99 \%$ (Bandyopadhyay et al., 2016). Treatment with Aflasafe ${ }^{\mathrm{TM}}$ protects crops throughout the growing cycle and storage period, with no impact on the overall level of fungal colonization or crop yields (Cotty et al., 2007). Similar aflatoxin biocontrol products have been used on food crops in the United States for over 15 years.

The first African country to register an aflatoxin biocontrol product was Nigeria. There, initial adopters of Aflasafe ${ }^{\mathrm{TM}}$ have largely been farmers producing maize used by poultry feed processors, as aflatoxin impedes weight gain and increases mortality among poultry (Bandyopadhyay et al., 2016). Aflasafe KE01 ${ }^{\mathrm{TM}}$ was approved by the Kenyan government for general use in June 2015, and domestic manufacturing began in 2017. The cost to produce one $\mathrm{kg}$ of Aflasafe ${ }^{\mathrm{TM}}$ at scale ranges between US $\$ 0.7$ and $\$ 1.2$ depending on currency exchange rates and price of materials (Bandyopadhyay et al., 2016). Due to the small volume produced in Kenya, the current price of Aflasafe KE01 ${ }^{\mathrm{TM}}$ is US \$1.6. 
We set the cost of Aflasafe KE01 ${ }^{\mathrm{TM}}$ in the study to $80 \mathrm{KSH}$ (US \$0.78) per kg; this lies within the range of production costs and takes into account the Government of Kenya's expressed support for a partial subsidy targeted to smallholders. ${ }^{19}$

\subsubsection{Study setting, population, and sample}

The population for this study consists of maize farmers who are members of existing farmer groups in Meru, Embu and Tharaka Nithi counties, Kenya. The three counties fall in the Eastern region of Kenya and are known for their high levels of aflatoxin contamination. The mean aflatoxin level in stored maize sampled from control group villages for a separate trial in the same region in 2015, when aflatoxin contamination was considered moderate, was $18.5 \mathrm{ppb}, 85 \%$ higher than the maximum allowable level in Kenya (Pretari et al. 2019). In 2010, recognized as an aflatoxin outbreak year, the mean level of contamination was $47 \mathrm{ppb}, 4.7$ times the legal limit (Mutiga et al. 2014). In both years, results from field trials cited above indicate that treating fields with Aflasafe $\mathrm{KE}^{\mathrm{TM}}$ would have brought the average level of contamination into the legal range. ${ }^{20}$

A list of approximately 250 farmer groups in the study area was acquired through the Cereal Growers' Association (CGA), a national member-based farmer organization, and the

${ }^{19}$ Together with rainfall insurance, which most farmers purchased when given the choice (and which those offered the Aflasafe ${ }^{\mathrm{TM}}$ plus insurance bundle had no choice but to purchase), the cost per kg was $100 \mathrm{KSH}$ (US \$0.97).

20 The mean level of contamination (as opposed to the probability of non-compliance for a particular farmer) is relevant both from a health and economic perspective, since most of the health burden of aflatoxin arises though cumulative exposure to moderate levels of the toxin over time, and because maize is tested by processors in large lots. 
Ministries of Agriculture in each of the three counties. From April to August 2017, 224 groups were visited and lists of their members were obtained. ${ }^{21}$ From these 224 groups, we selected 152 groups into our experiment. ${ }^{22}$

\subsection{Study design}

\subsubsection{Farmer training and sale of biocontrol product}

All 152 farmer groups in the experiment were given information on the benefits of aflatoxin biocontrol and instructions on its use. This was done through two rounds of training, delivered during a half-day meeting to which all group members were invited. The first round of training took place in September-October 2017, planting time in the study area. During these meetings, group members were given information about Aflasafe ${ }^{\mathrm{TM}}$ and how rainfall index insurance could be used to insure investment in this technology against weather related shocks. In addition, some of the groups were told they could earn a premium price of $100 \mathrm{KSH}$ per bag of maize grown using Aflasafe $^{\mathrm{TM}}$. They were informed that they could only purchase the biocontrol product through the project as it was not available in the study area.

A second round of training was conducted in November and early December, a few weeks after planting and just before the time at which Aflasafe ${ }^{\mathrm{TM}}$ should be applied. During these meetings, group members were trained on how to apply Aflasaf $\mathrm{e}^{\mathrm{TM}}$ and how to activate the rainfall

\footnotetext{
${ }^{21}$ Some of the groups in the initial list were members of the same Community Based Organization (CBO). In such cases, only one group per CBO was visited for our study.

${ }^{22}$ We selected the 152 groups in a way that minimized the baseline differences in groups assigned to the two insurance conditions. See Hoffmann, Kariuki et al. (2018) for details.
} 
insurance offered with the product. A demonstration of Aflasafe ${ }^{\mathrm{TM}}$ application was conducted on the farm of one member of each group. At the end of these meetings, those present were given an opportunity to purchase Aflasafe ${ }^{\mathrm{TM}}$ and an actuarially fair rainfall index insurance that was specifically designed to insure the investment in Aflasafe ${ }^{\mathrm{TM}}$ against weather related shocks. The biocontrol product was offered in packages of $4 \mathrm{~kg}$, a quantity sufficient to treat one acre of land. Farmers who wished to purchase less than $4 \mathrm{~kg}$ were asked to pair up with another group member and share a single package. ${ }^{23}$ Farmers who wished to purchase Aflasafe ${ }^{\mathrm{TM}}$ later were given a chance to do so through a subsequent sales visit by project staff.

Both rounds of training were conducted by extension agents employed by the CGA. CGA agents had been instructed on the use of Aflasafe ${ }^{\mathrm{TM}}$ by the International Institute of Tropical Agriculture (IITA), which also supplied the product.

\subsubsection{Experimental design}

Half of the participating farmer groups were randomly assigned to receive a premium price for safe maize (output market linkage). During the initial round of training, groups assigned to the output market linkage treatment were promised a bonus of $100 \mathrm{KSH}$ per $90-\mathrm{kg}$ bag for maize found to conform to the regulatory aflatoxin standard. The bonus was to be paid shortly after harvest. Members who purchased Aflasafe ${ }^{\mathrm{TM}}$ and wanted to sell their maize through the project would aggregate their maize at a central place to be identified by the group members. A rapid qualitative

\footnotetext{
${ }^{23}$ Farmers who paired up were recorded separately, as independent entries in our Aflasafe ${ }^{\mathrm{TM}}$ sales data sheets, showing their respective amounts depending on the amount of money paid by each farmer.
} 
aflatoxin test would be conducted on the aggregated maize to check if the maize had aflatoxin levels higher than the East African limit $(10 \mathrm{ppb})$. Farmers were informed that any aggregated maize that contained levels higher than $10 \mathrm{ppb}$ would not qualify for the bonus. They were advised to record the number of members who purchased Aflasafe ${ }^{\mathrm{TM}}$ in their group and the amount purchased by each member, and to ensure that only treated maize was aggregated for testing. Aggregation of maize and payment of the bonus took place in March-April 2018, at the same time as endline data collection, and shortly after completion of the maize harvest.

\subsubsection{Data}

A short survey of all 224 farmer groups on the initial list was conducted during meetings with these groups in April-August 2017 (henceforth referred to as census meetings) for the purposes of sample selection, stratification, and balance checks. Data on each group's geographical location, as well as their members' familiarity with weather insurance, awareness of aflatoxin, use of agricultural inputs, and levels of maize production and marketing were collected. Lists of the groups' members, and data on whether each of these was present during the initial meeting, were also obtained.

After selecting 152 groups into the study, baseline survey data were collected in September-October 2017. Both household and group-level surveys were administered immediately prior to the first training meeting, at the site of the meeting. Six farmers per group were randomly selected to be interviewed from among those present during the census meeting. If fewer than six farmers were present at the census meeting, additional farmers were selected from 
among those listed as members but not present. ${ }^{24}$ Of the 3605 group members listed during the census, 892 were interviewed at baseline. ${ }^{25}$ The baseline group-level questionnaire was administered to one or more of each group's leaders.

Administrative data on farmers' purchases of Aflasafe ${ }^{\mathrm{TM}}$ were collected during sales visits in November and early December 2017. For each farmer who purchased the product (including those who purchased less than $4 \mathrm{~kg}$ ), name, gender, land area under maize, and the amount of Aflasafe $^{\mathrm{TM}}$ purchased were recorded. These data were used to construct the main outcome variables: adoption (equal to 1 if the farmer purchased any Aflasafe ${ }^{\mathrm{TM}}$ and 0 if the farmer did not), and adoption intensity (a continuous variable indicating the amount purchased).

A follow-up survey with the same respondents interviewed at baseline was conducted in March-April 2018, after the completion of the maize harvest. Three of the baseline respondents could not be located, resulting in 889 observations at endline.

As the remainder of the paper makes use of different samples, we summarize important sample sizes in Table 3.1.

${ }^{24}$ In case any of the selected farmers were not available, replacements were selected from a randomly ordered list of six additional farmers, selected in the same fashion as the primary sample ${ }^{25}$ In 20 groups, it was not possible to interview six farmers and only five were interviewed. 
Table 3.1. Sample Sizes

\begin{tabular}{lccccccccc}
\hline & \multicolumn{3}{c}{ Market linkage } & \multicolumn{3}{c}{ No market linkage } & \multicolumn{3}{c}{ Total } \\
\cline { 2 - 9 } & Farmers & Groups & Villages & $\begin{array}{c}\text { Farm } \\
\text { ers }\end{array}$ & Groups & $\begin{array}{c}\text { Village } \\
\text { s }\end{array}$ & $\begin{array}{c}\text { Farmer } \\
\text { s }\end{array}$ & Groups & $\begin{array}{c}\text { Village } \\
\text { s }\end{array}$ \\
\hline $\begin{array}{l}\text { All } \\
\text { farmers }\end{array}$ & 1782 & 76 & 62 & 1823 & 76 & 62 & 3605 & 152 & 124 \\
$\begin{array}{l}\text { Surveyed } \\
\text { at baseline }\end{array}$ & 449 & 76 & 62 & 443 & 76 & 62 & 892 & 152 & 124 \\
$\begin{array}{l}\text { Not } \\
\text { surveyed } \\
\text { at baseline }\end{array}$ & 1333 & 76 & 62 & 1380 & 76 & 62 & 2713 & 152 & 124 \\
\hline
\end{tabular}

\subsubsection{Randomization}

The 152 farmer groups that participated in the experiment were located in 124 villages. To avoid within-village spillover effects, assignment to the market linkage treatment was randomized at the village level. Randomization was stratified by county and by rainfall index insurance treatment. Table 3.2 provides statistics describing individual and household-level characteristics of baseline survey respondents, farmer group characteristics and capacity, and agroecological conditions, by market linkage treatment assignment. As explained in Section 3.5.1, the sample used in the impact analysis consists of farmers who were listed during the farmer group census but not interviewed at baseline. Variables from the group census are available for all these farmers, and these values are similarly weighted as in impact regressions. Variables from the individual baseline surveys are only available for peers from the same group, and are reweighted such that the weight of each group equals the weight of the group in the impact regressions. We applied similar reweighting for group-level variables. The registered Pre-Analysis Plan contains a detailed description of the construction of the variables from survey data. ${ }^{26}$ In addition, we show the mean rainfall index insurance trigger by treatment group, obtained from the insurance provider, reflect historic rainfall

${ }^{26} \mathrm{https}$ //www.socialscienceregistry.org/trials/1373 
patterns at the location where the initial group census meeting was held. We find that the market linkage treatment groups are well-balanced on almost all observables.

Table 3.2. Balance at Baseline Across Market Linkage Treatments

\begin{tabular}{|c|c|c|c|c|c|c|c|}
\hline & \multicolumn{3}{|c|}{ Market linkage } & \multicolumn{3}{|c|}{ No market linkage } & \multirow{2}{*}{$\frac{\text { Diff }}{\mathrm{P}}$} \\
\hline & $\mathrm{N}$ & Mean & SD & $\mathrm{N}$ & Mean & SD & \\
\hline Bundled insurance & 76 & 0.535 & 0.556 & 76 & 0.504 & 0.543 & 0.769 \\
\hline \multicolumn{8}{|l|}{ Measured through the group census } \\
\hline Individual present during the census meeting & 1333 & 0.625 & 0.469 & 1380 & 0.537 & 0.503 & 0.375 \\
\hline Respondent is female & 1333 & 0.758 & 0.438 & 1380 & 0.786 & 0.421 & 0.339 \\
\hline \multicolumn{8}{|l|}{ Measured through the baseline individual farmer survey } \\
\hline \multicolumn{8}{|l|}{ Group mean of: } \\
\hline Age of the farmer (completed years) & 449 & 50.1 & 15.8 & 443 & 50.1 & 14.3 & 0.973 \\
\hline Years of education completed by head & 449 & 7.00 & 4.73 & 443 & 7.06 & 4.17 & 0.888 \\
\hline Relationship with the head & 449 & 0.593 & 0.549 & 443 & 0.582 & 0.534 & 0.838 \\
\hline Asset index & 449 & 5.55 & 2.52 & 443 & 5.79 & 2.50 & 0.245 \\
\hline Total land under maize main season previous year (acre) & 449 & 1.49 & 1.27 & 443 & 1.41 & 1.24 & 0.541 \\
\hline Maize harvest main season previous year $(\mathrm{kg})$ & 449 & 446 & 853 & 443 & 430 & 724 & 0.828 \\
\hline Maize marketing: whether sold any maize last season & 449 & 0.460 & 0.558 & 443 & 0.486 & 0.543 & 0.676 \\
\hline Total expenditures on agr. inputs \& labour main season previous year (KES) & 449 & 11081 & 12199 & 443 & 10652 & 12252 & 0.648 \\
\hline Propensity for social learning dummy & 449 & 0.487 & 0.561 & 443 & 0.475 & 0.542 & 0.823 \\
\hline Aflatoxin knowledge index & 449 & 0.012 & 0.895 & 443 & -0.057 & 0.885 & 0.331 \\
\hline Knowledge and experience with insurance & 449 & 1.35 & 0.93 & 443 & 1.30 & 0.87 & 0.513 \\
\hline Individual trust index & 449 & 0.014 & 0.605 & 443 & -0.038 & 0.589 & 0.252 \\
\hline Qualitative risk aversion & 449 & -0.423 & 2.169 & 443 & -0.648 & 2.101 & 0.209 \\
\hline \multicolumn{8}{|l|}{ Measured through the baseline group level survey } \\
\hline \multicolumn{8}{|l|}{ County: } \\
\hline - Meru & 76 & 0.462 & 0.570 & 76 & 0.406 & 0.543 & 0.588 \\
\hline - Tharaka Nithi & 76 & 0.175 & 0.389 & 76 & 0.169 & 0.363 & 0.938 \\
\hline - Embu & 76 & 0.364 & 0.520 & 76 & 0.425 & 0.537 & 0.546 \\
\hline Group capacity index & 76 & 0.094 & 0.791 & 76 & -0.103 & 0.526 & 0.081 \\
\hline Proportion of group members female & 76 & 0.777 & 0.284 & 76 & 0.796 & 0.249 & 0.655 \\
\hline \multicolumn{8}{|l|}{ Data provided by ACRE Africa } \\
\hline Rainfal index insurance trigger for vegetative stage & 76 & 35.6 & 12.8 & 76 & 34.9 & 14.3 & 0.782 \\
\hline Rainfal index insurance trigger for flowering stage & 76 & 1.46 & 0.64 & 76 & 1.40 & 0.71 & 0.678 \\
\hline Rainfal index insurance trigger for ripening stage & 76 & 94.3 & 17.6 & 76 & 94.3 & 17.7 & 0.996 \\
\hline
\end{tabular}

Notes: Group statistics are weighted by the number of farmers from each group in our sample; P-values corrected for village level clustering 


\subsubsection{Farmer expectations at baseline}

Table 3.3 shows summary statistics based on data collected at baseline, of the land farmers planned to plant with maize in the coming season and their expectations of the resulting harvest under normal, poor, and very good conditions. The amount of maize farmers expected to store for household consumption under a normal harvest, and the amount they expected to sell (assumed to be any maize not retained for household consumption) are also shown. Note that the mean expected harvest in a good season is 54\% higher than that expected during normal years, and nearly 4 times above that expected when the harvest is poor, indicating that farmers indeed face considerable upside risk to food safety investments that are not rewarded in the market.

Table 3.3. Maize Production and Sales Expectations at Baseline

\begin{tabular}{lcccc}
\hline & $\mathrm{N}$ & Mean & Median & $\mathrm{SD}$ \\
\hline Total land under maize this season (acres) & 892 & 1.68 & 1.00 & 1.30 \\
Expected harvest if season is normal (kg) & 892 & 925 & 500 & 1150 \\
Expected harvest if season is poor (kg) & 892 & 367 & 180 & 609 \\
Expected harvest if season is very good (kg) & 891 & 1431 & 900 & 1524 \\
Expected maize harvest this season (kg) & 891 & 1251 & 900 & 1338 \\
Amount stored for family consumption, normal harvest & & & & \\
(kg) & 892 & 283 & 225 & 213 \\
Calculated amount sold from a normal harvest (kg) & 892 & 630 & 270 & 998 \\
\hline
\end{tabular}

Note: Variables are winsorized at the 99th percentile 
Based on the statistics in Table 3.3, we can do a back-of-the-envelope calculation of the return on investment for Aflasafe ${ }^{\mathrm{TM}}$. Suppose an average (median) farmer in terms of land treats her entire maize plot with Aflasafe ${ }^{\mathrm{TM}}$ with the intention of selling this maize at a premium of $100 \mathrm{KSH}$ per 90-kg bag above the market price. With a premium of $100 \mathrm{KSH}$ per $90-\mathrm{kg}$ bag, the expected premium payment earned in a normal season is $1,028(556) \mathrm{KSH}$, while the cost of Aflasafe ${ }^{\mathrm{TM}}$ (including rainfall insurance) is 773 (460) KSH including the labor cost of application. ${ }^{27}$ With our price premium, the expected profit from investing in Aflasafe ${ }^{\mathrm{TM}}$ amounts to just $255 \mathrm{KSH}$ (approximately \$2.5 US) at the mean, and less than \$1 US for the median farmer. Moreover, risks associated with the effectiveness of the technology, the unobservable actions of fellow group members, and the buyer's delivery of the incentive payment all reduce farmers' expected return on investment. Investing in Aflasafe ${ }^{\mathrm{TM}}$ for the sole purpose of obtaining the market premium is thus unlikely to make sense for many farmers. We thus conclude that our price premium is modest relative to the costs of adopting Aflasafe ${ }^{\mathrm{TM}}$, so that we can empirically test Propositions 2 and 3 of our theoretical model.

When the price premium is modest, our model predicts that by providing farmers with the option to sell aflatoxin-safe maize at a premium price, the market linkage treatment should increase farmers' investment in the safety of maize for household consumption in the face of an uncertain

${ }^{27}$ We include the cost of insurance, since this was offered to all farmers, and most farmers purchased it, bringing the cost of Aflasafe ${ }^{\mathrm{TM}}$ to $400 \mathrm{KSH}$ per acre treated. The median of agricultural labour in the study area is 360 /day, and the median time spent on application was 1 hour per acre. We assume that a working day consists of 6 working hours. 
harvest. Treated maize would be used for household consumption first, but in the case of a bumper crop, the excess could be sold at a premium price.

To illustrate, using the mean (median) values shown in Table 3.3, a farmer would need to apply Aflasafe ${ }^{\mathrm{TM}}$ to $0.51(0.45)$ acres planted with maize in a normal year to grow a sufficient volume of treated maize for her family's consumption. The cost of Aflasafe ${ }^{\mathrm{TM}}$ in this scenario, including application, is 236 (207) $\mathrm{KSH}$. But in a bad year, Aflasafe ${ }^{\mathrm{TM}}$ would have to be applied to $1.30(1.25)$ acres to attain the same volume of treated maize, at a cost of 596 (575) KSH. While a farmer may wish to ensure safe maize for her family, without access to a premium market for safe maize, she might be hesitant to spend this much on Aflasafe ${ }^{\mathrm{TM}}$, and risk wasting over 350 $\mathrm{KSH}$ of this investment if harvest turns out to be normal (and even more in case of an exceptionally good harvest). But with the incentive, such a farmer could safely purchase enough Aflasafe $\mathrm{e}^{\mathrm{TM}}$ to ensure sufficient treated maize for household consumption even in a bad year, knowing that if the treated land yields more maize than her household requires, she will reap a premium price for this maize. In effect, the market linkage treatment thus reduces the expected cost of precautionary investment in the treatment of maize for home consumption. 


\subsection{Empirical strategy for estimation of treatment effects}

\subsubsection{Main sample}

While new group members were allowed to buy Aflasafe ${ }^{\mathrm{TM}}$, we restrict analysis to the farmers listed during the group census to avoid treatment effects on sample composition. ${ }^{28}$ Further, since being surveyed at baseline may affect later technology adoption behavior and bias treatment effect estimates in general (Zwane et al. 2014) and in our study specifically (Treurniet 2019a), treatment impacts on the sub-sample of surveyed farmers are not externally valid. We therefore focus our main analysis on farmers that were not surveyed at baseline. ${ }^{29}$ In the selection of survey respondents, preference was given to farmers who were present during the group census meeting. Present farmers are therefore under-represented in this non-surveyed sub-sample. We correct for this under-representation by re-weighting observations based on the likelihood of inclusion in the sample, given an individual's presence at the census meeting.

\footnotetext{
${ }^{28}$ For one group, the group census list was lost and re-taken later. Although the group size had not changed, this might have affected the sample composition. Excluding this one group from our analysis, however, does not affect our results.

${ }^{29}$ The proportion being surveyed at baseline did not significantly differ across treatment and control groups $(p=0.627)$.
} 


\subsubsection{Treatment effects}

To assess the effect of the premium market linkage treatment on farmers' adoption of Aflasafe ${ }^{\mathrm{TM}}$, we estimate the following equation both with and without controls: ${ }^{30}$

$$
\text { Adoption }_{i j v}=\alpha_{1}+\beta_{1} \cdot \text { Market }_{v}+\left(\gamma_{1} \cdot X_{i j}\right)+\varepsilon_{i j v 1}
$$

${\text { where } \text { Adoption }_{i j v} \text { represents Aflasafe }}^{\mathrm{TM}}$ adoption or amount of adoption by farmer $i$ in farmer group $j$ in village $v$, and Market $_{v}$ indicates whether the village was assigned to the market linkage treatment. $X_{i j}$ is the vector of controls, as specified in the Pre-Analysis Plan and listed in Table 3.2. ${ }^{31}$ However, in line with our Pre-Analysis Plan, we use group means for variables measured through the individual baseline survey. $\varepsilon_{i j v 1}$ is the error term. Standard errors are clustered at the village level. To test the impact of our market linkage treatment, we test whether $\beta_{1}=0$.

\subsubsection{Alternative samples}

We perform the same analysis on two alternative samples. First, although we randomly selected the sample to be surveyed, actual participation in the survey may be endogenous. Our primary sample, which excludes surveyed farmers, may thus be constituted of relatively less engaged members of participating farmer groups. As a robustness check, we therefore perform the same analysis as above on the subsample that excludes all twelve farmers who were randomly selected as primary or replacement survey respondents, while still correcting for the under-representation of farmers present at the census meeting. Second, we complete the analysis using the full sample,

\footnotetext{
${ }^{30}$ All estimates are intention-to-treat. We cannot estimate the effect of treatment on the treated, as we do not have information on which farmers were aware of the premium price.

${ }^{31}$ The vector $X_{i j}$ includes a dummy indicating assignment to the bundled insurance treatment.
} 
including the five to six farmers surveyed at baseline, as specified in our Pre-Analysis Plan. As being surveyed at baseline significantly affects adoption, we additionally control for baseline survey status in the specifications that include baseline controls.

\subsection{Results}

In Table 3.4 we report estimates of the impact of the premium market linkage treatment on adoption. We analyze whether farmers in groups assigned to the market linkage treatment were more likely to purchase any Aflasafe ${ }^{\mathrm{TM}}$ and whether the amount of adoption, measured as the quantity of Aflasafe ${ }^{\mathrm{TM}}$ purchased (in kg), was higher in these groups. Columns 1 and 2 of Table 3.4 show no significant impact of the market linkage treatment on the extensive margin of adoption. The point estimates suggest an increase in adoption of around four percentage points (close to one third of the control group mean), but the estimates are statistically insignificant. In contrast, the amount of Aflasafe ${ }^{\mathrm{TM}}$ purchased is significantly higher in groups assigned to the market linkage treatment. The estimates in columns 3 and 4 show that these farmers purchased 0.26- $0.28 \mathrm{~kg}$ more Aflasafe ${ }^{\mathrm{TM}}$ on average, an increase of almost $100 \%$ relative to the control group.

Table 3.4. Impact of Market Linkage Treatment

\begin{tabular}{lcccc}
\hline & \multicolumn{4}{c}{ Outcome variables } \\
\cline { 2 - 5 } & $(1)$ & $(2)$ & $(3)$ & $(4)$ \\
\cline { 2 - 5 } & Adoption & Adoption & Amount $(\mathrm{kg})$ & Amount $(\mathrm{kg})$ \\
\hline Market linkage & 0.036 & 0.042 & $0.276^{* * *}$ & $0.258^{* * *}$ \\
& $(0.026)$ & $(0.027)$ & $(0.083)$ & $(0.078)$ \\
Baseline controls & No & Yes & No & Yes \\
Villages & 124 & 124 & 124 & 124 \\
Observations & 2713 & 2713 & 2713 & 2713 \\
Mean of no market linkage & 0.128 & 0.128 & 0.290 & 0.290 \\
\hline Notes: Standard errors clustered at village level in parentheses; * $<<0.10, * * \mathrm{p}<0.05, * * *$ & & & \\
$\mathrm{p}<0.01$ & \multicolumn{5}{c}{}
\end{tabular}


In line with our model, these findings suggest that farmers who purchase Aflasafe ${ }^{\mathrm{TM}}$ use it first on maize produced for their own consumption. Indeed, endline descriptive statistics in panel A of Table 3.5 indicate that among farmers who purchased Aflasafe ${ }^{\mathrm{TM}}, 83 \%$ (in the market linkage group) to $89 \%$ (in the control group) reported doing so in order to have safe maize for household consumption. In contrast, the ability to sell maize at a premium price was reported by only $5 \%$ of farmers in the control group and $19.4 \%$ in the market linkage group. An index of aflatoxin knowledge (constructed to have a mean of zero and standard deviation of one at baseline) increased to the same extent in groups with and without the market linkage, and both groups held similar beliefs about the efficacy of Aflasafe ${ }^{\mathrm{TM}}$. This suggests that the market linkage treatment did not affect behavior through farmers' level of knowledge or beliefs, for example by focusing their attention during the training, or by providing evidence that maize buyers trusted Aflasafe $\mathrm{e}^{\mathrm{TM}}$ to be effective. 


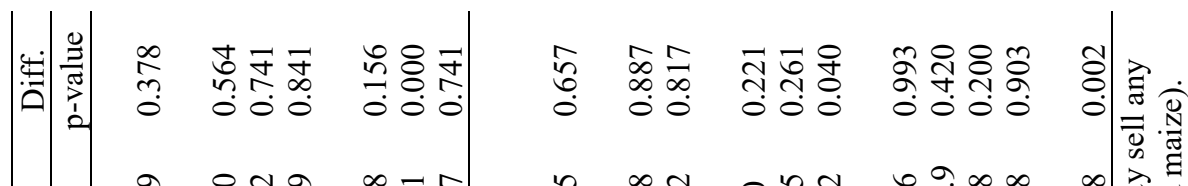

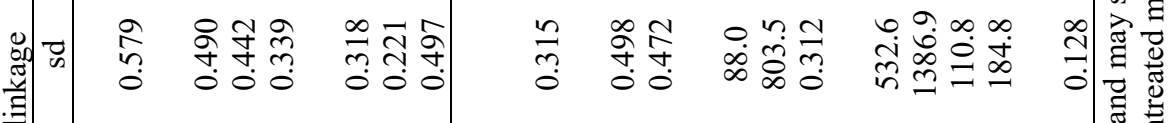

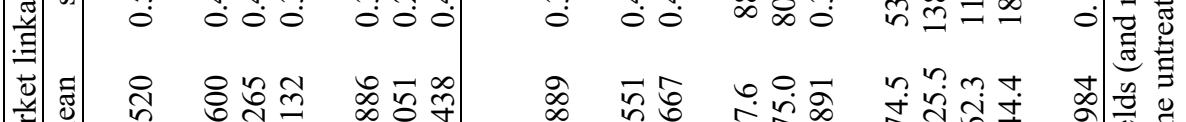

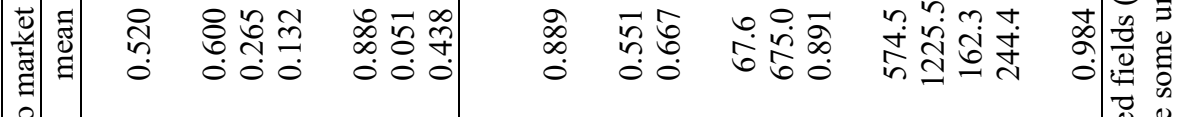

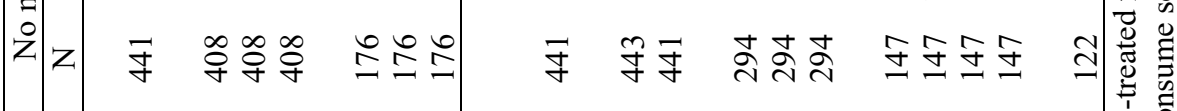

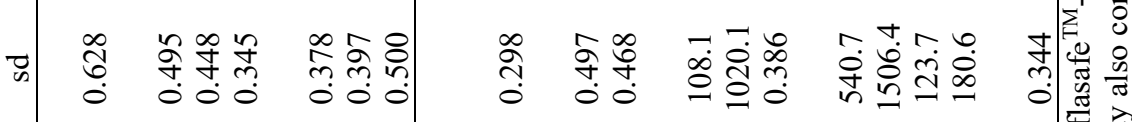

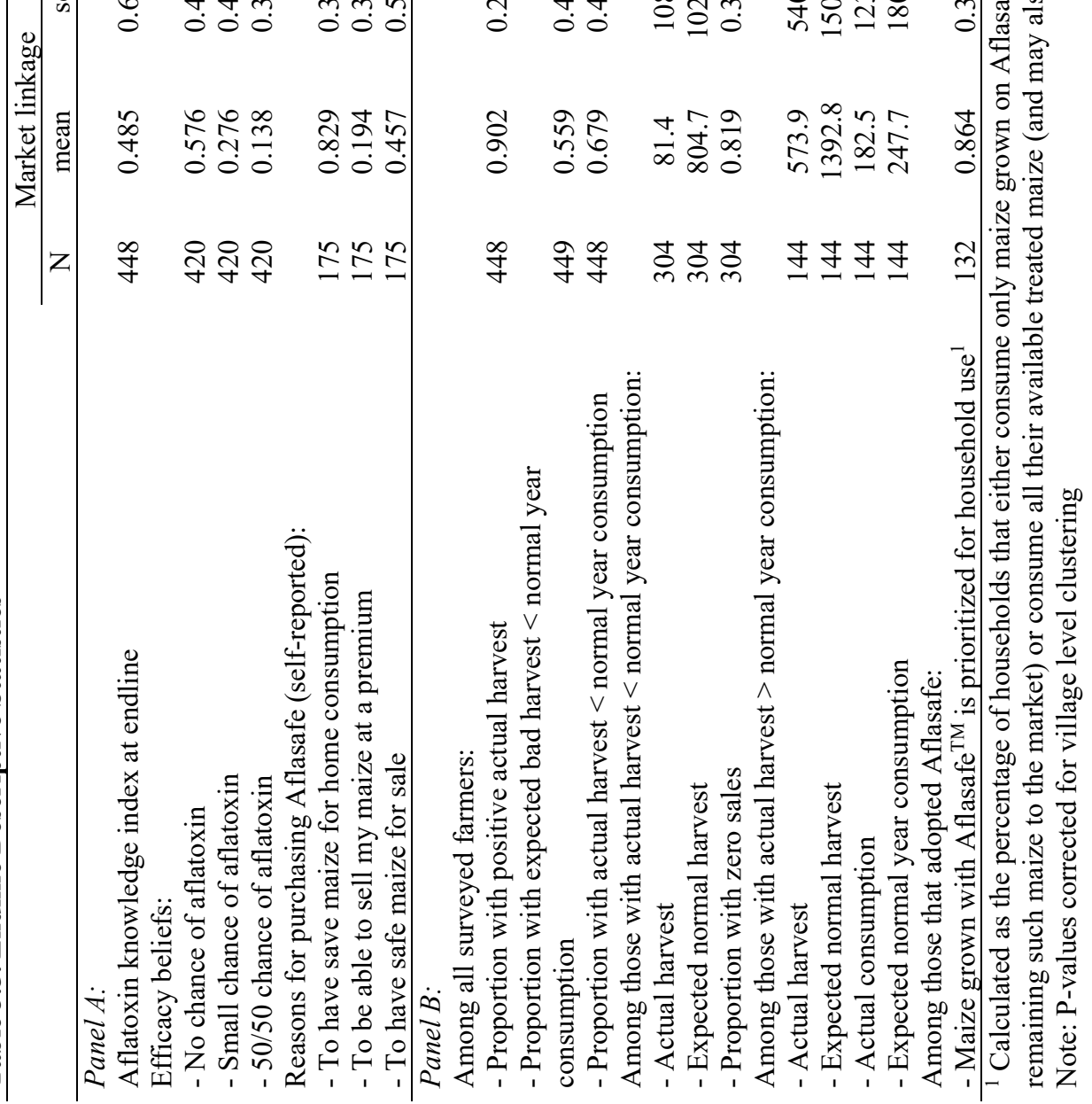


As the control group means in Table 3.4 indicate, control group adopters purchased $2.27 \mathrm{~kg}$ of Aflasafe $^{\mathrm{TM}}$, on average (dividing the mean amount by the proportion adopting). This is sufficient to treat 0.57 acres of land, very close to the mean value of 0.51 acres required to ensure safe maize for own consumption in a normal year based on the mean statistics shown in Table 3.3. Adopters in groups assigned to the market linkage treatment purchased an average of $3.22-3.45 \mathrm{~kg}$, sufficient to treat $0.81-0.86$ acres. Treating this area of land with Aflasafe ${ }^{\mathrm{TM}}$ means a family would be closer to producing enough safe maize to cover their own consumption needs even if the harvest is poor (though still short of the mean poor harvest requirement of 1.3 acres), while in the case of an exceptionally good harvest would stand to earn a premium payment of over $470 \mathrm{KSH}$, more than covering the cost of the investment in biocontrol.

The season we analyze turned out to be an exceptionally bad one. As an illustration of this, rainfall index insurance payouts were triggered for $98 \%$ of farmers who had purchased and activated a policy sold through the project. While Table 3.3 showed that the average (median) farmer expected to harvest $367(180) \mathrm{kg}$ in case of a poor season, the actual amount of maize harvested was much lower, with a mean of less than $240 \mathrm{~kg}$ and a median of $90 \mathrm{~kg}$. This falls short of the amount stored for home consumption in a normal year (see Table 3.3), which allows us to assess some features of our theoretical model.

As reported in Panel B of Table 3.5, the actual harvest fell short of normal year home consumption for two thirds of the farmers in our sample. Among these farmers, the vast majority did not sell any maize. For farmers whose harvest exceeded normal year home consumption, we see that the actual harvest was about $40 \%$ of the expected normal harvest, while actual consumption was about $70 \%$ of normal year consumption. This shows that the assumption, used 
in our theoretical model, that farmers consume their entire harvest up to some fixed subsistence need, while not strictly correct, does not deviate too far from reality.

Finally, the bottom row of Table 3.5 shows that most farmers consumed all maize grown on fields treated with Aflasafe ${ }^{\mathrm{TM}}$ themselves, and only sold this maize if the amount produced exceeded household consumption needs. This supports our assumption that farmers first use safe maize for household consumption.

\subsubsection{Robustness checks}

As discussed in Section 3.5.1, our main analysis focuses on the sub-sample of non-surveyed farmers. This approach is driven by the concern that being surveyed at baseline might itself affect technology adoption, and thus bias treatment effects. However, being surveyed at baseline was not entirely random. While we account for the probability of selection given presence at the census meeting through reweighting, we did not always manage to interview the first six sampled farmers. Whether or not a sampled farmer actually participated in the baseline survey could reflect unobserved characteristics correlated with the probability of adopting a new technology.

To assess the robustness of our results with respect to the estimation sample, we estimate treatment effects across two alternative samples. Appendix Table A3.1 in Appendix 3.2 presents these results. In columns 1 to 4 the sample excludes all farmers selected for the baseline survey (either within the primary list of six farmers, or in the ordered list back-up list of six additional farmers, as explained in Section 3.2.4), irrespective of whether or not they participated in the survey. Columns 5 to 8 present the estimates for the full sample, including all farmers surveyed at baseline. These results indicate that sample selection does not qualitatively affect our findings: the 
market linkage premium did not significantly affect Aflasafe ${ }^{\mathrm{TM}}$ adoption in either of these alternative samples, while it had a positive and significant effect on the amount purchased in both.

\subsection{Discussion}

Many food safety hazards, likely including contamination with fungal toxins, are most effectively addressed during production. Technologies appropriate for use by small-scale producers are available, but adoption is a challenge. In settings where the scale of production is small and output markets informal, incentives to invest in costly to observe attributes such as food safety are absent. To create the market conditions for pass-through of price rewards for food safety, farmers' produce must first be aggregated to a volume at which it can be tested for hazards at reasonable cost.

Another barrier to adoption of food safety technologies is production risk. These technologies must often be applied before the outcome of a stochastic production process is realized. Their use thus increases production costs with certainty but has an uncertain impact on the value of production. This is the case whether farm produce is consumed solely by the household or sold.

We tested the impact of a price premium for aflatoxin-safe maize on farmer demand for the new biocontrol product Aflasafe ${ }^{\mathrm{TM}}$. The value of the premium offered for safe maize was modest - approximately $5 \%$ of the value of maize in the year it was offered. We find that the premium offer increased the intensity of Aflasafe ${ }^{\mathrm{TM}}$ adoption but had no impact on the extensive margin of adoption.

To explain this finding, we reason that the premium offer reduced the expected cost of producing a sufficient quality of safe maize for subsistence given the production risk inherent to this rainfed maize system. Farmers offered the premium were more likely to treat enough land to 
ensure that in the case of a poor harvest, they would still have enough safe maize to meet their household needs, since in the case of a good harvest, they could sell the excess for a profit. This explanation is consistent with the observation that at the end of the maize growing season, which turned out to be a bad one, only 20 of 76 eligible groups actually aggregated any maize for sale at the premium price.

The finding that a quality premium too low to induce adoption from a purely profitmaximizing standpoint can affect technology adoption among smallholders is relevant to food safety policy in developing countries in which subsistence production is widespread. If demand for food safety among higher-income urban consumers can support even a low-value premium, this can have a significant impact on the amount of safe food produced - with positive health consequences for both subsistence producers and consumers of the premium product. Our results further show that members of producer groups are able to overcome potential barriers to collective action associated with group-level quality testing. As the transmission to farmers of market incentives for safer food will likely depend on such mechanisms, this is an encouraging finding. 


\section{Appendix}

\section{Appendix 3.1. Mathematical details}

$$
\begin{aligned}
& f(I)=\int_{q_{L}}^{q_{\text {home }} / I} I q \frac{1}{q_{H}-q_{L}} d q+\int_{\widetilde{\text { home }} / I}^{q_{H}} \widetilde{q_{\text {home }}} \frac{1}{q_{H}-q_{L}} d q \\
& =\left[\frac{1}{2} I q^{2} \frac{1}{q_{H}-q_{L}}\right]_{q=q_{L}}^{q=q \widetilde{\text { home }} / I}+\left[q \widetilde{q q_{\text {home }}} \frac{1}{q_{H}-q_{L}}\right]_{q=q_{\overparen{\text { home }} / I}^{q=q_{H}}} \\
& =\frac{1}{2} I\left[\left(\widetilde{\frac{q_{\text {home }}}{I}}\right)^{2}-q_{L}^{2}\right] \frac{1}{q_{H}-q_{L}}+\left[q_{H}-\widetilde{q_{\text {home }}}\right] \widetilde{q_{\text {home }}} \frac{1}{q_{H}-q_{L}} \\
& =\frac{1}{2} \frac{1}{q_{H}-q_{L}}\left[-{\widetilde{q_{\text {home }}}}^{2}-Q_{L} I+2 q_{H} \widetilde{q_{\text {home }}}\right] \\
& \frac{\partial f(I)}{\partial I}=\frac{1}{2} \frac{1}{q_{H}-q_{L}}\left[\widetilde{q_{\text {home }}} I^{2}-q_{L}\right]=\frac{1}{2} \frac{\left(\widetilde{q_{\text {home }}} / I-q_{L}\right)\left(\widetilde{q_{\text {home }}} / I+q_{L}\right)}{q_{H}-q_{L}}
\end{aligned}
$$

\begin{tabular}{|c|c|c|c|c|c|c|c|c|}
\hline & \multicolumn{8}{|c|}{ Outcome variables } \\
\hline & (1) & (2) & (3) & (4) & $(5)$ & $(6)$ & (7) & $(8)$ \\
\hline & $\begin{array}{c}\text { Adopti } \\
\text { on }\end{array}$ & $\begin{array}{c}\text { Adopti } \\
\text { on }\end{array}$ & $\begin{array}{l}\text { Amount } \\
(\mathrm{kg})\end{array}$ & $\begin{array}{c}\text { Amount } \\
(\mathrm{kg})\end{array}$ & $\begin{array}{c}\text { Adopti } \\
\text { on }\end{array}$ & $\begin{array}{c}\text { Adopti } \\
\text { on }\end{array}$ & $\begin{array}{c}\text { Amount } \\
(\mathrm{kg})\end{array}$ & $\begin{array}{l}\text { Amount } \\
(\mathrm{kg})\end{array}$ \\
\hline \multirow{2}{*}{ Market linkage } & 0.023 & 0.035 & $0.231 * *$ & $0.227 * * *$ & 0.021 & 0.021 & $0.215^{* *}$ & $0.168 * *$ \\
\hline & $(0.027)$ & $(0.027)$ & $(0.090)$ & $(0.084)$ & $(0.027)$ & $(0.026)$ & $(0.089)$ & $(0.078)$ \\
\hline \multirow[t]{2}{*}{ Baseline controls } & No & Yes & No & Yes & No & Yes & No & Yes \\
\hline & $\begin{array}{l}\text { Non- } \\
\text { listed }\end{array}$ & $\begin{array}{l}\text { Non- } \\
\text { listed }\end{array}$ & $\begin{array}{l}\text { Non- } \\
\text { listed }\end{array}$ & $\begin{array}{l}\text { Non- } \\
\text { listed }\end{array}$ & Full & Full & Full & Full \\
\hline Villages & 118 & 118 & 118 & 118 & 124 & 124 & 124 & 124 \\
\hline Observations & 1795 & 1795 & 1795 & 1795 & 3605 & 3605 & 3605 & 3605 \\
\hline Mean of no market & & & & & & & & \\
\hline linkage & 0.111 & 0.111 & 0.246 & 0.246 & 0.174 & 0.174 & 0.441 & 0.441 \\
\hline
\end{tabular}

Appendix 3.2. Additional table

Appendix Table A3.1. Impact of Market Linkage Treatment Alternative Samples 


\section{Chapter 4}

\section{The Role of Producer Organizations in the Adoption of a Food Safety Technology Sarah Wairimu Kariuki}

This chapter examines group characteristics that are correlated with individual group member's adoption of food safety technology. It also explores the mechanisms behind such correlations. Results show that the size of the group and member heterogeneity are negatively correlated with members' adoption of the technology. Further analysis seems to support the hypothesis of more social cohesion in smaller groups, that may facilitate information sharing and learning among members, and the idea that members are more likely to learn from similar members. Despite liquidity constraints being mentioned by several non-adopters as a major barrier to adoption, I did not find strong evidence that groups in this context help to relax this constraint. In conclusion, this chapter finds some evidence that groups may play a role in relaxing members' informational constraints to adoption. 


\subsection{Introduction}

Food safety hazards are responsible for a considerable burden of disease globally, with the Low and Middle-Income Countries (LMICs) bearing a higher burden than the rest of the world (Jaffee et al. 2018; WHO 2015). Also, food safety hazards may limit access to high-value markets with food safety standards (Munasib and Roy 2011a). Effective technologies to improve food safety at the farm level exist. However, adoption of these technologies by producers in LMICs may be hindered by several factors, including lack of information on the benefits and correct use of these technologies, liquidity constraints coupled with inefficient credit markets, and lack of market incentives for safe food (Ashraf, Giné, and Karlan 2009; Hoffmann, Magnan, et al. 2018; Hoffmann and Jones 2018; Jack 2013, Chapter 3). In this chapter, I examine whether producer organizations can affect members' adoption of food safety technology by relaxing some of these constraints.

Producer organizations may affect individual members' adoption of food safety technology in several ways. First, such organizations may act as sources of financial services, thus helping members overcome liquidity constraints to adoption. Second, groups may affect individual members' adoption decisions by facilitating information sharing and learning among the members. Third, producer organizations can be used to cost-effectively test compliance with food safety standards by small-scale farmers through the aggregation of produce at the group level. In such cases, members' adoption of food safety technologies may depend on their belief about the actions of other group members and the social cohesion among members.

Producer organizations may vary in their capacity to provide these benefits to members. One of the factors that may affect producer organizations' capacity to provide benefits to members is the group's structural characteristics, for instance, the number of members or member 
homogeneity. Group ${ }^{32}$ characteristics may affect the likelihood of achieving collective action in a group (Ostrom 2010; Shiferaw, Hellin, and Muricho 2011). Empirical studies have found group characteristics to be correlated with groups' capacity to provide collective output marketing, input access, and technical information to the members (Banaszak 2007; Barham and Chitemi 2009; Bernard and Seyoum 2012; Fischer and Qaim 2014; Ragasa and Golan 2014). These studies find mixed results that are highly contextual. This chapter examines group characteristics that are correlated with the member's adoption of new technology.

Knowledge of the type of groups that can facilitate the adoption of improved technologies by farmers in the LMICs is important. First, producer organizations are widespread in developing countries (Bernard et al. 2007), thus providing an opportunity that can be leveraged to increase the adoption of improved technologies. Second, knowledge of whether producer organizations can facilitate information sharing and learning among members is important in these contexts that are characterized by weak capacity in the public extension (Anderson and Feder 2004). Lastly, knowledge of whether producer organizations can act as a source of cheap credit or savings is also important given the inefficiencies in the financial markets (Jack 2013).

Several studies have examined the impact of membership to producer organizations on members' access to new technologies (Abdul-rahaman and Abdulai 2018; Chagwiza, Muradian, and Ruben 2016; Fischer and Qaim 2012; Jin and Zhou 2011; Verhofstadt and Maertens 2014). A general finding is that farmers who belong to producer organizations are more likely to adopt improved technologies compared to non-members. However, the literature on the type of groups that are likely to foster or hinder members' adoption of new technologies is scant. An exception is a study by Ragasa and Golan (2014) that examined the role of producer organizations' internal and

32 The term 'group' is used interchangeably with producer organization 
external characteristics on the performance of the group measured by a groups' ability to provide agricultural inputs and technical information to the members. The outcome variables in Ragasa and Golan's study were measured at the group level based on the group leaders' subjective assessment. The current study uses administrative data collected on individual group members to examine the role of group characteristics on individual member's adoption decisions.

The chapter also contributes to the literature on the role of collective action in improving food safety in the LMICs. A few case studies have documented the role that groups played in facilitating small-scale farmers' access to export markets with food safety requirements (Narrod et al. 2009). A study closely related to this chapter used quantitative methods to assess the role of structural and institutional characteristics of vegetable organizations in Vietnam on a group's ability to jointly comply with market requirements of safe pesticide use in vegetables (Naziri et al. 2014). This study's main outcome was measured as the level of pesticide toxicity in samples collected from three farmers per group.

The study by Naziri et al. is conceptually similar to the current study in that it explores the group characteristics that are likely to foster cooperation among members thus reduce free-riding among the members. In the current study, free riding can occur if some members of the group delay adoption, so that they learn about the technology from others (avoid bearing the risk of experimenting with new technology) or if some members believe that other members are likely to aggregate unsafe maize. The current study also explores other groups' roles, like credit provision and learning, that may facilitate technology adoption. Lastly, my outcome variable contains observations from all the group members, thus having a higher variation than the three samples per group used to construct the main outcome variable in the Naziri et al. study.

Results show a strong negative correlation between the group's size and the members' adoption of biocontrol. Further analysis shows that members in smaller groups have higher levels 
of trust among themselves. Small groups with high levels of trust among members may affect adoption through two channels. First, information sharing and learning among members-members can only learn from others if they trust the information shared by these members (Buck and Alwang 2011). Second, through the requirement to aggregate produce before testing for compliance. The data in this study does not support the second channel since the effect of group size is similar in groups that were not expected to aggregate their maize.

Member heterogeneity, measured in terms of age, education, the scale of operation, and asset ownership, is negatively correlated with members' adoption of the technology. Again, I do not find support that this characteristic affects adoption through the requirement to aggregate produce. I speculate that members are more likely to learn from members who have similar characteristics (BenYishay and Mobarak 2014); thus, more learning occurs in groups with homogeneous membership.

I find some weak evidence that groups with more female members are likely to increase members' probability of adoption. The age of the group, membership to a larger group, education level of members, and groups involved in rotating credit and savings activities are not correlated with members' probability of adoption. Thus, I do not find strong evidence that groups affect members' adoption by relaxing their liquidity constraints. Overall, these results support the information sharing hypothesis, an indicator that information is a constraint to the adoption of technologies in this context.

The rest of the paper proceeds as follows. I describe the study setting, including the project details in Section 4.2. Section 4.3 outlines the conceptual framework and the hypotheses tested, while Section 4.4 outlines the study design. I describe the empirical strategy in Section 4.5. Section 4.6 presents the results, and section 4.7 concludes. 


\subsection{Study setting}

\subsubsection{The biocontrol technology}

I study the adoption of Aflasafe ${ }^{\mathrm{TM}}$, a biocontrol for aflatoxin contamination, by small-scale farmers who are members of producer organizations in the Eastern region of Kenya. Aflatoxin contamination in maize is common in the study region. Aflatoxin levels above the Kenyan regulatory limit ${ }^{33}$ have been found in as much as $50 \%$ of samples collected from maize stored for home consumption and maize sold in the market (Daniel et al. 2011; Pretari et al. 2019). Biocontrol technology has been shown to be effective in reducing aflatoxin contamination in maize (Atehnkeng et al. 2014; Bandyopadhyay et al. 2019; Senghor et al. 2020; Chapter 5). The technology is relatively new in Africa. Production in Kenya started in 2017, two years after its approval by the Kenyan Government.

\subsubsection{Project details}

The current study consists of 152 producer organizations in Meru, Tharaka Nithi, and Embu counties in Eastern Kenya. Members were trained on the benefits and use of biocontrol. Extension agents from the Cereal Growers Association, a national member-based farmer organization, conducted farmer training. Group members were invited for two half-day trainings. During the first training, members were taught the dangers of consuming contaminated foods and the role of the biocontrol in reducing aflatoxin contamination in maize. In the second training, members were trained on how to apply the biocontrol product. The first training was conducted in September-

33 The current Kenyan limit for food meant for human consumption is $10 \mathrm{ppb}$. However, the regulatory limit was previously $20 \mathrm{ppb}$, and this is what is used in some of the studies cited here. 
October 2017 around the planting time in the study region, while the second was held in NovemberDecember 2017, some weeks after planting.

The biocontrol product was sold to the members during the November-December training, in packages of four $\mathrm{kg}$, at KES 320 (approximately USD 2.95). This cost is within the range of the cost of production and consideration for a potential subsidy (about 50\%) by the Kenyan Government (Hoffmann, Kariuki, et al. 2018).

In addition to being offered the technology, we offered some producer organizations a chance to sell their treated maize through the project at a bonus of KES 100 (approximately USD $0.92)$ per $90 \mathrm{~kg}$ bag. To qualify for the bonus, these farmers were required to aggregate their maize at the group level. A test was done on the aggregated maize to test if the aflatoxin levels were below the Kenyan regulatory total aflatoxins limit of $10 \mathrm{ppb}$. It was made clear during the training that the bonus would only be paid if the aggregated maize was found to be below the $10 \mathrm{ppb}$. Aggregation and payment of the bonus were done in March 2018, at the end of the season.

\subsubsection{Constraints to the adoption of the biocontrol}

The adoption of biocontrol technology in this context is likely to be constrained by several factors. First, Aflasafe ${ }^{\mathrm{TM}}$ is a new technology; thus, its correct use and associated benefits are not fully known by the farmers. Information on its benefits and correct use was provided to all the groups in the sample. However, the effect of information on an individual member's adoption decision may depend on other factors. For instance, individuals may vary in their ability to decode information, especially for technologies that are unfamiliar and hard to decipher (Foster and Rosenzweig 2010). In other cases, farmers may receive the information but later fail to act on it due to attentional challenges (Larochelle et al. 2019). While most of the existing aflatoxin 
management options for small scale farmers are easy to understand and use ${ }^{34}$, understanding how Aflasafe $^{\mathrm{TM}}$ works and its correct use is not trivial. Aflasafe ${ }^{\mathrm{TM}}$ displaces toxigenic fungi from the soil resulting in less accumulation of these fungi in the crop. Once applied to the maize fields, it does not affect the yield of the crop, or the nutritional value and taste quality of the harvested crop. Its ability to displace the toxic fungi depends on correct use in terms of the timing of application ( 2 weeks before the crop flowers) and application intensity (4 $\mathrm{kg}$ per acre) (Chapter 5$)$.

Attendance during the training was not a hundred percent in some groups. On average, around $56 \%$ of members attended the first meeting ${ }^{35}$, while around $50 \%$ attended the first training on aflatoxin and the role of biocontrol in reducing contamination. An individual member's adoption of the biocontrol may thus depend on how well individual members share information within a group.

Second, the biocontrol is applied while the maize is in the field, 2-3 weeks before flowering. The biocontrol was made available during this time. Given that this is a lean season for a majority of the farmers and that the technology was offered at a cost, liquidity constraints, and a lack of well-functioning financial markets may hinder its adoption.

Third, the bonus price - offered to a randomly selected subset of villages - was conditional on the aggregated maize testing below $10 \mathrm{ppb}$, the aflatoxin limit in Kenya. Given the volume of maize produced and sold by individual farmers in the study region, the cost of testing every individual member's maize can be very high. This cost is greatly reduced by aggregating maize at the group level and conducting a single test on the aggregated maize. In this context, an individual's

\footnotetext{
${ }^{34}$ For example a drying barrier (tarpaulin) or proper storage or manual sorting

35 The names of all the members in all the groups were recorded during this meeting, thus referred to as the census in the rest of the document
} 
adoption of the biocontrol is likely to be affected by their belief concerning the strategic actions of other members in the group and in the ability of the group to coordinate members' actions to minimize free-riding and ensure the aggregated maize meets the required standard.

Since the biocontrol was offered through the groups, some group members may have delayed adoption in the hope that others will adopt, thus allowing them to learn more about the technology. During the meetings, members were informed that the technology would eventually be available in the shops after the study. While the outcome associated with the adoption of biocontrol is not directly observable, some form of learning can take place during its use and application. For example, sporulation of the biocontrol product a few days after its application is observed and is an early indicator of its efficacy. The aggregation of maize at harvest and testing of the aggregated maize offers another learning opportunity for the members on the efficacy of the biocontrol, on the actualization of the bonus and on the ability of the group members to achieve collective action.

Table 4.1 shows farmers' subjective reasons for adoption or non-adoption of the biocontrol, as reported by a subset of members in every group interviewed during the follow-up survey at the end of the cropping season. A majority of farmers $(87 \%)$ stated the desire to have safe maize for home consumption as one of the reasons for purchasing the biocontrol. The desire to have safe maize for sale was stated by about half of the adopters. Only $10 \%$ of the adopters stated the desire to earn a bonus as a reason for purchasing the technology. Adoption of the biocontrol in this context seems to be mainly driven by a desire to have safe maize for home consumption.

Lack of money was stated as one of the reasons for not purchasing the technology by about half of the non-adopters. Absence during the meeting when the biocontrol was sold or a lack of opportunity to purchase the biocontrol was stated by almost $40 \%$ of the non-adopters. Other reasons include crop failure due to drought or pest damage reported by $4 \%$ of the non-adopters, and failure 
to find a partner in case the farmer wished to purchase less than one packet of Aflasafe ${ }^{\mathrm{TM}}$, stated by $3 \%$. In a few cases (one percent of cases), Aflasafe ${ }^{\mathrm{TM}}$ was offered when maize was past the stage when it should be applied. Overall, liquidity constraints and failure to attend the training seem to be major constraints to the adoption of Aflasafe ${ }^{\mathrm{TM}}$ for the farmers in our sample. The main aim of this chapter is to examine group characteristics that are likely to relax these constraints, thus encouraging members' adoption of Aflasafe ${ }^{\mathrm{TM}}$. 
Table 4.1. Farmers' Subjective Reasons for Purchasing or Failing to Purchase Aflasafe ${ }^{\mathrm{TM}}$

Proportion of

farmers

Reasons for purchasing the biocontrol $(N=300)$

To have safe maize for home consumption

0.87

To have safe maize for sale

0.48

To be able to sell my maize at a premium

0.12

To experiment with Aflasafe ${ }^{\mathrm{TM}}$

0.02

Convincing training

Reasons for not purchasing the biocontrol $(N=465)$

I did not have money to buy Aflasafe ${ }^{\mathrm{TM}}$

I was not available when Aflasafe ${ }^{\mathrm{TM}}$ was offered to the group/ I was not

offered Aflasafe ${ }^{\mathrm{TM}}$

My maize was destroyed by the fall armyworm/drought

0.04

I needed less than $4 \mathrm{~kg}$ and did not get anyone to team up with

0.03

I did not plant maize in the season when Aflasafe ${ }^{\mathrm{TM}}$ was offered

0.03

Aflasafe $^{\mathrm{TM}}$ was offered too late when my maize had already passed the

application stage

0.02

I did not see/understand the benefits of Aflasafe $\mathrm{e}^{\mathrm{TM}}$

0.01

Author's compilation from data collected during the follow-up individual-level survey 


\subsection{Conceptual framework and hypotheses}

This section provides a conceptual framework of how group characteristics may affect the members' adoption behavior by addressing the constraints to adoption described in Section 4.2. An individual member's adoption of the technology depends on their expected benefits and costs associated with the use of the technology. The main costs associated with the adoption of the biocontrol are the money required to purchase the technology and the labor requirements during the application. Its benefits include the health benefits of consuming safer food and, for some farmers, a bonus from the sale of safer food. An individual's realization of these benefits is likely to be influenced by other factors like the risks and uncertainties related to experimentation with the technology, the behavior of other members during the sales, shocks that may result in crop failure, and the prevailing market conditions for financial services. Such factors may lower an individual's expected benefits from adoption.

Liquidity constraint was the most stated reason for failing to purchase the biocontrol. Lack of access to affordable credit and other financial services like savings products is thus likely to constraint the adoption of Aflasafe ${ }^{\mathrm{TM}}$. Producer groups can be a source of cheap loans and savings to the members. I hypothesize that groups that offer credit and savings as one of the group's activities increase the likelihood of an individual member's adoption of the biocontrol.

Slightly over a third of farmers stated absence in training as a reason for failing to purchase the biocontrol. A farmer who was absent during the training can learn about the technology from others in the group. In this case, information flow among group members can affect an individual member's adoption decision. Besides, farmers with greater human capital skills in a group may decode information more efficiently, allowing an individual with lesser skills to learn more from his/her fellow group members. Also, information sharing among members may serve as reminders 
of the information provided during the training. Lastly, information sharing and coordination of group member's activities can minimize strategic delays by some members.

I test six group characteristics that may affect members' adoption through the informationsharing mechanism. First, I test the role of group size. The number of members in a group may affect the flow of information in a group through various channels. Group size may affect the intensity of the individual member's participation in the group, thus affecting the level of interaction among the members and information flow in the group (Fischer and Qaim 2014). More members in a group also imply that more information is available to the members. However, a large group may increase coordination costs, thus reducing the trust levels among group members (Aflagah, Bernard, and Viceisza 2019; Poteete and Ostrom 2004). Low levels of trust among members may reduce the effectiveness of information sharing among the members. The direction of the effect of the group size on adoption is thus difficult to predict a priori.

Second, I test the role of the age of the producer group. Trust and member commitment are likely to be higher in older groups, stimulating more interactions among the group members (Tadesse and Kassie 2017). Thus older groups are hypothesized to increase the likelihood of members' adoption Aflasafe ${ }^{\mathrm{TM}}$.

Third, groups that are members of an umbrella organization ${ }^{36}$ can increase the likelihood of members' adoption of the biocontrol since these may serve as sources of information on the biocontrol technology and aflatoxin in general. Such groups also tend to have more linkages with donors and other partners (Ragasa and Golan 2014). Having more information and knowledge on

\footnotetext{
36 An umbrella organization in this context is a larger group made of several producer organizations. While producer organizations are mostly formed at the village level, the umbrella organizations cover a larger geographical location for example the ward or the county.
} 
the issue of aflatoxin and benefits associated with reducing consumption of contaminated foods may increase the salience of the information provided during the training, thus increasing the likelihood of adoption.

Fourth, women are more likely to cooperate and interact more in a group (Ortmann and Tichy 1999; Tadesse and Kassie 2017); hence groups with a higher proportion of women are hypothesized to increase individual members' adoption of the technology.

Fifth, groups where leaders have gone through management training are expected to increase the probability of a member's adoption of the biocontrol. Building the capacity of the group leaders can improve their ability to provide technical advice to the members and improve their management skills, thus creating a conducive environment for information sharing among members. Management training was found to be positively correlated with the probability of a group providing technical advice to the members (Ragasa and Golan 2014). Also, training leaders, as well as members, may increase trust among the members and trust in leaders (Bernard et al. 2015), a factor that can facilitate information sharing among the members.

As stated earlier, more educated individuals can process information better than less educated individuals. A group with more educated members is hypothesized to increase the probability of a member's adoption of the biocontrol. Note that education can also affect adoption through the income effect (Foster and Rosenzweig 2010); that is, more educated people are likely to earn more. Therefore, groups with more educated members may have higher rates of adoption if there is some resource sharing among members.

Finally, member heterogeneity has an indeterminate effect on a member's adoption. On the one hand, member homogeneity is associated with higher levels of trust and interest in others (Tadesse and Kassie 2017). Also, learning may only occur among members with similar 
traits/characteristics (BenYishay and Mobarak 2014; Munshi 2004). On the other hand, heterogeneous individuals may complement each other in terms of skills, information, or resources (Bernard and Spielman 2009; Poteete and Ostrom 2004).

In groups that were offered a bonus price for safe maize, an individual's expected benefits may also depend on his/her belief about the actions of the rest of the members. Testing for aflatoxin was only done after the members aggregated their maize. Without testing individual member's maize before aggregation, some members may want to earn the bonus by bringing untreated maize for aggregation. Group characteristics that enhance cooperation among members may thus have a stronger impact on the adoption of the biocontrol in groups offered the bonus. However, I do not find significant effects on the interaction terms of the bonus price dummy with group characteristics that are likely to enhance cooperation (size, age, heterogeneity). This may be because the sample is not large enough to facilitate sub-group analysis along this dimension. Besides, the opportunity to sell safe maize at a premium price was not the main motivation for the adoption of the biocontrol (Table 4.1; Chapter 3).

\subsection{Study design}

\subsubsection{Data}

This chapter uses data from four sources. First, a short survey was administered to all the groups from April to August 2017. During this exercise, all the group members were invited to a meeting that was approximately two hours long. A list of all the members in each group was collected. The list included an indicator of whether the member was present during this meeting or not. A total number of 3605 members in all the groups were registered. Data on the groups' awareness and knowledge of aflatoxin were collected. Individual members maize production dtata was collected 
from a randomly selected subset of group members. I refer to this round of meetings as the census in the rest of the paper.

The second source of data is the baseline data collected in September-October 2017, a few weeks before the delivery of the biocontrol. A group-level survey was administered to a group representative, in most cases, one of the committee members. Data collected using the group-level tool include group characteristics like group size, group leadership characteristics, the age of the group, and the group's main activity. Besides the group-level survey, an individual-level questionnaire was administered to six (five in some groups) randomly selected members per group. A total of 892 individual group members participated in the interviews. The survey asked about the members' socioeconomic characteristics, knowledge on aflatoxin contamination and control, group participation, and their attitude towards group members and leaders.

The third source of data is the Aflasafe ${ }^{\mathrm{TM}}$ sales records collected during the sale of Aflasafe $^{\mathrm{TM}}$ in November and early December 2017. The records consist of a list of members in a group who purchased the biocontrol plus an indication of the amount purchased.

Lastly, a follow-up survey administered to the same members interviewed at baseline was used to collect data on the biocontrol use and application.

\subsubsection{Group characteristics and descriptive statistics}

This section describes the measurement of the group characteristics variables hypothesized to influence an individual's adoption of the biocontrol. Group size is a continuous variable indicating the total number of members in a group. The age of the group is measured as the number of years the group has been operational. Membership to an umbrella organization is a dummy variable equal to 1 if a group belongs to a larger umbrella organization (at the district or county level) and 
0 otherwise. The proportion of women in the group is a continuous variable indicating the proportion of female members in a group. A dummy that takes the value of 1 if the group is engaged in rotating savings and credit activities is the indicator for group activities related to access to credit. The strength of leadership is measured as a dummy equal to 1 if the group leadership received any form of training 12 months before baseline data collection. All these variables are measured using the group level survey administered at baseline ${ }^{37}$.

Group level education is the median of the years of formal schooling of the six members interviewed in the baseline survey. Member heterogeneity is measured using four indicators, namely heterogeneity in individual members' education level, asset ownership (number of assets), age, and scale of operation proxied by the amount of maize harvested in a normal season. For each of these, heterogeneity is measured as the coefficient of variation (ratio of the standard deviation to the mean). A heterogeneity index is calculated as the mean coefficient of variation across these four variables.

Table 4.2 shows the descriptive statistics of the groups in the sample. The groups have 25 members on average, with a range of 7 to 150 members. The groups are nine years old on average, with the oldest group being 42 years. Thus, the groups in our sample have existed for some time. Only 10 percent of the groups belong to an umbrella organization. Most groups had more female members; on average, 80 percent of the members in all groups were female. The majority of the groups mention savings and credit as one of the group's activities. The median number of years of schooling per group is seven years. Leaders received some form of training 12 months before the baseline survey in 39 percent of the groups. Leaders training included training on financial

\footnotetext{
37 The variable on membership of an umbrella organization was generated from the data collected during the census
} 
management (20 percent of the groups), training on group marketing in $26 \%$ of the groups, and training on group management in 22 percent of the groups.

There are four measures of heterogeneity of the group members within the groups. The coefficient of variation that measures education heterogeneity ranges from 0.13 to 1.45 , with an average of 0.59 , an indication that the groups are relatively heterogeneous with respect to members' education. The groups have more heterogeneous members in terms of their scale of operation, with a 0.61 coefficient of variation. Heterogeneity in terms of age and assets is lower (average values of the coefficient of variations 0.23 and 0.39 , respectively). 
Table 4.2. Descriptive Statistics

\begin{tabular}{lcccc}
\hline & 1 & 2 & 3 & 4 \\
\cline { 2 - 5 } & & Standard & & \\
& Mean & deviation & Minimum & Maximum \\
\hline Group size & 25.36 & 15.36 & 7.00 & 150 \\
Number of years the group has been in & & & & \\
operation & 8.67 & 6.47 & $0.00 \pm$ & 42.00 \\
Group belongs to an umbrella organization & 0.10 & 0.30 & 0.00 & 1.00 \\
Proportion of group members female & 0.79 & 0.24 & 0.00 & 1.00 \\
Mentioned rotating credit and savings as one & & & & \\
of the group's activity & 0.90 & 0.30 & 0.00 & 1.00 \\
Leaders received any form of training 12 & & & & \\
months before data collection & 0.39 & 0.49 & 0.00 & 1.00 \\
Median education level & 6.90 & 2.34 & 0.50 & 14.00 \\
Heterogeneity index & 0.46 & 0.11 & 0.21 & 0.74 \\
Assets heterogeneity & 0.39 & 0.13 & 0.12 & 0.74 \\
Scale heterogeneity & 0.61 & 0.27 & 0.12 & 1.37 \\
Education heterogeneity & 0.59 & 0.28 & 0.13 & 1.45 \\
Age heterogeneity & 0.23 & 0.08 & 0.07 & 0.42 \\
Observations & 152 & & & \\
\hline A & & & & \\
\hline
\end{tabular}

\pm A 0 value was assigned if a group was less than one year old

\subsubsection{Other observable characteristics}

This section presents the variables added as controls in the estimations. Group level controls include indicators for the three counties and an indicator for the bundled insurance treatment (see details in Hoffmann, Kariuki, et al. 2018). I also include an indicator for the villages assigned to receive a bonus for the Aflasafe $\mathrm{e}^{\mathrm{TM}}$ treated maize.

There are two sets of individual-level control variables, depending on data availability. The first set of the individual-level variables are the variables for which data is available for the full 
sample (all the group members). These are the gender of the member (coded using names in the group lists) and an indicator of the member's presence during the census meeting. Also, I add an indicator for those surveyed at baseline since being surveyed has been shown to affect an individual's adoption of the biocontrol (Treurniet 2019a). I refer to these set of controls as the fullsample individual-level controls in the rest of the paper.

The second set of controls is the individual and household level variables for which data is available only for a subset of members interviewed at baseline. Individual member characteristics include age, age squared, education level, relationship to the household head, general trust levels, risk aversion index, and a measure of member's propensity to punish. Household characteristics included as controls are the asset index and maize farming practices in the previous season. They include the land under maize, the amount of maize harvested, sale of maize, and the value of all the agricultural inputs, including labor. Both the individual and household characteristics are measured using the baseline individual-level survey. Appendix Table A4.1 describes how each of these variables was measured. I refer to these as the surveyed sample individual and household level controls.

Descriptive statistics of these variables are presented in the appendix, Appendix Table A4.1.

\subsection{Estimation strategy}

\subsubsection{Main outcomes}

An individual member's adoption is measured using two indicators. The adoption status measured as a dummy variable that takes the value of 1 if a farmer purchased the biocontrol and 0 otherwise. 
The intensity of adoption is a continuous variable indicating the amount in $\mathrm{kg}$ of the biocontrol purchased. Both variables are measured using the administrative data collected during sales.

\subsubsection{Sample}

I use as the primary sample the full sample that consists of all the 3605 members registered during the group census meeting. As a robustness check, I also use the surveyed sample, that is, the 892 members for whom detailed individual and household data were collected during the baseline survey. While the size of the surveyed sample is considerably smaller than that of the full sample, the main upside of this sample is that it allows for controlling of more household and individuallevel characteristics, which may increase the precision of the estimates.

\subsubsection{Modeling approach}

This section describes the estimation strategy for the two primary outcomes, adoption status and the intensity of adoption. An individual member's decision to adopt the biocontrol can be modeled using the random utility framework. A member will adopt the biocontrol if the utility from adoption is higher than the utility from non-adoption. The utility difference between adoption and non-adoption depends on the benefits and costs associated with the adoption of Aflasafe ${ }^{\mathrm{TM}}$, which may depend on the characteristics of one's group and her individual and household characteristics. The utility difference is unobserved and can be presented by a latent variable denoted $y_{i j v}^{*}$ as follows:

$$
y_{i j v}^{*}=X_{1 j} \beta_{1}+X_{2 j} \beta_{2}+X_{3 v} \beta_{3}+X_{4 i j} \beta_{4}+\varepsilon_{i j v}
$$

where $y_{i j v}^{*}$ denotes unobserved utility difference between adopting and not adopting for individual $\mathrm{i}$ in group $\mathrm{j}$ in village v. $X_{1 \mathrm{j}}$ denotes characteristics of $\mathrm{i}$ 's producer group hypothesized to influence 
adoption and include; the group size, age of the group, indicator for membership to a larger group, the proportion of women in the group, an indicator for the group involvement in rotating credit and savings activities, an indicator for leadership training, median education of the group members and member heterogeneity. $X_{2 j}$ denotes other group characteristics used as controls (county indicators and an indicator of the assignment the bundled insurance treatment). $X_{3 v}$ is an indicator of the villages assigned to the bonus price treatment. $X_{4 i j}$ denotes individual and household characteristics for $\mathrm{i}$, included as control variables. $\varepsilon_{i}$ is the error term.

Individual i's decision to adopt is observed and can be denoted by $y_{i j v}$. I assume i will decide to adopt if the utility difference, $y_{i j v}^{*}$, is greater than 0 . Thus we observe $y_{i j v}=$ 1 if $y_{i j v}^{*}>0$ and $y_{i j v}=0$ otherwise. The probability of adoption can be presented as:

$$
\begin{aligned}
& P\left(y_{i j v}=1\right)=P\left(y_{i j v}^{*}>0\right)=P\left(X_{1 j} \beta_{1}+X_{2 j} \beta_{2}+X_{3 v} \beta_{2}+X_{4 i j} \beta_{3}+\varepsilon_{i j v}>0\right)= \\
& P\left(-\varepsilon_{i j v} \leq X_{1 j} \beta_{1}+X_{2 j} \beta_{2}+X_{3 v} \beta_{3}+X_{4 i j} \beta_{4}\right)=F\left(X_{1 j} \beta_{1}+X_{2 j} \beta_{2}+X_{3 v} \beta_{3}+\right. \\
& \left.X_{4 i j} \beta_{4}\right)
\end{aligned}
$$

Where $\mathrm{P}$ denotes probability and $\mathrm{F}$ is the distribution function of $\varepsilon_{i}$. By assuming a standard normal distribution, I estimate Equation (4.2) using a probit model.

The intensity of adoption is a continuous variable indicating the amount of the biocontrol purchased by individual $\mathrm{i}$. The variable takes a value 0 for members who did not purchase Aflasafe $^{\mathrm{TM}}$ and a positive value for adopters. The amount purchased depends on the marginal costs and marginal benefits of adoption, which may also depend on the characteristics of one's group and her individual and household characteristics.

For this outcome, we observe $y_{i j v}=y_{i j v}^{*}$ if $y_{i j v}^{*}>0$ and $y_{i j v}=0$ if $y_{i j v}^{*} \leq 0$. Thus, a farmer who is willing to purchase a negative amount $y_{i j v}^{*}$ is observed as purchasing 0 amount. 
Given that most observations have 0 values ( 82 percent of the full sample), Equation (4.1) is best estimated using a Tobit model for the adoption intensity outcome.

The Tobit model assumes that the same underlying process affects both the probability of a positive value for $y$ and the distribution of y given that it is positive (Smith and Brame 2003). That is, the probability of adoption and the amount adopted conditional on adoption are influenced by the same group, household, and individual characteristics and with the same sign. I use a modification of the Tobit model to relax this assumption, the double hurdle model described in (Cragg 1971), and also used in Xu et al. (2009). This modification allows the two processes to be estimated in two separate steps. The first step estimates the probability of adoption using a probit model (same as the adoption dummy model). The second step involves the estimation of a truncated normal regression involving only those with positive values for $\mathrm{y}$.

Since group characteristics were not exogenously varied through random assignment, their effect on adoption may be endogenous. Data on these characteristics were collected before the biocontrol was made available to the farmers, thus reducing the possibility of reverse causality. However, the effect of these characteristics may suffer from omitted variable bias if an unobserved variable affects both adoption and the group characteristics. Therefore, I do not claim causality in the estimated effects of group characteristics.

\subsubsection{Potential mechanisms}

In this study, group characteristics are expected to affect individual member's adoption of the biocontrol through two channels: relaxing the members' liquidity constraints and information sharing among the members. As stated earlier, I do not find heterogeneous effects of group characteristics by bonus price treatment. To test the role of the information-sharing mechanism, I 
regress three other outcomes on the group characteristics: group-level trust among the members, individual-level trust in other members, and member participation in group meetings. Information sharing and learning will occur if members trust the source of information, in this case, other members. Lastly, I test the liquidity access channel through one other outcome, the proportion of members in a group who have ever acquired a loan.

The information-sharing proxies are constructed using data from the baseline individual level survey. The trust variable was measured by asking each of the interviewed members the number of fellow group members he/she can trust with a given task (a responsibility to deliver some planting seedlings on behalf of the member). A trust variable is generated by calculating the proportion of members trusted. Participation in group meetings is measured as the proportion of members regularly attending group meetings, measured by asking each of the members interviewed at baseline to state the proportion of members who regularly participate in group meetings. A group-level outcome for the trust and participation variables is constructed by calculating the group mean of the individual-level variable.

The proportion of members who have ever acquired a loan was measured using data from the group census. This was measured by asking the number of members who had ever acquired a loan out of the total members who were present in the census meeting.

To test if group characteristics affect adoption through these channels, I follow the following steps (Mehmetoglu 2018). First, I test whether these variables are correlated with the group characteristics. Second, I rerun the main estimation (adoption model) but control for each of the mechanism variables. If a group characteristic is: i) significant in the main estimation ii) is significantly correlated with the mechanism variable iii) the mechanism variable is significantly correlated with adoption decision iv) the effect of the group characteristic is reduced in the 
adoption estimation model that controls for the mechanism variable, then this is taken as evidence that the given group characteristic affect adoption through that channel. Lastly, for such mechanism and group characteristic variables, I conduct a Sobel test to test whether the mediation effect is statistically significant (Mehmetoglu 2018).

\subsection{Results}

\subsubsection{Group characteristics and members' technology adoption}

Table 4.3 shows the results of the double-hurdle models. Columns 1 and 2 show the average marginal effect from the probit model estimated using the full and the surveyed samples. Columns 3 and 4 show the average marginal effects for the amount adopted conditional on adoption. The specifications using the surveyed sample include more individual level controls, as described in Section 4.5.2, but the sample is considerably smaller.

Results in column 1 show that the size of a group has a negative effect on an individual member's probability of adopting the biocontrol. Column 2 shows a similar result for the specification that uses the surveyed sample. The result supports the hypothesis of increased coordination costs for larger groups that may lower trust levels among members. Group size is not correlated with the amount purchased conditional on adoption ${ }^{38}$.

The age of the group is not correlated with the probability of adoption. However, this characteristic is positively correlated with the amount purchased once one decides to adopt.

\footnotetext{
${ }^{38}$ Note that group size may affect adoption through the requirement of aggregation of treated maize. However, results show that the effect of group size and member heterogeneity are the same in both the bonus treatment and the control villages.
} 
However, the coefficient is only significant (marginally) in the specification that uses the full sample.

Results in column 1 show that being in a group that belongs to an umbrella organization does not significantly affect an individual member's probability of adopting the biocontrol. However, as shown in column 2, the coefficient on this group characteristic is bigger and significant at $10 \%$ in the specification that includes more individual and household level controls (surveyed sample). These findings suggest increased access to information for the groups that have a membership to higher tier groups, although the result is not robust across both specifications.

The proportion of women in a group is positively correlated with the members' probability of adoption. The effect is significant (at the 10\% level) for the full sample only, although higher in magnitude for the surveyed sample (with a p-value $=0.115$ ). The effect of this variable could be a result of the hypothesis that women are more likely to cooperate in group settings or because groups with a higher proportion of women are more homogeneous, thus members are more likely to cooperate. To test whether the positive effect on this variable is due to more cooperation by women or due to increased homogeneity in groups with a higher proportion of women, I reestimate the model using a quadratic form of this variable (proportion of women and proportion of women squared). If an inverted $\mathrm{u}$-shaped effect exists, the correlation between the proportion of women variable and adoption is a result of homogeneity in the group (Williams and Meân 2004). However, I do not find evidence of an inverted $u$-shape effect. This suggests that the positive coefficient on this variable in Table 4.3 is as a result of more cooperation from groups with more women. The proportion of women in the group does not affect the amount purchased once the adoption decision has been made. 
Contrary to the expectation, groups that mentioned rotating credit and savings as one of the group's activities are not more likely to increase individual member's probability of adoption compared to other groups. However, we find some weak evidence that adopters in such groups adopt more biocontrol.

Leadership training does not affect members' adoption of biocontrol. Also, being in a group with more educated members does not affect the probability of adoption. However, being in a group with more educated members increases the amount purchased by the adopters. The positive effect on the amount purchased may reflect an income effect, that is groups with more educated members may have richer members, and if there is resource sharing among members, this may increase the amount purchased by those who already decide to adopt.

Member heterogeneity in terms of education, assets, age, and scale of production is negatively correlated with the probability of adoption. The effects of this variable are comparable in magnitude across the two samples, although only significant for the specification that uses the full sample ( $p$-value in the surveyed sample $=0.108$ ). The negative impact of member heterogeneity may be as a result of increased coordination costs in more heterogeneous groups or due to less learning opportunities among members with dissimilar characteristics. Member heterogeneity does not affect the amount purchased by the adopters. 
Table 4.3. Effect of Group Characteristics on Individual Member's Adoption of Aflasafe ${ }^{\mathrm{TM}}$

\begin{tabular}{|c|c|c|c|c|}
\hline & 1 & 2 & 3 & 4 \\
\hline & \multicolumn{2}{|c|}{ Adoption status } & \multicolumn{2}{|c|}{ Intensity of adoption } \\
\hline & AME & AME & CAME & CAME \\
\hline Group size \pm & $\begin{array}{c}-0.003 * * * \\
(0.001)\end{array}$ & $\begin{array}{l}-0.005^{* *} \\
(0.002)\end{array}$ & $\begin{array}{c}0.002 \\
(0.011)\end{array}$ & $\begin{array}{l}-0.000 \\
(0.012)\end{array}$ \\
\hline $\begin{array}{l}\text { Number of years the group } \\
\text { has been in operation } \pm\end{array}$ & $\begin{array}{c}0.001 \\
(0.002)\end{array}$ & $\begin{array}{l}-0.004 \\
(0.004)\end{array}$ & $\begin{array}{l}0.041 * \\
(0.021)\end{array}$ & $\begin{array}{c}0.018 \\
(0.022)\end{array}$ \\
\hline $\begin{array}{l}\text { Group belongs to an } \\
\text { umbrella organization }\end{array}$ & $\begin{array}{c}0.033 \\
(0.040)\end{array}$ & $\begin{array}{l}0.137 * \\
(0.072)\end{array}$ & $\begin{array}{c}0.415 \\
(0.286)\end{array}$ & $\begin{array}{c}0.466 \\
(0.346)\end{array}$ \\
\hline $\begin{array}{l}\text { Proportion of group members } \\
\text { female }\end{array}$ & $\begin{array}{l}0.096^{*} \\
(0.057)\end{array}$ & $\begin{array}{c}0.158 \\
(0.101)\end{array}$ & $\begin{array}{c}0.206 \\
(0.644)\end{array}$ & $\begin{array}{l}-0.214 \\
(0.520)\end{array}$ \\
\hline $\begin{array}{l}\text { Rotating credit and savings } \\
\text { as one of the group's activity }\end{array}$ & $\begin{array}{l}-0.037 \\
(0.041)\end{array}$ & $\begin{array}{l}-0.042 \\
(0.060)\end{array}$ & $\begin{array}{c}0.376 \\
(0.385)\end{array}$ & $\begin{array}{l}0.695 * \\
(0.361)\end{array}$ \\
\hline $\begin{array}{l}\text { Leaders received any form of } \\
\text { training }\end{array}$ & $\begin{array}{c}0.011 \\
(0.026)\end{array}$ & $\begin{array}{l}-0.032 \\
(0.043)\end{array}$ & $\begin{array}{l}-0.097 \\
(0.234)\end{array}$ & $\begin{array}{l}-0.277 \\
(0.271)\end{array}$ \\
\hline Median education level & $\begin{array}{l}-0.003 \\
(0.006)\end{array}$ & $\begin{array}{l}-0.006 \\
(0.010)\end{array}$ & $\begin{array}{c}0.123 * * * \\
(0.047)\end{array}$ & $\begin{array}{l}0.084^{*} \\
(0.050)\end{array}$ \\
\hline Heterogeneity index & $\begin{array}{l}-0.245^{*} \\
(0.144)\end{array}$ & $\begin{array}{l}-0.329 \\
(0.217)\end{array}$ & $\begin{array}{c}0.211 \\
(1.165)\end{array}$ & $\begin{array}{c}0.338 \\
(1.073)\end{array}$ \\
\hline Sample & Full & Surveyed & Full & Surveyed \\
\hline Observations & 3605 & 892 & 3605 & 892 \\
\hline Mean of the sample & $\begin{array}{c}0.184 \\
(0.006)\end{array}$ & $\begin{array}{c}0.335 \\
(0.016)\end{array}$ & $\begin{array}{c}2.967 \\
(0.074)\end{array}$ & $\begin{array}{c}3.008 \\
(0.100)\end{array}$ \\
\hline
\end{tabular}

\pm Winsorized at 0,95 percentile

Notes: Standard errors in parentheses; clustered at the village level. ${ }^{*} \mathrm{p}<0.10, * * \mathrm{p}<0.05, * * *$ $\mathrm{p}<0.01$. AME: Average marginal effects. CAME: Average marginal effects conditional on $\mathrm{y}>0$. Specifications 1 and 3 include the group-level controls (county indicators, bonus price and bundled insurance treatment indicators) and the full sample individual-level controls (indicators for presence in the census meeting, sex of the member, and an indicator for being interviewed during the baseline survey). Specifications 2 and 4 include the group-level controls, two of the full sample individual-level controls (indicators for presence in the census meeting and sex of the member), and the surveyed sample individual and household level controls (as described in Section 4.4.3). 


\subsubsection{Potential mechanisms}

This section describes the results on the additional four outcomes used as proxies for information sharing and financial support provision, the two main channels through which group characteristics may influence individual members' adoption of Aflasafe ${ }^{\mathrm{TM}}$. These outcomes are group-level trust among the members, individual-level trust, the proportion of members who regularly attend group meetings, and the proportion of members in a group who had ever gotten a loan.

Columns 1,3,5 and 7 of Table 4.4 show the regressions of the four additional outcomes on each of the group characteristics. Columns 2,4,6 and 8 show the main estimation models described in section 4.6.1 but includes each of the mechanism variables.

In section 4.6.1, I found strong evidence of a negative correlation between the size of the group and the probability of adoption. Results in columns 1 and 3 of Table 4.4 shows that group size is negatively correlated with the trust variables. The trust variables are positively correlated with adoption. A Sobel test shows that group size affects adoption partly through the trust variables ( $\mathrm{z}$ value of -2.273 and -2.938 ). Group size is not correlated with members' participation in meetings or the proportion of members who had ever acquired a loan. Therefore, smaller groups are likely to have higher levels of social capital that may facilitate learning and information sharing among members.

Member heterogeneity in terms of education, assets, age, and scale is negatively correlated with the probability of adoption. The heterogeneity variable is negatively correlated with the trust variables but only significant for the group-level trust variable. Also, the Sobel test shows that the mediation effect of trust variables between heterogeneity index and adoption is not statistically significant. Thus, I find weak evidence that member heterogeneity affects adoption through increased coordination costs, thus reduced trust. The effect of member heterogeneity on adoption 
may result from the fact that farmers are more likely to learn about new technologies from similar individuals. Lastly, member heterogeneity is not correlated with member participation in group meetings and on the proportion of members that have ever acquired a loan.

Next, I look at the variable on the proportion of women in a group. This variable is not correlated with the measures of trust. Results in columns 5 and 7 shows that groups with more women are more active and more members are likely to have ever gotten a loan. However, these two mechanism variables are not correlated with the adoption of biocontrol. The member participation variable is positively correlated but only marginally significant (p-value 0.149 ).

Groups involved in rotating savings and credit activities have a higher proportion of members who have ever acquired a loan. However, the latter is not correlated with the adoption dummy and the amount adopted conditional on adoption, and thus we cannot confidently conclude that the loan acquired from these groups was used to purchase the biocontrol.

Lastly, the variables on the members' education level, the age of the group, and membership to an umbrella organization are not correlated with any of the four mechanism variables. 


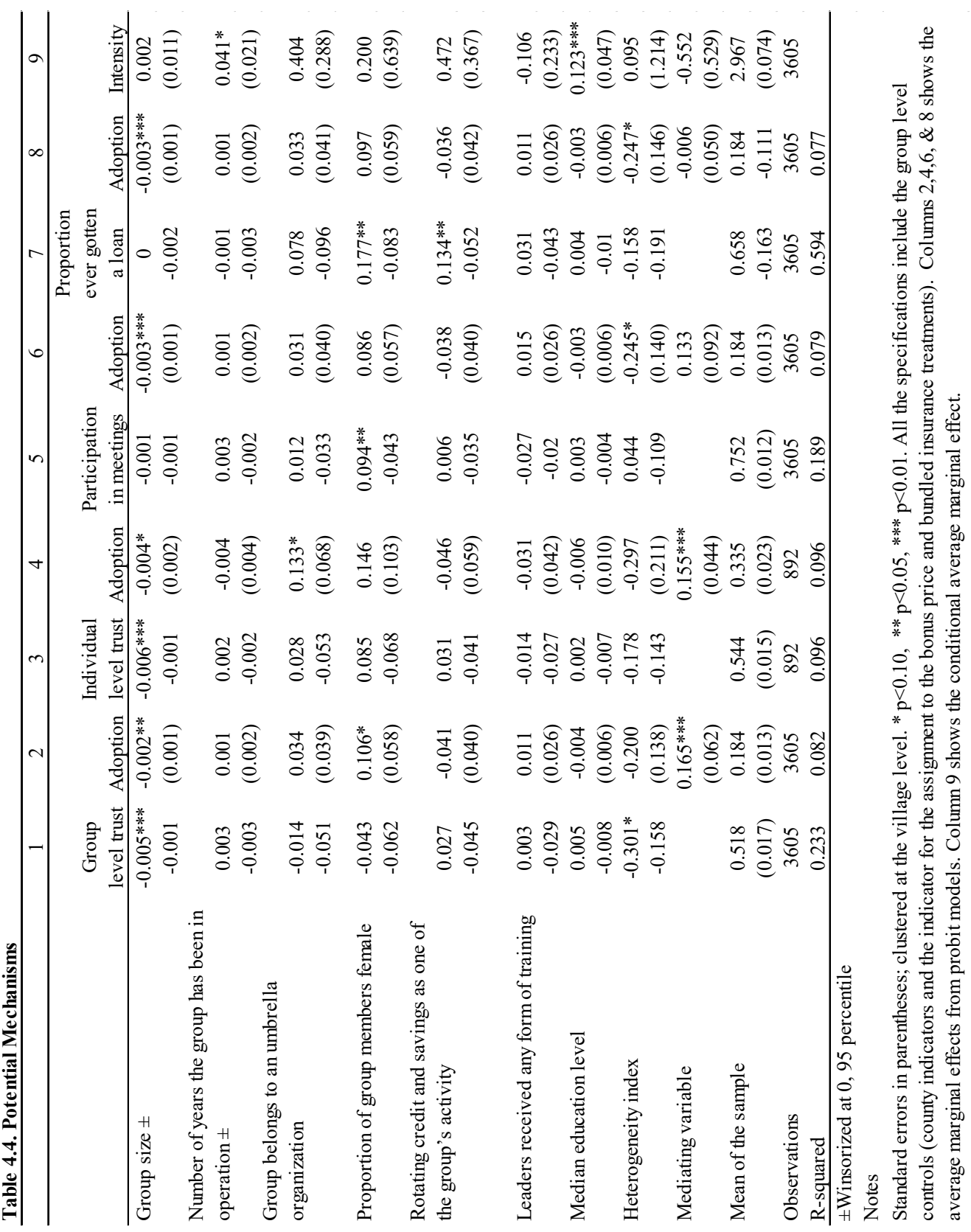




\subsection{Conclusions}

Lack of information is one of the constraints to the adoption of food safety technologies by farmers in low and middle-income countries. Additionally, liquidity constraints in the presence of poorly functioning financial markets can further constrain adoption, even in cases where farmers are familiar with the technology.

Producer organizations are one avenue through which farmers can access technical information and financial services. Yet, little is known about the type of producer organizations that are likely to be most effective in facilitating access to these services by the members. This study examines the role of one aspect of the producer organizations-structural characteristics- on members' adoption of a new food safety technology used mainly for the production of safer food for home consumption and sale in case of surplus.

I find strong evidence that small groups were likely to increase member's adoption of new technology. Members in smaller groups had higher trust in other members. I conclude that this fosters information sharing and learning among the members.

Groups with more homogeneous membership in terms of education, assets, age, and scale of operation were likely to increase members' adoption of the technology. I speculate that this result is because more learning is likely to occur for members who have similar characteristics.

I found some suggestive evidence that groups with a higher proportion of women were more likely to increase member's adoption of the technology. Groups with more women were likely to participate more in group meetings and had more members who acquired a loan. However, I cannot conclude that the positive effect of the proportion of women on adoption is a result of increased participation or increased access to financial services. 
Despite liquidity constraints being mentioned by several non-adopters as a major barrier to adoption, I did not find strong evidence that groups help to relax this constraint. Groups involved in rotating credit and savings were likely to have more members who had acquired a loan, but this did not translate to higher adoption rates in these groups. This may suggest that the loan is used for other purposes.

This chapter finds some evidence that information may be a barrier to the adoption of food safety technology in this setting. The finding that some producer group characteristics can be used to increase learning and information sharing among members after a general training is particularly important in the LMICs where there is limited capacity in the public extension services. While some studies have found that liquidity constraints act as barriers to the adoption of food safety technologies in the same context as the current study (Hoffmann and Jones 2018), I do not find evidence that producer organizations play a role in relaxing these constraints. 


\section{Appendix}

Appendix 4.1. Definition of Baseline Sample Individual and Household Level Controls

\begin{tabular}{|c|c|}
\hline Name of the variable & Definition \\
\hline $\begin{array}{l}\text { Age of the farmer (completed } \\
\text { years) }\end{array}$ & Age of the member in years \\
\hline Age of the farmer squared & Age of the member squared \\
\hline $\begin{array}{l}\text { Years of education completed by } \\
\text { the respondent }\end{array}$ & Years of formal education completed by the member \\
\hline Farmer is the household head & $\begin{array}{l}\text { Dummy variable with a value of } 1 \text { if the member is the } \\
\text { household head }\end{array}$ \\
\hline Asset index & $\begin{array}{l}\text { An index computed as the sum of dummy variables indicating } \\
\text { ownership of } 14 \text { household and livestock assets }\end{array}$ \\
\hline $\begin{array}{l}\text { The total land under maize } \\
\text { primary season previous year } \\
\text { (acre) }\end{array}$ & Total land owned under maize in the last season in acres. \\
\hline $\begin{array}{l}\text { Maize harvest previous season } \\
(90 \mathrm{~kg})\end{array}$ & $\begin{array}{l}\text { The amount of maize harvested in the previous season in } 90 \mathrm{~kg} \\
\text { bags. }\end{array}$ \\
\hline Maize marketing: & $\begin{array}{l}\text { A dummy indicator of participation in the maize market in the } \\
\text { previous season. }\end{array}$ \\
\hline $\begin{array}{l}\text { Total expenditures on agr. inputs } \\
\& \text { labor primary season previous } \\
\text { year (KES) }\end{array}$ & $\begin{array}{l}\text { The total amount of money in Kenyan shillings spent on } \\
\text { agricultural inputs and labor in the last season. }\end{array}$ \\
\hline Punishment index & $\begin{array}{l}\text { An individual's propensity to punish calculated as the } \\
\text { standardized mean to responses ( } 1=\text { completely disagree; } \\
2=\text { disagree; } 3=\text { Neither agree nor disagree; } 4=\text { agree; } 5= \\
\text { completely agree) to two general statements; i) if treated } \\
\text { unjustly, you will take revenge even if there is a cost of doing so } \\
\text { and ii) if someone treats others unfairly, you are willing to } \\
\text { punish them even if there is a cost of doing so). The higher the } \\
\text { index, the higher the propensity to punish for a given individual. }\end{array}$ \\
\hline General trust level & $\begin{array}{l}\text { An indicator of a member's general trust level measured as the } \\
\text { response ( } 1=\text { completely disagree; } 2=\text { disagree } 3=\text { neither agree nor } \\
\text { disagree } 4=\text { agree } 5=\text { completely agree) to the statement: "People } \\
\text { generally have the best intention." }\end{array}$ \\
\hline Quantitative risk aversion score & $\begin{array}{l}\text { Members risk aversion level measured through a set of } \\
\text { hypothetical questions involving three interdependent choices } \\
\text { between a lottery and a certain amount. A higher value indicates } \\
\text { a higher level of risk aversion. }\end{array}$ \\
\hline
\end{tabular}


Appendix Table A4.1. Descriptive Statistics of the Variables Used as Control Variables in the Regressions

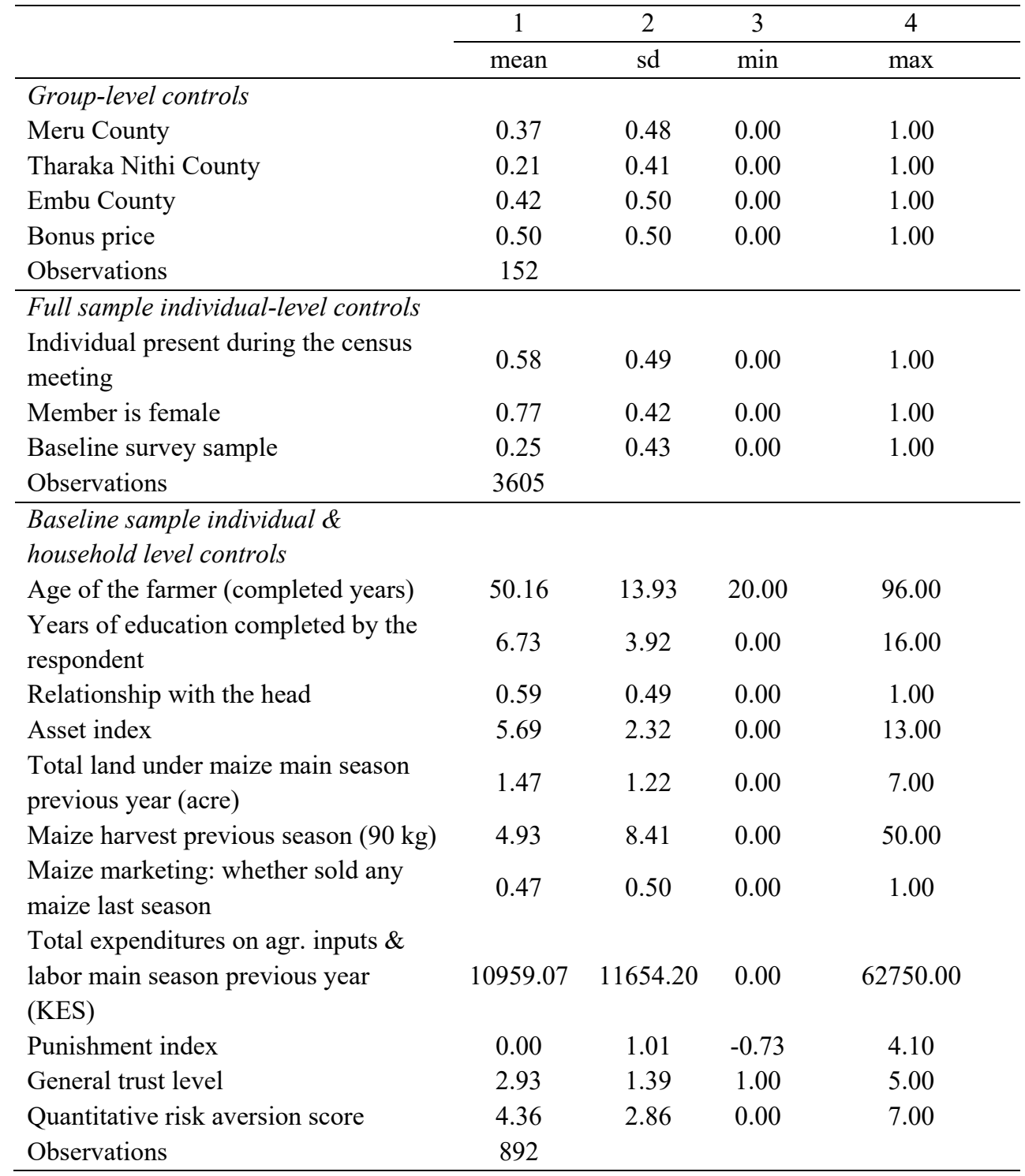




\section{Chapter 5}

\section{Efficacy of a Food Safety Technology in Farmers' Fields Under Varied Levels of Farmer Training}

\section{Sarah Wairimu Kariuki, Asha Bakari, Charity Mutegi, Ranajit Bandyopadhyay and Vivian Hoffmann}

Correct use of technologies by farmers, particularly new technologies that require precise implementation, is important for realizing the full potential of the technologies. While training farmers may result in the correct use of these technologies, training numerous small-scale farmers requires a significant amount of resources. Knowledge of the level of training needed to ensure the proper use of new technologies can thus be used to allocate scarce resources. In this chapter, we conduct a field experiment to test the effectiveness of a new food safety technology-a biocontrol for aflatoxin contamination-under varied levels of farmer training and support. Our results show that the biocontrol was effective in reducing aflatoxin for farmers who received a one-off training when compared to farmers who did not use the biocontrol. However, the application of the biocontrol was more successful, and its effectiveness stronger, for farmers who were supported beyond the one-off training. These results indicate that the returns to this technology, and the subsequent adoption, will depend on the level of farmer training, which will require a significant amount of resources. 


\subsection{Introduction}

Rates of return to agricultural technologies are typically highly sensitive to variations in the technology's application. For example, average rates of return to fertilizer in farmers' fields in western Kenya are high when optimally applied, but negative at other rates of application (Duflo, Kremer, and Robinson 2008). If farmers fail to apply a technology at the correct time or the right rate or using the correct application method, the technology may be ineffective and returns from it may be low or even negative. This experience can then depress adoption in subsequent seasons. Providing farmers with training on technologies - particularly new technologies - is therefore critical for ensuring early success and widespread adoption in the longer term. Because such training uses scarce resources, understanding the level of farmer training and follow-up required to enable the successful use of new technology is important. In this chapter, we examine the impact on aflatoxin contamination of providing farmers with a new food safety technology - a biocontrol product for aflatoxin contamination - in combination with either training alone, or training plus supervision of application.

Aflatoxin biocontrol is highly effective in reducing aflatoxin contamination- a naturally occurring fungal contaminant- in experimental trials (Atehnkeng, Ojiambo, Cotty, \& Bandyopadhyay, 2014). However, there is limited evidence on the performance of the biocontrol product when applied independently by smallholder farmers.

There are three main concerns regarding the performance of the biocontrol product in farmers' fields. First, the biocontrol product is new in Kenya, registered for use since 2015, and thus not familiar to farmers. ${ }^{39}$ Second, the product requires precise application in terms of both

\footnotetext{
${ }^{39}$ Biocontrol products for aflatoxin control were first developed in the USA in the early 1990s, and have been used for almost two decades (Cotty, Antilla, and Wakelyn 2007;
} Dorner 2009). 
timing and dosage to achieve the desired results (Weaver et al. 2015). Third, to the extent that the efficacy of biocontrol sometimes depends on environmental conditions after application (Bandyopadhyay et al., 2016), its effectiveness in farmers' fields may differ from the efficacy reported in the experimental trials.

At least two factors can explain why farmers may fail to use a given technology correctly. First, farmers may lack information on the correct use of technology. In this case, providing information in a timely manner should result in better outcomes (Casaburi et al. 2014). Second, farmers may receive the information but fail to attend to the information or some aspects of the information due to psychological distortions like biased beliefs about the technology and how it works (Handel and Schwartzstein 2018). Additionally, the correct use of technology may require farmers to remember to execute certain tasks at a specific time or in a particular way in the future. The ability of farmers to remember such specific information may be affected by the fact that farmers face several tasks that compete for their attention, which may result in limited attention to some tasks relative to others (Schilbach, Schofield, and Mullainathan 2016). Examples where biased beliefs or limited attention may result in the incorrect use of technology include cases where farmers forget to apply an input on time, overapply hoping for a stronger impact, or under-apply to cover a larger area of land.

The current study contributes to two strands of research. The first contribution is to the literature on the gap between potential and realized returns to agricultural technologies. A study by Hanna, Mullainathan, and Schwartzstein (2017) showed that seaweed farmers in Indonesia failed to attend to some aspects of an existing production technique, resulting in unexploited potential. The study further showed that farmers' reactions to information on the previously overlooked aspects depended on how the information was presented. Participating in on-farm demonstrations did not result in a change in farmer's practice until summaries of the results of the trials were made available to the farmers. In a separate study, sending text reminders in 
addition to a one-day training increased farmers' reported knowledge about the technologies studied (Larochelle et al. 2019). Lastly, a study comparing the effect of a participatory video training and the video plus phone-based reminders to farmers reported a higher effect of the additional phone-based audio messages on farmers' knowledge levels (Cai and Steinfield 2018). Together, these studies show that the level of training may affect how well farmers learn about a technology or a particular aspect of technology. A study by Casaburi et al. (2014) examined the role of providing timely information on agricultural tasks to farmers via a set of text messages on plot level productivity. While the study did not vary the level of training, the study showed that such reminders can increase farmers' yields.

This chapter adds to this literature in three ways. First, we study a new technology that farmers in our study were using for the first time and thus have limited knowledge of its proper use. Second, we exogenously vary the level of farmer training on the new technology to test the intensity of training on the effectiveness of the technology. We do this by providing training to all the farmers (except those in the control group) and then providing additional support of monitoring and supervision during field application to a subset of the trained farmers. Lastly, we measure the impact of training only and training plus support on three outcomes: farmers' reported knowledge during follow-up, observed farmer practice, and an objective measure of the effectiveness of the technology-aflatoxin concentration. This helps us to distinguish whether the additional support led to higher levels of knowledge thus acted as a source of information (like in the case of Cai and Steinfield 2018; Larochelle et al. 2019) or as a reminder of what was previously taught (thus no effect on knowledge levels). Knowing the distinction between these two potential mechanisms has important implications in designing training programs in a cost-effective way.

Second, our study adds to the few studies testing the effectiveness of the biocontrol for aflatoxin control. Evidence on the optimal level of training and follow-up needed to ensure the 
correct use of this new technology by farmers will help design farmers' training programs. Three previous studies have assessed the efficacy of similar biocontrol products in Africa in farmers' fields. A 10-year study in Nigeria and a 5-year study in Senegal both reported significantly lower levels of aflatoxins in biocontrol treated samples compared to untreated samples (72-95\% lower in Nigeria and 58-100\% lower in Senegal) (Bandyopadhyay et al. 2019; Senghor et al. 2020). A 2-year efficacy study with two biocontrol products in 800 farmers' fields in Ghana recorded 76-100\% (mean 99\%) lower aflatoxin than fields that were not treated. Farmers in these trials received training on the use of the biocontrol product and supervision from the project staff and extension agents during the application. The current research adds to these studies by testing the effectiveness of the biocontrol in farmers' fields when farmers are provided with a one-time training before application, versus the same training combined with monitoring before application and supervision during application. While monitoring and direct supervision of application are expected to lead to higher efficacy than training alone, the cost of the former in the study setting is high due to the small scale of farms and variation in the timing of application across farms due to differences in planting dates and crop maturation.

The next section describes the materials and methods used in the study. Section 5.3 presents the results, and Part 5.4 concludes.

\subsection{Materials and methods}

\subsubsection{Population and sample}

The study was carried out in six counties in the Eastern region of Kenya: Meru, Tharaka Nithi, Embu, Machakos, Makueni and Kitui. A list of villages in maize-growing sub-counties within the study counties was generated using data from the authors' previous research projects and the agricultural extension officers. All the villages involved in earlier research projects on the adoption of the biocontrol were removed from the list, as were villages within two kilometers 
of the prior research villages to avoid the influence of previous training on farmers' behavior or previous product application to or near farmers' fields on fungal populations. ${ }^{40}$ The remaining list of 729 villages was used as the sampling frame, from which 120 villages were randomly selected for inclusion in the study.

Community leaders from the selected villages were asked to list all the households in their respective villages that grew between 0.5 and 5 acres of maize. One farmer was then randomly selected from each of the 120 villages using a predetermined random number and order (ascending/descending). If the selected farmer grew less than 0.5 or more than 5 acres of maize or had previously used Aflasafe, the next farmer on the list was selected.

\subsubsection{Baseline survey}

Each of the selected farmers was visited at their homes and administered an informed consent procedure to participate in the study at the beginning of the $2019 / 2020$ season (from $12^{\text {th }}$ September to $18^{\text {th }}$ October 2019). After obtaining consent, a short survey was administered that included questions on farmers' knowledge about aflatoxin and the biocontrol product, and maize practices, including (expected) maize planting date.

\subsubsection{Experimental design and farmer training}

Random assignment of villages to one of the three treatment groups was conducted using the Stata software package prior to the selection of farmers. Of the 120 villages, 60 were assigned to the control group, while 30 were assigned to each of the two treatment groups. Randomization of the villages in Embu, Tharaka Nithi, and Meru counties was stratified at the

\footnotetext{
${ }^{40}$ Biocontrol spores are prone to air dispersal thus may spread from a treated field to the nearby fields (Bock, Mackey, and Cotty 2004).
} 
county level, based on the number of villages in each county in the sampling frame. Randomization in the rest of the counties (Makueni, Machakos, and Kitui) was stratified at the sub-county level.

Farmers in villages assigned to the control group did not receive any further intervention after being surveyed at baseline. Farmers in the villages assigned to the first treatment group were visited again after the baseline survey in November 2019. During this visit, farmers were taught about aflatoxin and aflatoxin management strategies. Part of the training included introducing the biocontrol product to farmers as one of aflatoxin management options and training them on how to use it correctly. The training was done by staff from the International Institute of Tropical Agriculture (IITA) and the Ministry of Agriculture. The trainers used the IITA farmers' training manual (IITA 2018) and a pictorial flyer that illustrated the method and timing of application, as well as post-application instructions. After the training, each farmer was given a sufficient amount of the biocontrol product to treat their maize field at the recommended rate of $4 \mathrm{~kg} / \mathrm{acre}$. Farmers in this group were then left to use the product according to the instructions provided during the training. We refer to this group as the biocontrol training and treatment group.

Farmers assigned to the second treatment group received the same training as those in the biocontrol and training treatment group. Also, these farmers received additional support from the project staff. First, their crop was monitored to determine the correct stage for application through follow-up calls by trainers. Once the right time of application was determined, the farmers were visited again for support and supervision of the application of the product. We refer to this group as the biocontrol, training, and support treatment group. 


\subsubsection{Field monitoring and follow-up survey}

Farmers assigned to both treatment groups were revisited in December 2019. Two activities were conducted during this visit: a follow-up survey and monitoring of the field where the biocontrol product was applied. The follow-up survey was used to collect data on farmers' knowledge of the biocontrol and its correct use, as a measure of how well the farmers learned from the training and the subsequent support offered.

Field monitoring involved observing the field where the product was applied for the presence of sporulation of the active ingredients of the biocontrol on the formulated product. Sporulation of the active ingredient of the product occurs a few days after field application and is an early indicator of its effectiveness. The formation of spores may depend on the prevailing weather conditions. Too much rainfall after application can wash away the product, while lack of moisture can result in poor spore formation (Pitt 2019). Also, the presence of the product on the field and consequently sporulation rate can be reduced if poultry consumes the sorghum grains used as carriers.

The rate of application of the product and sporulation on the product were assessed within four quadrants, placed in different areas of each of the biocontrol-treated farms. The total number of granules of the formulated product and the number of granules that had sporulated per one square meter quadrant were counted, and these counts were used to calculate the rate of sporulation per farm.

\subsubsection{Aflatoxin samples and quantification}

Maize samples from all farmers in the study (120 samples) were collected in January through March of 2020. From each farmer's field, 20 to $29 \mathrm{~kg}$ of mature maize cobs were harvested in a zig-zag manner. The cobs were shelled by hand, grains mixed, and subdivided by quartering method to obtain approximately $1.5 \mathrm{~kg}$ samples for aflatoxin analysis. The samples were packed 
in khaki kraft papers and transported to the Kenya Agricultural Research Organization (KARLO) lab in Katumani for aflatoxin analysis.

In the lab, the samples were oven-dried at $45^{\circ} \mathrm{C}$ for 48 hours and sun-dried for three days to obtain a requisite moisture content of less than $13 \%$. The samples were then ground using a coffee mill grinder, weighed, and stored at $-20^{\circ} \mathrm{C}$ prior to aflatoxin analysis. Aflatoxin analysis was conducted using Neogen Reveal Q+ strips and Accuscan Pro reader.

\subsection{Results}

\subsubsection{Farmers' knowledge and maize practices at baseline}

In this section, we provide a brief description of the farmers in our sample. First, we show their awareness of aflatoxins and the biocontrol product at baseline, followed by some characteristics of their maize farms during the 2019/2020 season. Column 1 of Table 5.1 shows these characteristics for all the farmers in the sample, while Columns 2-4 show the characteristics of farmers per treatment group. Columns 5-7 present p-values for the difference in means for each variable between each treatment group and the control group, and between the two treatment groups. Given the limited sample size of each group, we report randomized inference (RI) pvalues that test the sharp null hypothesis of no difference in means across groups. The validity of the RI p-values does not depend on the sample size and is used in studies with a small sample size (Fujiwara and Wantchekon 2013). In this method, all observations are reassigned to a treatment 5000 times, and differences in means between groups are calculated under each reassignment. The RI p-value is then calculated as the proportion of the re-estimated coefficients that are larger than the coefficient from the original assignment. If the proportion is too small (less than 0.10 ), then the null hypothesis of no difference across treatment groups is rejected. We generate the RI p-values using the Stata commands described in Heß (2017). 
Awareness of and knowledge about aflatoxin were high among farmers in the study sample. Ninety-five percent of farmers indicated that they had heard of aflatoxin before. When asked to describe aflatoxin, $72 \%$ described it as poison, $20 \%$ described it as a disease, and $8 \%$ did not know how to describe it. Almost all the farmers (95\%) identified maize as one of the crops affected by aflatoxin. Beans were the next most frequently reported crop (mentioned by $34 \%$ of farmers), followed by Sorghum (21\%). Only 3\% of farmers identified groundnuts as affected by aflatoxin, notable as this is one of the crops most susceptible to contamination, though not widely grown in the study area. Other crops identified as affected included millet (7\%), green grams $(7 \%)$, cereals generally $(4 \%)$, cassava $(2 \%)$, and vegetables $(1 \%)$. Four percent of farmers were not able to identify any crop that is affected by aflatoxin.

Awareness of the biocontrol was low. Fewer than a fifth of farmers $(18 \%)$ said they had heard about the biocontrol at baseline. The primary source of information on the biocontrol was radio, mentioned by $68 \%$ of those who had heard about the product. Other sources of information included extension officers (18\%) and other farmers (9\%). None of the farmers had used the product before.

The size of the land under maize in the October 2019- March 2020 season for farmers in our sample ranged from 0.5 to 5 acres (reflecting the eligibility criteria), with a geometric mean of 1.38 acres and a median of 1.375 acres. Maize was intercropped with at least one other crop in $68 \%$ of the farms. Over $90 \%$ of farmers used fertilizer on their maize.

Farmers' knowledge and maize practices are generally similar across the three groups. 


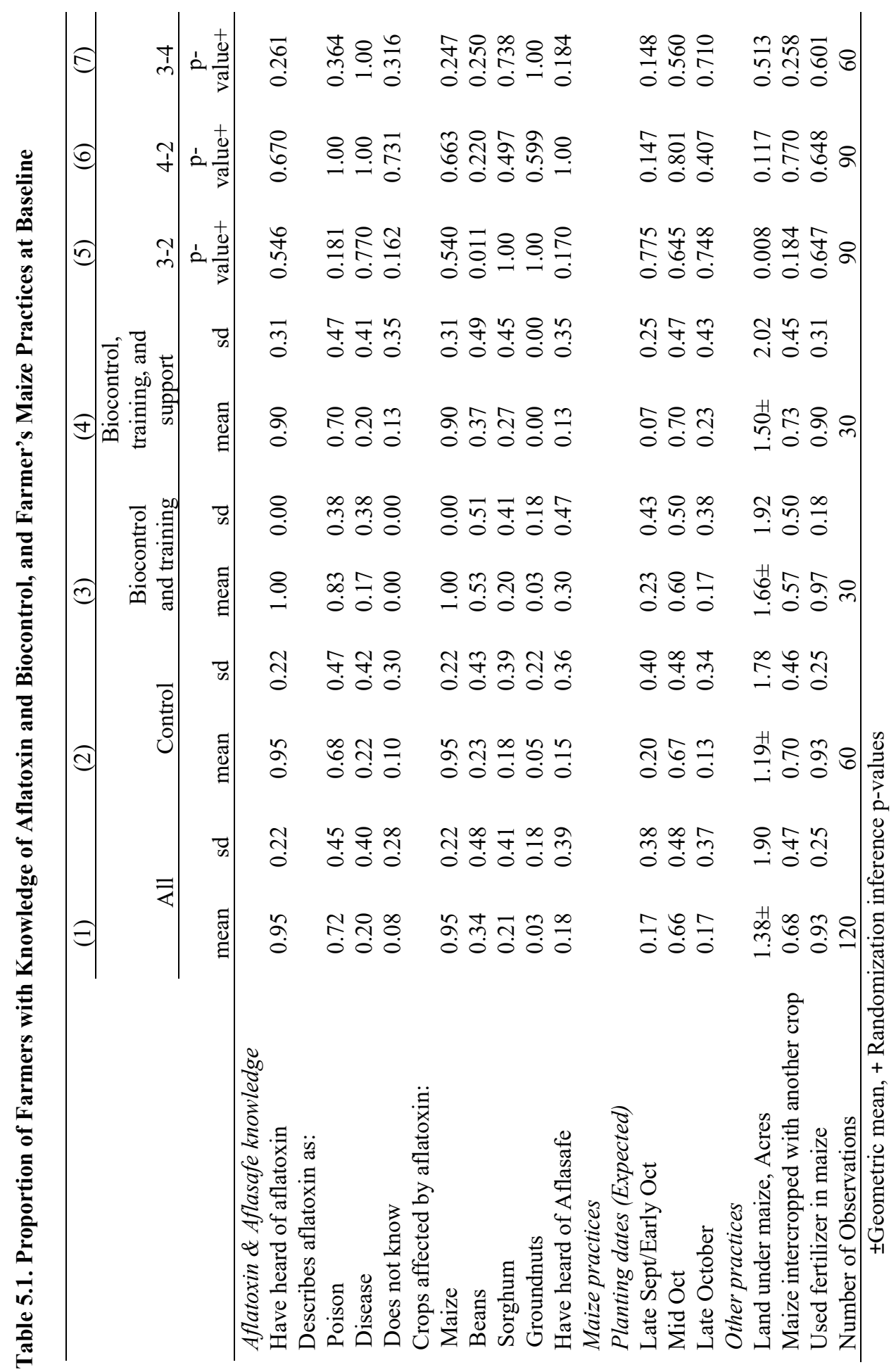




\subsubsection{Biocontrol knowledge and correct use indicators during follow-up}

This section presents results from the follow-up survey on knowledge about the biocontrol and the field monitoring exercise carried out among farmers assigned to either of the treatment groups. Table 5.2 shows the mean and the standard deviation of each outcome by treatment group.

Seven statements were used to assess farmers' knowledge about the product at followup. First, farmers were asked to describe the biocontrol product. Second, farmers were asked to state the stage at which the biocontrol should be applied. All the farmers in both treatments stated the correct stage of maize development for the application. The third statement asked about the rate of application. A majority of farmers almost equally in both treatment groups ( $80 \%$ versus $77 \%$ ) were able to state the correct rate of the biocontrol use. The next three statements were related to guarding the formulated product against loss after application. Lastly, farmers were asked whether the biocontrol product is poisonous to the farmer.

We create a knowledge index from the seven statements by assigning the value of one to any correct response and adding these values. The index thus ranges from zero to seven, with an average value of 6.73 and 6.90 in the two groups, and the difference statistically indistinguishable from zero.

In terms of the timing of application, farmers in the biocontrol and training group applied the product approximately 52 days on average after planting. Farmers in the biocontrol, training, and support group used the product about 49 days on average after planting. The difference is not statistically significant.

When asked about the stage when the biocontrol was applied using pictures of maize at different stages of growth, all farmers in the biocontrol and training and support group indicated that they applied at the correct stage. Only $80 \%$ of farmers in the biocontrol and training group showed the right stage, indicating a difference of $20 \%$ when compared to the proportion in the 
group that received additional support. The difference is significant at the $5 \%$ level. The remaining $20 \%$ of farmers in the biocontrol and training group applied later than the recommended stage.

Next, we present results from the monitoring exercise. The average number of granules per meter squared was 7.43 for the biocontrol and training group and 7.47 in the biocontrol, training, and support treatment group. The difference in the average number of granules is not statistically different.

The rate of sporulation, however, differs between the two treatment groups. The sporulation rate is calculated as the number of sporulated granules in a one-meter square quadrant divided by the total number of granules in the quadrant. The average sporulation rate in the fields where farmers were supported and supervised during application was $92 \%$, while the average sporulation rate for the farmers who did not receive additional support and supervision during application use was much lower, at 34\%. The difference in sporulation rates between the two treatments is significant at a $1 \%$ significance level. The proportion of farms for which $100 \%$ of granules sporulated also differed, $80 \%$ in the training and support group, compared to $53 \%$ of farms in the group that did not receive additional support. This difference is statistically significant.

The difference in sporulation rates may have been as a result of the late application, such that at the time of field monitoring by the project staff, the spores in these fields had not yet sporulated. This is supported by the fact that the observed average number of granules was almost similar in the two treatments. 
Table 5.2. Farmers' Knowledge of Biocontrol Product And the Observed Rate of

\section{Application and Sporulation}

\begin{tabular}{|c|c|c|c|c|c|}
\hline & \multicolumn{2}{|c|}{1} & \multicolumn{2}{|c|}{2} & \multirow{2}{*}{$\begin{array}{c}3 \\
\text { Difference }\end{array}$} \\
\hline & \multicolumn{2}{|c|}{$\begin{array}{l}\text { Biocontrol and } \\
\text { training only }\end{array}$} & \multicolumn{2}{|c|}{$\begin{array}{l}\text { Biocontrol, } \\
\text { training plus } \\
\text { support }\end{array}$} & \\
\hline & mean & sd & mean & sd & p-value+ \\
\hline \multicolumn{6}{|l|}{ Biocontrol product knowledge } \\
\hline Describes biocontrol correctly & 0.77 & 0.43 & 0.90 & 0.31 & 0.298 \\
\hline States the correct stage of product application & 1.00 & 0.00 & 1.00 & 0.00 & 1.00 \\
\hline Describes correct rate of application & 0.80 & 0.41 & 0.77 & 0.43 & 0.832 \\
\hline $\begin{array}{l}\text { States the correct reason for guarding biocontrol } \\
\text { product against poultry }\end{array}$ & 0.97 & 0.18 & 0.87 & 0.35 & 0.295 \\
\hline $\begin{array}{l}\text { The biocontrol should not be applied at the } \\
\text { same time with other inputs like fertilizer }\end{array}$ & 0.73 & 0.45 & 0.70 & 0.47 & 0.842 \\
\hline $\begin{array}{l}\text { One should not weed field immediately after the } \\
\text { application }\end{array}$ & 0.87 & 0.35 & 0.73 & 0.45 & 0.505 \\
\hline The biocontrol does not harm the farmer & 0.83 & 0.38 & 0.93 & 0.25 & 0.323 \\
\hline Knowledge index at follow-up & 6.73 & 1.17 & 6.90 & 1.27 & 0.870 \\
\hline \multicolumn{6}{|l|}{ Timing of biocontrol application } \\
\hline $\begin{array}{l}\text { Numbers of days between planting and } \\
\text { application }\end{array}$ & 52 & 8 & 49 & 9 & 0.372 \\
\hline Aflasafe applied at the correct stage & 0.80 & 0.41 & 1.00 & 0.00 & 0.076 \\
\hline \multicolumn{6}{|l|}{ Formulated product $(F P)$ in the treated fields } \\
\hline $\begin{array}{l}\text { The average number of granules of FP present } \\
\text { in per square meter }\end{array}$ & $7.43 \pm$ & 4.11 & $7.47 \pm$ & 2.54 & $0.988 \pm$ \\
\hline $\begin{array}{l}100 \% \text { sporulation observed on FP, } 1=y e s ; \\
0=\text { otherwise }\end{array}$ & 0.53 & 0.51 & 0.8 & 0.41 & $0.029 \pm$ \\
\hline Sporulation rate on FP per square meter & $33.67 \pm$ & 6.09 & $92.08 \pm$ & 1.34 & $0.004 \pm$ \\
\hline Number of observations & 30 & & 30 & & 60 \\
\hline
\end{tabular}

\pm Geometric mean $(\mathrm{GM}),+$ Randomization inference $\mathrm{p}$-value, \pm Normal $\mathrm{p}$ values 


\subsubsection{Total aflatoxins level in maize samples}

Table 5.3 shows the mean aflatoxin levels in samples collected from the farmers' fields. Aflatoxin levels are generally low, indicating that this was a non-outbreak year. Aflatoxin levels in samples from the control farms ranged from 0.85 to $89.4 \mathrm{ppb}$, with a geometric mean (GM) of $2.39 \mathrm{ppb}$. This average is below the Kenyan regulatory limit of $10 \mathrm{ppb}$. A previous study reported aflatoxin levels that ranged from below the limit of detection (LOD) to 2,500 ppb and a mean (GM) of $1.95 \mathrm{ppb}$ in maize samples collected from Eastern Kenya in 2007, a year considered as a non-outbreak year in the study (Daniel et al. 2011). The average aflatoxin levels in the study by Daniel et al. are comparable to the levels in the current study.

Aflatoxin concentration in samples from the biocontrol and training only group ranged from $0.15-22.60 \mathrm{ppb}$, with a GM of $1.58 \mathrm{ppb}$. This mean is $34 \%$ lower and significantly less (randomization inference $\mathrm{p}$-value $=0.041$ ) than the mean level in samples from the control farms.

Aflatoxin levels in samples from the biocontrol, training, and support farmers ranged from $0.15-42.10 \mathrm{ppb}$. The GM of contamination was $1.13 \mathrm{ppb}$, which is $53 \%$ lower than that for samples from control fields. This difference is significant (randomization inference pvalue $<0.001$ ). The mean level for this group differed from that of samples from the biocontrol and training group (randomization inference $\mathrm{p}$-value $=0.051$ ).

The reductions in aflatoxin contamination due to the use of the biocontrol observed in this chapter are lower than those found by most of the trials conducted in Nigeria and Senegal (Bandyopadhyay et al. 2019; Senghor et al. 2020). These moderate impacts can be attributed to the fact that the contamination levels in the control farms were generally low. The lowest reduction rate reported by Bandyopadhyay et al. (2019) was $72 \%$ and coincided with the year when the mean aflatoxin level in untreated maize samples was the lowest at $6.1 \mathrm{ppb}$ (arithmetic 
mean). The smallest reduction rate recorded in Senegal in the case of groundnuts is $58.3 \%$ and is comparable to the rate reported for the training and support group in the current chapter.

Next, we show the distribution of aflatoxin levels in each treatment group. We categorize maize samples into a) samples with aflatoxin levels below $2 \mathrm{ppb}, \mathrm{b}$ ) samples with aflatoxins between 2 and $10 \mathrm{ppb}$, and c) samples with aflatoxin levels above $10 \mathrm{ppb}$. The proportion of samples per category by treatment group are presented in figure 5.1. Based on Fisher's exact test, the distribution of aflatoxin across these categories differs by treatment group $(\mathrm{p}=0.012)$. Comparing the distribution across two treatment groups at a time, we find that the biocontrol, training, and support group differs from both the control group $(p=0.008)$ and the biocontrol and training only group $(\mathrm{p}=0.010)$. The distribution of aflatoxin levels in the samples from the control group is not statistically different from that of the samples from the biocontrol and training group ( $\mathrm{p}$-value $=0.576)$.

The biocontrol, training, and support treatment group has the highest proportion of samples with aflatoxin below $2 \mathrm{ppb}$, which accounted for $90 \%$ of all the samples collected from this treatment group. Sixty percent of samples from the biocontrol and training treatment group are in this category, which is almost the same as the proportion of samples from control fields $(57 \%)$.

The highest proportion of samples in the second category (levels between 2 and $10 \mathrm{ppb}$ ) are from the training only group, accounting for $37 \%$ of samples from this treatment. Thirty percent of samples from the control farms fall in this category. Only $6 \%$ of samples in the group that received additional support had levels between 2 and $10 \mathrm{ppb}$.

Lastly, samples from the control fields had the highest proportion of samples with aflatoxin levels above $10 \mathrm{ppb}$ (the Kenyan regulatory limit). However, this only accounts for $10 \%$ of all the samples from the control fields. Only $3 \%$ of the samples from each treatment group have levels above $10 \mathrm{ppb}$. 
Table 5.3. Total aflatoxins in Freshly Harvested Maize Samples

\begin{tabular}{|c|c|c|c|c|c|c|c|}
\hline \multirow{5}{*}{$\begin{array}{l}\text { Samples from: } \\
\text { Control group }\end{array}$} & \multicolumn{6}{|c|}{ Total aflatoxin levels in ppb } & \multirow{4}{*}{$\begin{array}{c}\text { Aflatoxin } \\
\text { reduction } \\
\quad(\%)\end{array}$} \\
\hline & \multirow{4}{*}{$\begin{array}{l}\mathrm{N} \\
60\end{array}$} & \multirow{4}{*}{$\begin{array}{l}\min \\
0.85\end{array}$} & \multirow{4}{*}{$\frac{\max }{89.40}$} & \multirow{4}{*}{$\begin{array}{c}\text { Geometric } \\
\text { mean }\end{array}$} & \multirow{3}{*}{\multicolumn{2}{|c|}{$\begin{array}{l}95 \% \text { Conf. } \\
\text { Interval of } \\
\text { the mean }\end{array}$}} & \\
\hline & & & & & & & \\
\hline & & & & & & & \\
\hline & & & & & 1.83 & 3.13 & \\
\hline Biocontrol and training & 30 & 0.15 & 22.60 & $1.58 * *$ & 1.17 & 2.13 & 34 \\
\hline \multirow{2}{*}{$\begin{array}{l}\text { Biocontrol, training and } \\
\text { support }\end{array}$} & & & & & & & \\
\hline & 30 & 0.15 & 42.10 & $1.13 * * *$ & 0.81 & 1.59 & 53 \\
\hline
\end{tabular}

** Mean different from the control samples mean at 5\% significance level *** Mean different from the control samples mean at $1 \%$ significance level (the test are conducted using p-values from randomization inference).

Note: Percent reduction is calculated as (1-(mean of treated/mean of untreated $))^{*} 100$ 


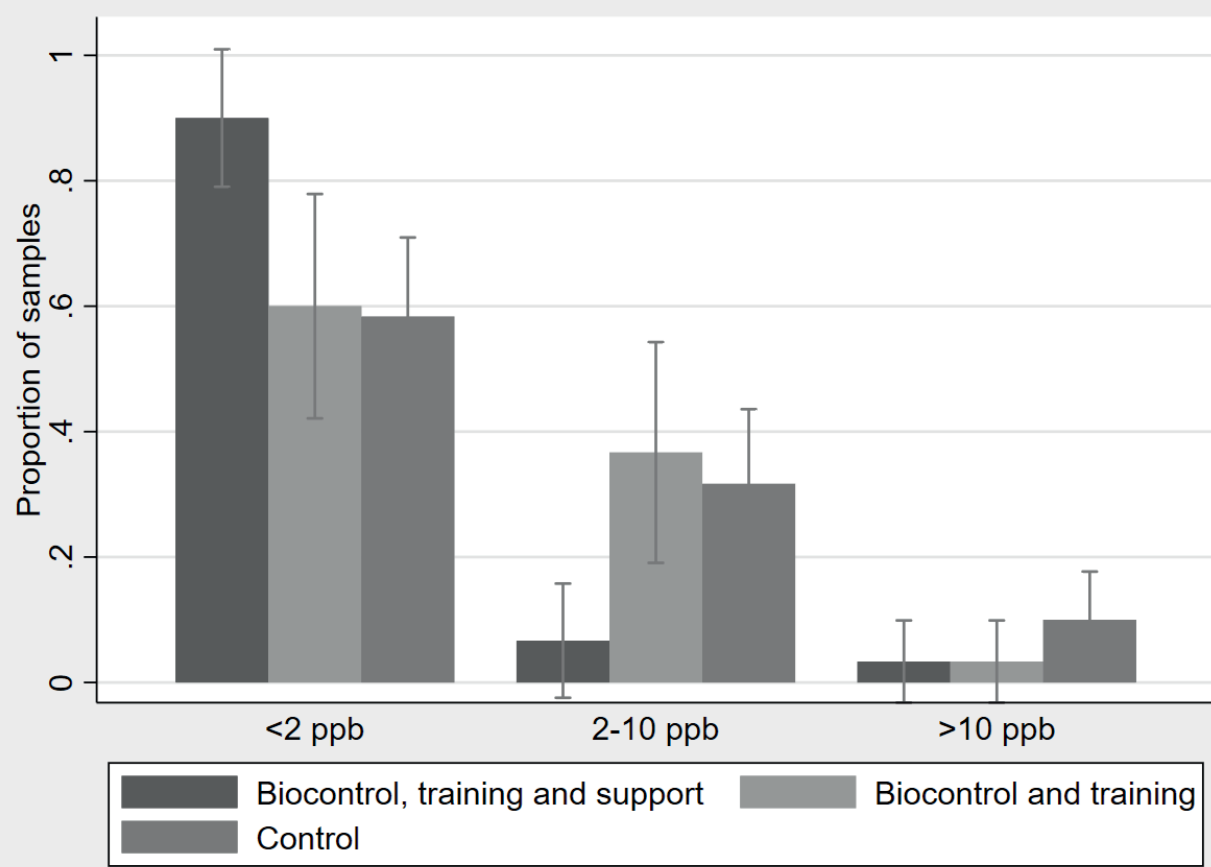

Figure 5.1. Proportion of samples in each category based on aflatoxin levels. The vertical lines are $95 \%$ confidence intervals

\subsection{Discussions and conclusions}

Exposure to aflatoxin, a naturally occurring carcinogenic hazard, is relatively high for households in SSA. High exposure is a result of high consumption of frequently contaminated staples that are mostly produced and consumed on the farm. Besides the public health concerns, aflatoxin contamination may hinder farmers' access to high-value markets where they can market their maize surplus at better prices. Effective technologies to reduce contamination at the farm level are needed to improve the safety of the food consumed at home and increase farmers' access to higher-value markets (Hoffmann, Kariuki, et al. 2018). 
In this chapter, we test the efficacy of a new aflatoxin control technology under farmers' conditions and practices. We compare the performance of this technology under two levels of farmer training and support to determine the level of training required to ensure proper use of the technology. The technology that we study is Aflasafe KE01, a biocontrol product that was recently approved for use in Kenya. Aflasafe is used while the crop is still in the field. It protects the crop throughout the growing season and after harvest (Bandyopadhyay et al., 2019; Senghor et al., 2020), making it a potentially attractive option for both farmers wishing to sell to premium markets, and governments aiming to reduce population exposure to aflatoxin.

Our results show that while the use of the biocontrol product by farmers who received a one-off training did reduce total aflatoxin, the application was more successful, and the effect of the technology was stronger, for those who were supported beyond the initial training. Farmers who received a one-off training acquired the necessary knowledge about the technology but several failed to apply the product at the correct time, an essential determinant of its efficacy. Providing additional support, including phone calls to remind farmers to assess the maize growth stage, and supervision during application, improved the timing of application and the sporulation rate, leading to a stronger impact on aflatoxin contamination.

A limitation of our study is that we are not able to determine which aspect or aspects of the additional support contributed most to the greater impact observed in the training plus support treatment group. This is important since it has cost implications. For example, if phone calls are sufficient to remind farmers to monitor their fields and apply the biocontrol at the correct stage, then this would be the most economical method after the farmers receive the one-time training. Individual visits to the farmers to supervise the application imply hefty budgetary requirements. Future studies could test the impact of less costly approaches to improving farmers' use of aflatoxin biocontrol, such as sending text messages or broadcasting radio announcements to remind farmers of the correct time of application. 
Chapter 6

General Discussion

Sarah Wairimu Kariuki 


\subsection{Overview}

Most lower-middle-income countries are undergoing rapid transformations in the agri-food value chains (Reardon et al. 2012, 2015; Tschirley, D., Haggblade, S., Reardon 2014). At the same time, food safety management systems in these countries, and especially within the public sector, remain weak (Jaffee et al. 2018). Market-based solutions have been proposed as one of the options for improving food safety and livelihoods (ANH 2017; GFSP 2019). Such solutions are desirable in these settings that are characterized by low public regulation capacity but are at the same time undergoing transformations in the agri-food value chains that can be leveraged for improved safety.

The potential for market-based approaches to improve safety and livelihoods in lowermiddle-income countries is not fully known. This thesis provides new evidence on the impact of market-based solutions on the production and supply of safe food through the adoption of food safety technology. It also provides some additional insights on other drivers of food safety technology adoption by farmers.

Overall, existing evidence and evidence from this thesis show that there is scope for market-based solutions to improve food safety for the consumers (including the farmers) and potentially improve farmers' livelihoods. However, to achieve these objectives, both the public and private sectors will play significant roles. Public action is primarily required in the area of consumer education and risk communication. Public and private partnerships are needed to enable the production and supply of safe food. A market-based approach, however, is not sufficient to ensure safe food for all consumers. Therefore, other policy tools will be needed to ensure food safety for all.

In the next sections, I discuss the specific lessons that we learn from this thesis and provide some policy recommendations. First, I start with areas that require significant effort 
from public sector-consumer education. I then discuss areas where there is a high potential for public-private partnerships-incentivizing the production and supply of safe food, farmer training, and building the capacity of producer organizations. I then discuss the role of farmer training and credit on the adoption of food safety technology ${ }^{41}$. I finalize with the limitations of this thesis and give some suggestions for further research.

\subsection{Potential area for public action}

\subsubsection{Leveraging consumer demand}

Food safety is typically a credence attribute that is mostly not observable during purchase. Additionally, most of the health effects due to unsafe foods are not experienced immediately after food consumption and are difficult to attribute to a specific food item. Consumers, therefore, may not have complete information about the safety of food during purchase. The private sector (through certification and labeling) or the government can provide food safety information to the consumers to enable them to make informed choices.

Several studies have assed consumers' Willingness To Pay (WTP) for food safety attributes. A general finding is that consumers in LMICs are willing to pay a significant premium for food safety attributes (De Groote et al. 2016; Hoffmann and Gatobu 2014; Hoffmann et al. 2019; Ortega and Tschirley 2017). However, emerging evidence is pointing towards a potential upward bias in the methods applied in these studies (Brown et al. 2017; Hoffmann, Moser, et al. 2020).

The findings from Hoffmann et al. (2020) provide additional insights to the literature on consumer demand for safety; that is, there is limited scope for the private sector to stimulate

\footnotetext{
${ }^{41}$ This is not necessarily specific to the role of market-based solutions but relates to food safety technology adoption in general, either for safe food for home consumption or for sale
} 
demand for food safety through labeling and certification. Thus, it is unlikely that firms (at least in the Kenyan context) will invest in the provision of food safety information to consumers.

Chapter 2 provides some new evidence into this literature. In this chapter, the effect of information on consumers' product choice was measured nine weeks after information was provided. The chapter shows that providing independent information (based on a previous study) on the safest maize flour brands does not lead to a change in consumer behavior, as measured by the consumption of any of the safest brands and the per-unit expenditure of the consumed brand. However, providing additional information on exposure to risk in the form of a test result of the brand consumed by the household increased the probability that a household consumed any of the safer brands at follow-up. Other studies on the role of information in stimulating demand for protective health, in general, have found similar results (Dupas and Miguel 2017). That is, information on relative risk has a higher effect on behavior than general information.

Results from Chapter 2 can be scaled up by publicizing information on the relative contamination of the existing brands or compliance by vendors. The public sector can take up this role. Whether information on the relative riskiness of the existing brands or vendors can have similar effects with the risk information from the individualized tests is an open question that may warrant further attention. For example, to the extent that the results in Chapter 2 were mainly driven by the salience of providing personalized tests (for example, the act of enumerators conducting a test at an individual's house) and not due to the actual information on risk (that is, information indicating the level of contamination), then the effects of the two may vary. Two studies from the water treatment literature that controlled for the effect of the 'testing' in their design (Brown et al. 2017) or compared the effect of household vs. sourcelevel information (Luoto, Levine, and Albert 2011a) suggest that risk information through 
individualized tests may have a similar effect as information on the relative risk of the brands in the market.

A policy of releasing information on the relative riskiness of existing brands will require careful planning to determine what and how the information will be communicated (National Research Council 2011). At the minimum, there is a need to strengthen the capacity of government staff and the infrastructure required to conduct the tests credibly. The government can tap the private sector expertise to enhance its testing capacity through quality control programs like Aflatoxin Proficiency Testing and Control in Africa (Herrman et al. 2020).

Public release of information on relative contamination may cause widespread fear among consumers, which may result in unintended consequences like consumers avoiding certain foods altogether. Again this calls for careful planning to decide what information to disclose. For example, the government can start with firms with the highest level of noncompliance. Also, consumer education should include more details on food hazards and risks to try and put the results of the tests into perspective.

Another risk of releasing such information is that of pushing small firms out of business. In some cases, such firms may be willing to comply but may have limited capacity to do so. Public funds may be required to assist such firms to be compliant, for instance, through the provision of infrastructure (for example, testing laboratories).

\subsection{Potential areas for public-private partnerships}

\subsubsection{Incentivizing production and supply of safe food}

Market incentives have been shown to stimulate farmers to invest in quality-enhancing inputs in milk and onion production in Indonesia, Senegal, and Vietnam (Bernard et al. 2017; Saenger et al. 2013; Treurniet 2019b). Three other studies have assessed the impact of price premiums on the adoption of food safety technologies. A study in Ghana showed positive impacts of a 
modest price premium ( $15 \%$ above the prevailing price in year $1 ; 8-25 \%$ in year 2 ) on farmers' adoption of a non-divisible food safety technology - a drying sheet that protects maize against aflatoxin contamination (Hoffmann, Magnan, et al. 2018). In Kenya, an experiment that tested the impact of a relatively high premium (approximately $50 \%$ above the prevailing price) also showed a positive effect of the price premium on the use of drying technology for aflatoxin control (Hoffmann and Jones 2018). In Nigeria, incentives were given to aggregators for maize treated with a biocontrol product for aflatoxin contamination, and results showed that this trickled to contracted commercial farmers resulting in increased adoption of biocontrol and higher prices for the farmers ( $4 \%$ above that of control farmers) (Bell et al. 2018).

Chapter 3 adds to these studies by testing the role of a small price premium $(5 \%$ the value of maize) on the adoption of a divisible food safety technology, a biocontrol for aflatoxin contamination, by small-scale farmers. These farmers mainly produce maize for home consumption and sell some in case of a surplus. The chapter shows that the price premium did not affect adoption in the extensive margin, but it increased adoption on the intensive margin. With a premium price, farmers treated a larger portion of their land. In this context, the primary motivation for farmer adoption was to have safe produce for home consumption. However, the premium harnessed upside risk so that farmers were induced to purchase more of the biocontrol to treat a greater area of land. That is, in the event of a good season, the farmer produces enough safe maize for her consumption while the surplus high-value produce is sold at a premium price. In case of a bad season, the farmers produce enough treated maize for home consumption.

Farmer's concerns about how quality/safety is assessed during produce sale may reduce the expected benefits from the technology, thus reducing the impact of incentives on adoption (Abate and Bernard 2017; Saenger, Torero, and Qaim 2012). However, the evidence presented in the above studies shows that farmers react to incentives when quality is evaluated by a private buyer (Bell et al. 2018; Treurniet 2019b), or third-party (Bernard et al. 2017; Hoffmann, 
Magnan, et al. 2018; Saenger et al. 2013) or by the project staff (Chapter 3; Hoffmann \& Jones, 2018).

We learn a few lessons from these studies. First, in the absence of market incentives, farmers will not invest in food safety technologies for their marketed produce. However, we find that even a small premium for safe food can have significant benefits in terms of improved safety of the marketed surplus, home consumed food, and (potentially) increased incomes. Chapter 3 shows that a small premium can increase the amount of safe food available for the farmers' consumption during a bad season and the safety of marketed surplus in case of a good season, thus resulting in improved health. Additionally, farmers can earn additional revenue from the sale of safer maize.

To link farmers to markets that value food safety, public-private partnerships can be harnessed. An example of such partnerships is the case of AgResults pilot in Nigeria, where public funds were used to incentivize aggregators to aggregate biocontrol treated maize mainly for sale to the export market and the poultry feed manufacturers (Bell et al. 2018). The incentive, which was USD 18.75 per ton on top of any other premium the aggregators were able to get, was conditional on verification by a third party that the aggregated produce was indeed treated. The government may initiate such partnerships by carefully selecting the private actors and explicitly stating the expected outcomes (including the requirement to work with small-scale farmers), risks, and rewards.

Such partnerships with the private sector may offer additional benefits. The private sector can provide contracts to the farmers that include the provision of yield-enhancing inputs and credit at the beginning of the season. For a technology like the biocontrol, the net returns depend on farmer's yield. At the current retail price (USD 7.80 per acre) and assuming an incentive of the same magnitude with the one studied in chapter 3 (approximately USD 0.93 per 90-kilo bag), the net return for an average farmer, given the average yields (from data in 
Chapter 3) in Eastern Kenya is negative. Thus an increase in the yield would make the investment more attractive. Some cost subsidy from the government may also be needed.

One risk of working with the private sector is the risk of exclusion of small scale farmers (other risks are mentioned in the farmer training section). Collective action among farmers can be leveraged to minimize the transaction costs involved in working with small scale farmers. I come back to the point on the role of collective action in the next section.

In the absence of such partnerships, farmers can be linked directly to millers, to ensure that the incentives for safe food trickle down to farmers.

\subsubsection{Farmer training}

While evidence has shown that some farmers adopt food safety technologies when offered market incentives (Bell et al., 2018; Hoffmann \& Jones, 2018; Hoffmann et al., 2018; Chapter 3), widespread adoption may be depressed by low returns due to incorrect use of the technology (Duflo et al. 2008).

In chapter 5 of this thesis, we show that the effectiveness of the biocontrol product depends on the timing of application, which in turn depends on the level of farmer training and support. In our experiment, farmers who received a one-off training acquired the necessary knowledge about the technology, but some failed to apply the product at the correct time. Providing additional support, including phone calls to remind farmers to assess the maize growth stage, and supervision during the application, improved the timing of application, leading to a stronger impact on the effectiveness of the biocontrol.

Our findings suggest that farmers' failure to apply the biocontrol at the correct time was not due to a lack of knowledge on the timing of application, but may have been due to farmers' failure to remember to apply the biocontrol on time. In this case, sending timely reminders at around the time of application may be useful (Casaburi et al. 2014). However, whether such 
reminders can achieve the same level of efficacy for the biocontrol without physical supervision during application, remains an open question.

While the private sector can provide training and support to farmers to ensure compliance with market standards (Bandyopadhyay et al. 2019), some oversight from the public sector may be required. The private sector may only provide information that favors their interests. For instance, they may want the farmer to sell most of the treated produce to them, thus fail to emphasize the importance of the safe food to the farmer (Bell et al. 2018). While this may result in higher revenues, it may not result in an overall improvement in health. Thus public extension will be needed to complement the training by the private sector and to train farmers on health risks of contaminated food.

Various options can be explored for the public extension. Information and Communication Technologies (ICT) can be harnessed to send specific and timely information to farmers (Aker 2011; Casaburi et al. 2014; Cole and Fernando 2012). An example is sending reminders to farmers at harvest on the importance of consuming safe food. Also, social learning among farmers can be leveraged (BenYishay and Mobarak 2014).

\subsubsection{Building the capacity of local producer organizations}

Collective action through POs will be required to reduce training, monitoring and product certification costs. Other benefits of collective action include information sharing, joint input purchase, and joint marketing.

While success stories of successful collective action exist mainly for the export market (Narrod et al. 2009; Roy and Throat 2008), a significant challenge of most of the POs is their weak capacity. To improve the capacity of the existing farmer groups, the public sector can again tap into the private sector's innovation. In such partnerships, private entities may partner with the producer organizations to build the producer organizations' capacity and bargaining 
power. A scalable example of such a public-private partnership initiative is the case of Mahagrapes in India that partners with farmer cooperatives, thus enabling them to meet the standards in the export markets (Roy and Throat 2008). Other organizations that can be harnessed to build producer organizations' capacity are the national-level producer groups organizations like the Cereal Growers Association (CGA) in Kenya.

\subsection{Other drivers of adoption}

Lack of information on the benefits and correct use of technologies is one of the constraints to the adoption of agricultural technologies in developing countries (Jack 2013). For food safety technologies, the benefits include improved health and increased revenue from the sale of safe foods. Farmers are not likely to adopt these technologies if they are unaware of these benefits.

Existing studies have shown that information is a constraint to the adoption of agricultural technologies in general, including food safety technologies (Ashraf et al. 2009; Cole and Fernando 2012; Hoffmann, Magnan, et al. 2018; Hoffmann and Jones 2018). The findings in these studies reflect the inefficiencies in the public extension in developing countries (Anderson and Feder 2004).

Other studies have shown that the level/frequency of information may affect farmer knowledge and the adoption of technologies. For instance, sending text reminders to farmers after their attendance to a field day increased the adoption of integrated pest management practices (Larochelle et al. 2019). Such reminders may serve to focus farmers' attention to the content of the training, thus improving their knowledge about the technologies, correct use of the technology, and their decisions to adopt technologies.

Chapter 4 adds to this evidence by showing some suggestive evidence of the existence of informational and learning constraints among farmers in the Kenyan context. The chapter tests the correlation between farmer group characteristics and member's adoption of 
technology. Results show that group size and member heterogeneity (education, age, assets, and scale of operation) are negatively correlated with member's adoption of food safety technology. A closer look at the data suggests that these characteristics may affect member adoption through information sharing and learning. Small groups were found to have high levels of social capital; this may facilitate information sharing and learning among members (Buck and Alwang 2011). Finally, members are likely to learn from similar members (BenYishay and Mobarak 2014); thus, more learning may take place in groups with homogeneous membership.

Overall, these studies show that information in these settings is a potential barrier to the adoption of food safety technologies. Besides, it is likely to constrain adoption further if farmers are not appropriately trained and supported to realize the full potential of these technologies (Chapter 5). Significant resources are thus needed to achieve the full potential of these technologies. However, the training needs may reduce as farmers become more familiar with the technologies.

Lastly, another barrier to the adoption of technologies in LMICs is liquidity constraints in an environment of inefficient financial markets (Hoffmann, Magnan, et al. 2018; Hoffmann and Jones 2018; Jack 2013). Producer organizations may be a source of cheap credit and savings to members, thus easing their liquidity constraints. However, I do not find evidence that groups involved in rotating savings and credit activities were more likely to increase the probability of members' adoption of the technology. However, a higher proportion of members in such groups were more likely to have acquired a loan. This may imply that groups act as sources of financial services, but there is no evidence to support that this money is used to adopt technologies. This finding suggests that other ways of relaxing the farmer's liquidity constraints may be needed. Cost subsidies have been shown to increase the adoption and use of food safety technologies among farmers (Hoffmann, Magnan, et al. 2018; Hoffmann and Jones 2018). 


\subsection{A market-based approach does not ensure safe food for all}

The evidence presented in this thesis shows that there is a scope for using market-based approaches to improve the safety of the food consumed in lower-middle-income countries. However, this approach is only likely to serve a proportion of consumers. In Chapter 2, we note that not all consumers changed their behaviour in response to information, even among those who received a result indicating contamination. In fact, a majority did not change. Similarly, most farmers did not adopt food safety technology even after receiving information on the dangers of consuming contaminated foods. Other policies may thus be needed to ensure food safety for all consumers. One option is to enforce the existing food safety regulations. Since market-based solutions may concentrate unsafe foods on the poor consumers' markets, enforcing regulation may avert such undesirable effects.

\subsection{Limitations and scope for future research}

The role of agriculture in the supply of safe and nutritious food in the LMICs has, in recent years, received heightened attention from the governments, research community, and donors. While our understanding of the total health burden and costs of food-related illnesses in these countries is far from complete, the current level of evidence shows that the burden is high and is likely to be increasing if the current status of food safety management persists (Jaffee et al. 2018; WHO 2015). Therefore, more evidence on the area of food safety management is almost warranted.

On the other hand, a vast literature examines the adoption and the impact of improved technologies in the LMICs. Much of this work is devoted to increasing our understanding of the barriers to the adoption of improved technologies. Empirical studies have found these barriers to include information constraints (Ashraf et al. 2009; Hanna et al. 2017; Hoffmann, Magnan, et al. 2018), inefficient financial markets (Croppenstedt, Demeke, and Meschi 2003; 
Hoffmann and Jones 2018), downside risk (Emerick et al. 2016), behavioral biases (Duflo et al. 2011) and heterogeneity in returns (Suri 2011). A significant development in this work is in the methodological aspect-use of RCTs-to identify the causal effects of interventions. On the contrary, only a few studies have used RCTs in the area of food safety management.

This thesis provides some new insights into the above two distinct but related strands of literature. The specific findings are i) from the consumer side; we learn that information identifying safe food does not stimulate demand for these foods by consumers. However, providing information on the risk of exposure translates to a significant change in behavior ii) from the supply side, we learn that a modest premium ( $5 \%$ above the value of maize at the time of the study) can increase the amount of safe food produced and consumed by consumers (including the farmers). However, significant farmer training and support are needed to realize the full potential of food safety technologies. Lastly, we learn that producer organizations, under certain conditions, may facilitate members' adoption of food safety technology.

While Chapter 2 contributes to our understanding of how information can stimulate demand for safer food (and by extension, nutritious foods), I highlight some aspects of the study that could be improved in future studies. First, as stated earlier, the risk information treatment may affect consumer behavior through two channels: the non-informative aspects of the treatment; for instance, the act of testing at the household or through the risk information. Separating the effect of these two channels is relevant in studies whose objective is to test the impact of the risk information. However, knowledge on whether non-informative aspects of information affect consumer behavior can also be relevant in our setting. Such knowledge can be used to increase the salience of marketing interventions and information interventions (DellaVigna and Gentzkow 2009; Just, Mancino, and Wansink 2007).

Such studies can follow a similar design to the one in Chapter 2 but include another treatment where participants receive the test result but conduct the actual testing in the absence 
of the participants. If the interest is to isolate the effect of the risk information, one could also maintain the design in Chapter 2, offer tests to households in all the treatments, but vary the sharing of the results. This last suggestion also allows for testing of the causal effect by test results by allowing the researcher to compare similar households based on the test result. The current design in Chapter 2 is limited with this respect, so we only estimate the average effect of the testing treatment.

Another reflection is on the idea that consumers in the LMICs may differ in their level of trust in the information source, which in our study was the researchers. Also, while measuring the effect of information nine weeks after the information was delivered is a significant improvement in consumer demand literature, one wonders whether similar results would be obtained a year after the information intervention, or what the effects would look like if such information is supplied regularly. Therefore, more studies are needed to test the validity of our results.

Future studies can attempt to improve our understanding of why there is a limited effect (at least in the context of our study) of positive information (information on safe products) either through labeling and marketing (Hoffmann, Moser, et al. 2020) or from an independent source (Chapter 2). Various explanations for this finding include; failure by consumers to sufficiently value health relative to prices and income, inaccurate beliefs about the likelihood of being sick, a general belief that food is generally safe, lack of trust in the current food industry, or psychological biases in information processing that make consumers behave differently to negative (e.g. risk information) vs. positive information (information on safer food) (Verbeke et al. 2007).

Information on consumers beliefs and subjective expectations about the safety of the existing foods, their trust in food players ability and willingness to supply safe food, the likelihood of getting sick from different food safety hazards, and the likelihood of getting sick 
from consuming a particular food type could increase our understanding on this subject. While in Chapter 2 we collected some information on risk awareness and knowledge and found this to be affected by both types of information, there is need for more methods that may stimulate truthful revelation of consumers' beliefs (Costanigro, Deselnicu, and Kroll 2015; Delavande, Giné, and McKenzie 2011; Lusk, Schroeder, and Tonsor 2014). Such information could be useful in designing future information interventions.

From the supply side, a primary recommendation is for studies to assess the impact of food safety technology adoption on livelihood outcomes. A premium price for safe food may not translate into improved livelihoods for rural farmers if there are significant fixed costs associated with technology access or if adoption results in behavioral changes that may divert farmers' attention from other important tasks (Bulte et al. 2014).

Also related to the above point is the finding in Chapter 3 that shows upside risk (expectation of a good harvest) as a driver of adoption, at least in the intensive margin. Efforts to help farmers cope with weather-related downside risks (which is increasing due to climate change) has led to the development of variance reducing technologies like the drought-tolerant varieties (Arslan, Belotti, and Lipper 2017; Kostandini, La, and Abdoulaye 2013). If such technologies reduce farmers' expectation of a good harvest, without increasing the average yields, then the adoption of food safety technology may be affected. Therefore, more studies are needed to identify the extent to which the adoption of food safety technology may be affected by or may affect the adoption of other technologies.

Since producer groups are likely to play a vital role in facilitating small-holders participation in high-value markets, more work is needed on their role in achieving group compliance and limit free-riding by members. Studies that test the effect of testing for compliance at the individual versus group-level on farmers' adoption decisions (Hoffmann et al. 2019) could provide further insights. 
Besides, more studies may be needed on the role of these groups in information sharing and learning among members. While it may not be feasible to randomize some of the group characteristics, testing the correlations between adoption and group characteristics in different contexts could be used to test the validity of the results in Chapter 4. It may also be informative to collect more information on information sharing mechanisms among the members. Such studies could also test if there are information spillovers from members of producer organizations to other community members.

While producer organizations are one of the recommended institutions to link smallscale farmers to high-value markets (Hoffmann et al. 2019; Jaffee et al. 2018; Unnevehr 2015; Chapter 3; Chapter 4), one caveat remains. Research on which type of farmers are likely to join producer organizations have found a "middle-class" effect on the likelihood of joining a producer organization. That is, the poorest and the relatively well-off farmers are less likely to join farmer organizations (Bernard and Spielman 2009; Fischer and Qaim 2012). More work is needed on how the poorest may be incentivized to join such organizations.

My last reflection is on our understanding of the relative efficacy of aflatoxin reducing technologies. While the main objective in Chapter 5 was to study the effect of different training levels on the effectiveness of biocontrol products, more work is needed on this topic. Testing the cost-effectiveness of different options for aflatoxin control is necessary to inform policy on which technologies to scale up. Some studies have examined the effictiveness of aflatoxin control technologies in various contexts (Kaaya and Kyamuhangi 2010; Pretari et al. 2019; Williams et al. 2014). However, our ability to compare benefits among technologies is limited by the fact that aflatoxin varies by season and space. Studies that compare different technologies in different seasons and under the same conditions are needed. 


\section{References}

Abate, Gashaw Tadesse and Tanguy Bernard. 2017. "Farmers' Quality Assessment of Their Crops and Its Impact on Commercialization Behavior: A Field Experiment in Ethiopia.” IFPRI - Discussion Papers 01624.

Abdul-rahaman, Awal and Awudu Abdulai. 2018. "Do Farmer Groups Impact on Farm Yield and Efficiency of Smallholder Farmers? Evidence from Rice Farmers in Northern Ghana.” Food Policy 81(June):95-105.

Aflagah, FO Kodjo Dzinyefa, Tanguy Bernard, and Angelino Viceisza. 2019. "Cheap Talk and Coordination in the Lab and in the Field: Collective Commercialization in Senegal." NBER Working Paper Series 26045.

Aker, Jenny C. 2011. 'Dial 'A' for Agriculture: A Review of Information and Communication Technologies for Agricultural Extension in Developing Countries.” Agricultural Economics 42(6):631-47.

Aker, Jenny C., Rachid Boumnijel, Amanda Mcclelland, and Niall Tierney. 2012. "Zap It to Me : The Impacts of a Mobile Cash Transfer Program." Unpublished Manuscript.

Anderson, Jock R. and Gershon Feder. 2004. “Agricultural Extension : Good Intentions and Hard Realities." The World Bank Research Observer 19(1):41-60.

Anderson, Michael L. 2008. "Multiple Inference and Gender Differences in the Effects of Early Intervention: A Reevaluation of the Abecedarian, Perry Preschool, and Early Training Projects.” Journal of the American Statistical Association 103(484):1481-95.

ANH. 2017. "Research Program on Agriculture for Nutrition and Health." Proposal for Phase II 2017-2022 2018.

Antle, John M. 1996. "Efficient Food Safety Regulation in the Food Manufacturing Sector." American Journal of Agricultural Economics 78(5):1242-47. 
Aramyan, Lusine, Natalia Valeeva, Matteo Vittuari, Silvia Gaiani, Gheoldus Manuela, Patrick Mahon, Silvia Scherhaufer, Dora Paschali, Balazs Cseh, Katalin Ujhelyi, and Ole Jørgen Hanssen. 2016. "Market-Based Instruments and Other Socio-Economic Incentives Enhancing Food Waste Prevention and Reduction.” Fusions Final Report.

Arslan, Aslihan, Federico Belotti, and Leslie Lipper. 2017. "Smallholder Productivity and Weather Shocks : Adoption and Impact of Widely Promoted Agricultural Practices in Tanzania." Food Policy 69:68-81.

Ashraf, Nava, Xavier Giné, and Dean Karlan. 2009. "Finding Missing Markets (and a Disturbing Epilogue): Evidence from an Export Crop Adoption and Marketing Intervention in Kenya." American Journal of Agricultural Economics 91(4):973-90.

Atehnkeng, J., P. S. Ojiambo, P. J. Cotty, and R. Bandyopadhyay. 2014. "Field Efficacy of a Mixture of Atoxigenic Aspergillus Flavus Link: FR Vegetative Compatibility Groups in Preventing Aflatoxin Contamination in Maize (Zea Mays L.).” Biological Control $72: 62-70$.

Azziz-baumgartner, Eduardo, Kimberly Lindblade, Karen Gieseker, Helen Schurz Rogers, Stephanie Kieszak, Henry Njapau, Rosemary Schleicher, Leslie F. Mccoy, Ambrose Misore, Kevin Decock, Carol Rubin, and Laurence Slutsker. 2005. "Case - Control Study of an Acute Aflatoxicosis Outbreak, Kenya, 2004.” Environmental Health Perspectives 113(12):1779-83.

Banaszak, I. 2007. “Testing Theories of Cooperative Arrangements in Agricultural Markets: Results from Producer Groups in Poland." in IAAE- 104th EAAE Seminar.

Bandyopadhyay, R., A. Ortega-Beltran, A. Akande, C. Mutegi, J. Atehnkeng, L. Kaptoge, A. L. Senghor, B. N. Adhikari, and P. J. Cotty. 2016. "Biological Control of Aflatoxins in Africa: Current Status and Potential Challenges in the Face of Climate Change." World Mycotoxin Journal 9(5):771-89. 
Bandyopadhyay, Ranajit, Joseph Atehnkeng, Alejandro Ortega-beltran, Adebowale Akande, Titilayo D. O. Falade, and Peter J. Cotty. 2019. ““ Ground-Truthing' Efficacy of Biological Control for Aflatoxin Mitigation in Farmers ' Fields in Nigeria : From Field Trials to Commercial Usage , a 10-Year Study.” Frontiers in Microbiology 10(2528):118.

Barham, James and Clarence Chitemi. 2009. "Collective Action Initiatives to Improve Marketing Performance : Lessons from Farmer Groups in Tanzania.” Food Policy 34(1):53-59.

BBC News. 2019. "Kenya’s Ugali Scare: How Safe Is Your Maize Flour?”

Bell, Stephen, Judy Geyer, Kate Hausdorff, and Tulika A. Narayan. 2018. "Can ResultsBased Prizes to Private Sector Incentivize Technology Adoption by Farmers? Evidence from AgResults Nigeria Pilot That Uses Prizes to Incentivize Adoption of Aflasafe." Agricultural \& Applied Economics Association Annual Meeting, Washington, D.C., August 5-August 7.

Benjamini, Yoav, Abba M. Krieger, and Daniel Yekutieli. 2006. “Adaptive Linear Step-up Procedures That Control the False Discovery Rate.” Biometrika 93(3):491-507.

Bennear, Lori, Alessandro Tarozzi, Alexander Pfaff, Soumya Balasubramanya, Kazi Matin, and Alexander Van Geen. 2013. "Impact of a Randomized Controlled Trial in Arsenic Risk Communication on Household Water-Source Choices in Bangladesh.” J Environ Econ Manage 65(2):225-40.

BenYishay, Ariel and A. Mushfiq Mobarak. 2014. "Social Learning and Communication." NBER Working Paper Series 20139.

Bernard, Tanguy, Marie-hélène Collion, Alain De Janvry, Pierre Rondot, and Elisabeth Sadoulet. 2007. "Do Village Organizations Make a Difference in African Rural Development? A Study for Senegal and Burkina Faso.” World Development 36(11):1- 
41.

Bernard, Tanguy, Markus Frölich, Andreas Landmann, Pia Naima Unte, Angelino Viceisza, and Fleur Wouterse. 2015. "Building Trust in Rural Producer Organizations in Senegal: Results from a Randomized Controlled Trial.” IZA Discussion Papers, No. 9207.

Bernard, Tanguy, Melissa Hidrobo, Agnes Le Port, and Rahul Rawat. 2018. "Nitrition-Based Incentives in Dairy Contract Farming in Nothern Senegal.” American Journal of Agricultural Economics 101(2008):404-35.

Bernard, Tanguy, Alain De Janvry, Samba Mbaye, and Elisabeth Sadoulet. 2017. "Expected Product Market Reforms and Technology Adoption by Senegalese Onion Producers.” American Journal of Agricultural Economics 99(4):1096-1115.

Bernard, Tanguy and Alemayehu Seyoum. 2012. "Returns to Scope? Smallholders' Commercialisation through Multipurpose Cooperatives in Ethiopia." Journal of African Economies 21(3):440-64.

Bernard, Tanguy and David J. Spielman. 2009. "Reaching the Rural Poor through Rural Producer Organizations ? A Study of Agricultural Marketing Cooperatives in Ethiopia.” Food Policy 34:60-69.

Beuningen, Coen van and Peter Knorringa. 2009. Inclusive Improvement: Standards and Smallolders-Taking Stock and Moving On. HIVOS, The Hague.

Bock, C. H., B. Mackey, and P. J. Cotty. 2004. "Population Dynamics of Aspergillus Flavus in the Air of an Intensively Cultivated Region of South-West Arizona." Plant Pathology 53(4):422-33.

Bovay, John. 2016. "FDA Refusals of Imported Food Products by Country and Category." Economic Information Bulletin (151).

Brown, Joe, Amar Hamoudi, Marc Jeuland, and Gina Turrini. 2017. "Seeing, Believing, and Behaving : Heterogeneous Effects of an Information Intervention on Household Water 
Treatment." Journal of Environmental Economics and Management 86:141-59.

Buck, Steven and Jeffrey Alwang. 2011. “Agricultural Extension, Trust, and Learning:

Results from Economic Experiments in Ecuador.” Agricultural Economics 42(6):68599.

Bulte, Erwin, Gonne Beekman, Salvatore Di Falco, Joseph Hella, and Pan Lei. 2014.

"Behavioral Responses and the Impact of New Agricultural Technologies: Evidence Froma Double-Blind Field Experiment in Tanzania." American Journal of Agricultural Economics 96(3):813-30.

Burchardi, Konrad B., Selim Gulesci, Benedetta Lerva, and Munshi Sulaiman. 2019. "Moral Hazard: Experimental Evidence from Tenancy Contracts.” The Quarterly Journal OfEconomics (2019) 134(1):281-347.

Cai, Tian and Charles Steinfield. 2018. "The Impact of Audio Phone Reminders on Kenya Farmers' Knowledge and Uptake of Drought Tolerant (DT) Maize.” Agricultural \& Applied Economics Association Annual Meeting, Chicago, Illinois, July 30-August 1.

Casaburi, Lorenzo, Michael Kremer, Sendhil Mullainathan, and Ravindra Ramrattan. 2014.

“Harnessing ICT to Increase Agricultural Production: Evidence From Kenya." Harvard Business School Working Paper (September 2013):1-33.

Casaburi, Lorenzo and Rocco Macchiavello. 2015. "Loyalty, Exit, and Enforcement :

Evidence from a Kenya Dairy Cooperative.” American Economic Review 105(5):286-90. Chagwiza, Clarietta, Roldan Muradian, and Ruerd Ruben. 2016. "Cooperative Membership and Dairy Performance among Smallholders in Ethiopia.” Food Policy 59:165-73.

Checkley, William, Gillian Buckley, Robert H. Gilman, Ana Mo Assis, Richard L. Guerrant, Saul S. Morris, Kåre Mølbak, Palle Valentiner-Branth, Claudio F. Lanata, and Robert E. Black. 2008. "Multi-Country Analysis of the Effects of Diarrhoea on Childhood Stunting." International Journal of Epidemiology 37(4):816-30. 
Cole, Shawn Allen and A. Nilesh Fernando. 2012. "The Value of Advice: Evidence from Mobile Phone-Based Agricultural Extension.” SSRN Electronic Journal.

Costanigro, Marco, Oana Deselnicu, and Stephan Kroll. 2015. "Food Beliefs : Elicitation, Estimation and Implications for Labeling Policy.” Journal of Agricultural Economics 66(1):108-28.

Cotty, Peter J., Larry Antilla, and Phillip J. Wakelyn. 2007. “Competitive Exclusion of Aflatoxin Producers: Farmer-Driven Research and Development." Pp. 241-53 in Biological control: A global perspective.

Cragg, John G. 1971. "Some Statistical Models for Limited Dependent Variables with Application to the Demand for Durable Goods." Econometrica 39(5):829-44.

Croppenstedt, Andre, Mulat Demeke, and Meloria M. Meschi. 2003. “Technology Adoption in the Presence of Constraints: The Case of Fertilizer Demand in Ethiopia." Review of Development Economics 7(1):58-70.

Daniel, Johnni H., Lauren W. Lewis, Yanique A. Redwood, Stephanie Kieszak, Robert F. Breiman, W. Dana Flanders, Carlos Bell, John Mwihia, George Ogana, Sopiato Likimani, Masja Straetemans, and Michael A. McGeehin. 2011. "Comprehensive Assessment of Maize Aflatoxin Levels in Eastern Kenya, 2005-2007.” Environmental Health Perspectives 119(12):1794-99.

Delavande, Adeline, Xavier Giné, and David McKenzie. 2011. "Measuring Subjective Expectations in Developing Countries: A Critical Review and New Evidence.” Journal of Development Economics 94(2):151-63.

DellaVigna, Stefano and Mathew Gentzkow. 2009. Persuasion: Empirical Evidence. Vol. 15298.

Dercon, Stefan and Luc Christiaensen. 2011. "Consumption Risk, Technology Adoption and Poverty Traps: Evidence from Ethiopia.” Journal of Development Economics 96(2):159_ 
73.

Donovan, Jason A., Julie A. Caswell, and Elisabete Salay. 2001. "The Effect of Stricter Foreign Regulations on Food Safety Levels in Developing Countries: A Study of Brazil.” Review of Agricultural Economics 23(1):163-75.

Dorner, J. W. 2009. "Development of Biocontrol Technology to Manage Aflatoxin Contamination in Peanuts." Peanut Science 36(1):60-67.

Duflo, Esther, Michael Kremer, and Jonathan Robinson. 2008. "How High Are Rates of Return to Fertilizer? Evidence from Field Experiments in Kenya.” The American Economic Review 98(2):482-88.

Duflo, Esther, Michael Kremer, and Jonathan Robinson. 2011. "Nudging Farmers to Use Fertilizer : Theory and Experimental Evidence from Kenya." American Economic Review 101(October):2350-90.

Dupas, Pascaline. 2011. "Do Teenagers Respond to HIV Risk Information? Evidence from a Field Experiment in Kenya.” American Economic Journal: Applied Economics 3(1):134.

Dupas, Pascaline and Edward Miguel. 2017. "Impacts and Determinants of Health Levels in Low-Income Countries.” Pp. 3-93 in Handbook of Economic Field Experiments. Elsevier Ltd.

Edwards, Adrian, Kerenza Hood, Elaine Matthews, Daphne Russell, Ian Russell, Jacqueline Barker, Michael Bloor, Philip Burnard, Judith Covey, Roisin Pill, Clare Wilkinson, and Nigel Stott. 2000. “The Effectiveness of One-to-One Risk-Communication Interventions in Health Care: A Systematic Review.” Medical Decision Making 20(3):290-97.

Emerick, Kyle, Alain De Janvry, Elisabeth Sadoulet, and Manzoor H. Dar. 2016.

“Technological Innovations, Downside Risk, and the Modernization of Agriculture.” American Economic Review 106(6):1537-61. 
Fischer, Elisabeth and Matin Qaim. 2012. "Linking Smallholders to Markets: Determinants and Impacts of Farmer Collective Action in Kenya." World Development 40(6):1255-68.

Fischer, Elisabeth and Matin Qaim. 2014. "Smallholder Farmers and Collective Action: What Determines the Intensity of Participation?” Journal of Agricultural Economics 65(3):683-702.

Flint, James A., Yvonne T. Van Duynhoven, Fredrick J. Angulo, Stephanie M. DeLong, Peggy Braun, Martyn Kirk, Elaine Scallan, Margaret Fitzgerald, Goutam K. Adak, Paul Sockett, Andrea Ellis, Gillian Hall, Neyla Gargouri, Henry Walke, and Peter Braam. 2005. "Estimating the Burden of Acute Gastroenteritis, Foodborne Disease, and Pathogens Commonly Transmitted by Food: An International Review." Clinical Infectious Diseases 41(5):698-704.

Foster, Andrew D. and Mark R. Rosenzweig. 2010. "Microeconomics of Technology Adoption." The Annual Review of Economics 2:395-424.

Fujiwara, Thomas and Leonard Wantchekon. 2013. "Can Informed Public Deliberation Overcome Clientelism? Experimental Evidence from Benin.” American Economic Journal: Applied Economics 5(4):241-55.

Garcia Martinez, Marian, Andrew Fearne, Julie A. Caswell, and Spencer Henson. 2007. "CoRegulation as a Possible Model for Food Safety Governance: Opportunities for PublicPrivate Partnerships.” Food Policy 32(3):299-314.

GFSP. 2019. "Food Safety in Africa:Past Endeavors and Future Directions." Global Food Safety Partnership.

Gong, Y. Y., K. Cardwell, A. Hounsa, S. Egal, P. C. Turner, A. J. Hall, and C. P. Wild. 2002. "Dietary Aflatoxin Exposure and Impaired Growth in Young Children from Benin and Togo : Cross Sectional Study.” BMJ 325(7354):20-21.

Grace, Delia. 2017. "Food Safety in Developing Countries: Research Gaps and 
Opportunities.” White Paper.

De Groote, Hugo, Clare Narrod, Simon C. Kimenju, Charles Bett, Rosemarie P. B. Scott, Marites M. Tiongco, and Zachary M. Gitonga. 2016. "Measuring Rural Consumers' Willingness to Pay for Quality Labels Using Experimental Auctions: The Case of Aflatoxin-Free Maize in Kenya." Agricultural Economics (United Kingdom) 47(1):3345.

Handel, Benjamin and Joshua Schwartzstein. 2018. "Frictions or Mental Gaps: What's behind the Information We (Don't) Use and When Do We Care?' Journal of Economic Perspectives 32(1):155-78.

Hanna, Rema, Sendhil Mullainathan, and Joshua Schwartzstein. 2017. "Learning Through Noticing: Theory and Evidence from a Field Experiment." Quarterly Journal of Economics 53(9):1689-99.

Hansen, Ben B. and Jake Bowers. 2008. "Covariate Balance in Simple, Stratified and Clustered Comparative Studies.” Statistical Science 23(2):219-36.

Häsler, Barbara, Paula Dominguez-Salas, Kimberly Fornace, Maria Garza, Delia Grace, and Jonathan Rushton. 2017. "Where Food Safety Meets Nutrition Outcomes in Livestock and Fish Value Chains: A Conceptual Approach.” Food Security 9(5):1001-17.

Havelaar, A. H., M. A. S. De Wit, R. Van Koningsveld, and E. Van Kempen. 2000. "Health Burden in the Netherlands Due to Infection with Thermophilic Campylobacter Spp.” Epidemiology and Infection 125(3):505-22.

Havelaar, AH, MD Kirk, PR Torgerson, and HJ Gibb. 2015. "World Health Organization Global Estimates and Regional Comparisons of the Burden of Foodborne Disease in 2010." PLoS Med 12(12).

Hell, K., K. F. Cardwell, M. Setamou, and H. M. Poehling. 2000. “The Influence of Storage Practices on Aflatoxin Contamination in Maize in Four Agroecological Zones of Benin, 
West Africa.” Journal of Stored Products Research 36(4):365-82.

Herrman, Timothy J., Vivian Hoffmann, Anne Muiruri, and Cindy McCormick. 2020.

“Aflatoxin Proficiency Testing and Control in Kenya.” Journal of Food Protection 83(1):142-46.

Heß, Simon. 2017. "Randomization Inference with Stata: A Guide and Software.” Stata Journal 17(3):630-51.

Hoffmann, Vivian and Ken Mwithirwa Gatobu. 2014. “Growing Their Own: Unobservable Quality and the Value of Self-Provisioning." Journal of Development Economics 106(C):168-78.

Hoffmann, Vivian, Kelly Jones, and Jef L. Leroy. 2018. “The Impact of Reducing Dietary Aflatoxin Exposure on Child Linear Growth: A Cluster Randomised Controlled Trial in Kenya.” BMJ Global Health 3(6).

Hoffmann, Vivian and Kelly M. Jones. 2018. "Improving Food Safety on the Farm:

Experimental Evidence from Kenya on Agricultural Incentives and Subsidies as Public Health Investments.” IFPRI Discussion Paper (01746).

Hoffmann, Vivian, Sarah Kariuki, Janneke Pieters, and Mark Treurniet. 2018. "Can Markets Support Smallholder Adoption of A Food Safety Technology?” IFPRI Project Note (December).

Hoffmann, Vivian, Nicholas Magnan, Gissele Gajate Garrido, Daniel Akwasi Kanyam, and Nelson Opoku. 2018. “Information, Technology, and Market Rewards: Incentivizing Aflatoxin Control in Ghana." in Annual Meeting of the Allied Social Sciences Association (ASSA), January 5-7, 2018 in Philadelphia, PA.

Hoffmann, Vivian and Christine Moser. 2017. "You Get What You Pay for: The Link between Price and Food Safety in Kenya." Agricultural Economics (United Kingdom) 48(4):449-58. 
Hoffmann, Vivian, Christine Moser, and Timothy Herrman. 2018. "Demand for AflatoxinSafe Maize in Kenya: Dynamic Response to Price and Advertising. Annual Meeting, July 30-August 1, Chicago, Illinois from Agricultural and Applied Economics Association.” P. 24 in Annual Meeting, July 30-August 1, Chicago, Illinois from Agricultural and Applied Economics Association.

Hoffmann, Vivian, Christine M. Moser, and Timothy J. Herrman. 2020. “Demand for Aflatoxin-Safe Maize in Kenya: Dynamic Response to Price and Advertising." American Journal of Agricultural Economics 00(00):1-21.

Hoffmann, Vivian, Christine Moser, and Alexander Saak. 2019. "Food Safety in Low and Middle-Income Countries: The Evidence through an Economic Lens.” World Development 123:104611.

Hoffmann, Vivian, Samuel K. Mutiga, Jagger W. Harvey, Rebecca J. Nelson, and Michael G. Milgroom. 2020. “Observability of Food Safety Losses in Maize: Evidence from Kenya.” Food Policy (April):101895.

IITA. 2018. Management of Aflatoxins in Maize and Groundnuts in Kenya: A Farmers ' Training Manual. edited by J. Atehnkeng, C. Mutegi, A. Ortega-beltran, J. Augusto, A. Akande, L. A. Senghor, T. Falade, J. Akello, and P. J. Cotty.

Jack, B. Kelsey. 2013. "Market Inefficiencies and the Adoption of Agricultural Technologies in Developing Countries.” Agricultural Technology Adoption Initiative J-PAL (MIT) CEGA (Berkeley).

Jaffee, Steven and Spencer Henson. 2004. "Standards and Agro-Food Exports from Developing Countries: Rebalancing the Debate." World Bank Policy Research Working Paper 3348:29-30.

Jaffee, Steven, Spencer Henson, Laurian Unnevehr, Delia Grace, and Emilie Cassou. 2018. "The Safe Food Imperative: Accelerating Progress in Low and Middle_Income 
Countries." The World Bank.

Jalan, Jyotsna and E. Somanathan. 2008. "The Importance of Being Informed : Experimental Evidence on Demand for Environmental Quality.” Journal of Development Economics $87: 14-28$.

Jin, Shaosheng and Jiehong Zhou. 2011. “Adoption of Food Safety and Quality Standards by China's Agricultural Cooperatives.” Food Control 22(February 2011):204-8.

Johnson, N., J. Mayne, D. Grace, and A. Wyatt. 2015. "How Will Training Traders

Contribute to Improved Food Safety in Informal Markets for Meat and Milk? A Theory of Change Analysis.” IFPRI - Discussion Papers (1451).

Johnson, Nancy and Delia Grace. 2015. “The Potential of Farm-Level Technologies and Practices to Contribute to Reducing Consumer Exposure to Aflatoxins: A Theory of Change Analysis.” International Food Policy Research Institute (July).

Just, David R., Lisa Mancino, and Brian Wansink. 2007. Could Behavioral Economics Help Improve Diet Quality for Nutrition Assistance Program Participants.

Just, Richard E. and Rulon D. Pope. 1978. "Stochastic Specification of Production Functions and Economic Implications." Journal of Econometrics 7(1):67-86.

Kaaya, A. N. and W. Kyamuhangi. 2010. "Drying Maize Using Biomass-Heated Natural Convection Dryer Improves Grain Quality During Storage.” Journal of Applied Sciences 10(11):967-74.

Kadjo, Didier, Jacob Ricker-Gilbert, Gerald Shively, and Tahirou Abdoulaye. 2019. "Food Safety and Adverse Selection in Rural Maize Markets." Journal of Agricultural Economics 71(2):412-38.

Kaitibie, S., A. O. Omore, K. Rich, B. Salasya, N. Hooton, D. Mwero, and P. Kristjanson. 2008. "Influence Pathways and Economic Impacts of Policy Change in the Kenyan Dairy Sector.” International Livestock Research Institute Research Report 15:58. 
Kaitibie, Simeon, Amos Omore, Karl Rich, and Patti Kristjanson. 2010. "Kenyan Dairy Policy Change: Influence Pathways and Economic Impacts.” World Development 38(10):1494-1505.

Kassam, Amir and Saurav Barat. 2008. "Food Safety Considerations for CGIAR Research." Journal of Agricultural \& Food Information 33(2003):128-37.

Kilimo Trust. 2017. "Characteristics of Maize Markets in the EAC: Regional East African Community Trade in Staples (REACTS).”

Kirimi, Lilian, Nicholas Sitko, T. S. Jayne, Francis Karin, Megan Sheahan, James Flock, and Gilbert Bor. 2011. “A Farm Gate to Consumer Analysis Analysis of Kenya’s Maize Marlet.” MSU International Development Working Paper No. 11.

Klich, Maren A. 2007. “Aspergillus Flavus: The Major Producer of Aflatoxin.” Molecular Plant Pathology 8(6):713-22.

Konlambigue, Matieyedou, Oscar Jacob, Nneka Eze, and Tracy Shanks. 2019. “Our Journey from Incubation to Market : Status of Aflasafe Commercialisation in Africa." ATTC.

Kostandini, Genti, Roberto La, and Tahirou Abdoulaye. 2013. "Potential Impacts of Increasing Average Yields and Reducing Maize Yield Variability in Africa." Food Policy 43:213-26.

Ksoll, Christopher, Helene Bie Lilleør, Jonas Helth Lønborg, and Ole Dahl Rasmussen. 2016. "Impact of Village Savings and Loan Associations: Evidence from a Cluster Randomized Trial.” Journal of Development Economics 120:70-85.

Lapar, Ma. Lucila, Ram Deka, Johanna Lindahl, and Delia Grace. 2014. "Quality and Safety Improvements in Informal Milk Markets and Implications for Food Safety Policy.” Larochelle, Catherine, Jeffrey Alwang, Elli Travis, Victor Hugo Barrera, and Juan Manuel Dominguez Andrade. 2019. "Did You Really Get the Message? Using Text Reminders to Stimulate Adoption of Agricultural Technologies." Journal of Development Studies 
55(4):548-64.

Lee, David S. 2009. “Training, Wages, and Sample Selection : Estimating Sharp Bounds on Treatment Effects.” Review of Economic Studies 76(1071-1102):1071-1102.

Leroy, Jef L., Jia-sheng Wang, and Kelly Jones. 2015. "Social Science \& Medicine Serum a Fl Atoxin B 1 -Lysine Adduct Level in Adult Women from Eastern Province in Kenya Depends on Household Socio-Economic Status : A Cross Sectional Study.” Social Science \& Medicine 146:104-10.

Lewis, L., M. Onsongo, H. Njapau, H. Schurz-Rogers, G. Luber, S. Kieszak, J. Nyamongo, L. Backer, AM Dahiye, A. Misore, K. DeCock, and C. Rubin. 2005. “Aflatoxin Contamination of Commercial Maize Products during an Outbreak of Acute Aflatoxicoses in Eastern and Central Kenya.” Environmental Health Perspectives 113(12):1763-67.

Liu, Yan and Felicia Wu. 2010. "Global Burden of Aflatoxin-Induced Hepatocellular Carcinoma: A Risk Assessment.” Environmental Health Perspectives 118(6):818-24. Luoto, Jill, David Levine, and Jeff Albert. 2011a. "Information and Persuasion: Achieving Safe Water Behaviors in Kenya.” RAND Working Paper WR-885.

Lusk, Jayson L., Ted C. Schroeder, and Glynn T. Tonsor. 2014. “Distinguishing Beliefs from Preferences in Food Choice.” European Review OfAgricultural Economics 41(4):62755.

Mahuku, George, Henry Sila, Charity Mutegi, Fred Kanampiu, Clare Narrod, and Dan Makumbi. 2019. "Pre-Harvest Management Is a Critical Practice for Minimizing Aflatoxin Contamination of Maize.” Food Control 96:219-26.

McDermott, John and Alan De Brauw. 2020. "National Food Systems: Inclusive Transformation for Healthier Diets." 54-65.

McMillan, Amy, Justin B. Renaud, Kevin M. N. Burgess, Adebola E. Orimadegun, Olusegun 
O. Akinyinka, Stephen J. Allen, J. David Miller, Gregor Reid, and Mark W. Sumarah. 2018. "Aflatoxin Exposure in Nigerian Children with Severe Acute Malnutrition.” Food and Chemical Toxicology 111(September 2017):356-62.

Mead, Paul S., Laurence Slutsker, Vance Dietz, Linda F. McCaig, Joseph S. Bresee, Craig Shapiro, Patricia M. Griffin, and Robert V. Tauxe. 1999. "Food-Related Illness and Death in the United States.” Emerging Infectious Diseases 5(5):607-25.

Mehmetoglu, Mehmet. 2018. "Medsem : A Stata Package for Statistical Mediation Analysis." Int. J. Computational Economics and Econometrics 8(1):63-78.

Munasib, Abdul and Devesh Roy. 2011b. "Sanitary and Phytosanitary Standards as Bridge to Cross.” IFPRI Discussion Paper 01140.

Munshi, Kaivan. 2004. "Social Learning in a Heterogeneous Population: Technology Diffusion in the Indian Green Revolution.” Journal of Development Economics 73(1):185-213.

Mutegi, C. K., P. J. Cotty, and R. Bandyopadhyay. 2018. "Prevalence and Mitigation of Aflatoxins in Kenya (1960-to Date).” World Mycotoxin Journal 11(3):341-57.

Mutiga, S. K., V. Were, V. Hoffmann, J. W. Harvey, M. G. Milgroom, and R. J. Nelson. 2014. "Extent and Drivers of Mycotoxin Contamination : Inferences from a Survey of Kenyan Maize Mills.” Post Harvest Pathology and Mycotoxins 104(11):1221-31.

Muyanga, Milu, T. S. Jayne, G. Argwings-Kodhek, and Joshua Ariga. 2005. "Staple Food Consumption Patterns in Urban Kenya: Trends and Policy Implications.” Tegemeo Institute of Agricultural Policy and Development Working Paper 19.

Narrod, Clare, Devesh Roy, Julius Okello, Belem Avendaño, Karl Rich, and Amit Thorat. 2009. "Public - Private Partnerships and Collective Action in High Value Fruit and Vegetable Supply Chains.” Food Policy 34(1):8-15.

National Research Council. 2011. "The Potential Consequences of Public Release of Food 
Safety and Inspection Service Establishment-Specific Data." Washington DC: The National Academies Press 1-97.

Naziri, Diego, Magali Aubert, Jean-marie Codron, Nguyen Thi Tan Loc, and Paule Moustier. 2014. "Estimating the Impact of Small-Scale Farmer Collective Action on Food Safety : The Case of Vegetables in Vietnam.” Journal of Development Studies 50(5):715-30.

Omore, A. and D. Baker. 2009. "Integrating Informal Actors into the Formal Dairy Industry in Kenya through Training and Certification.” 281-91.

Omotilewa, Oluwatoba J., Jacob Ricker-Gilbert, John Herbert Ainembabazi, and Gerald E. Shively. 2018. "Does Improved Storage Technology Promote Modern Input Use and Food Security? Evidence from a Randomized Trial in Uganda.” Journal of Development Economics 135(June 2017):176-98.

Ortega, David L. and David L. Tschirley. 2017. "Demand for Food Safety in Emerging and Developing Countries: A Research Agenda for Asia and Sub-Saharan Africa.” Journal of Agribusiness in Developing and Emerging Economies 7(1):21-34.

Ortmann, Andreas and Lisa K. Tichy. 1999. "Gender Differences in the Laboratory : Evidence from Prisoner' s Dilemma Games.” Journal of Economic Behavior \& Organization 39:327-39.

Ostrom, Elinor. 2010. “Analyzing Collective Action.” Agricultural Economics 41:155-66.

Otsuki, Tsunehiro, John S. Wilson, and Mirvat Sewadeh. 2001. "Saving Two in a Billion: Quantifying the Trade Effect of European Food Safety Standards on African Exports.” Food Policy 26(5):495-514.

Pitt, J. I. 2019. "The Pros and Cons of Using Biocontrol by Competitive Exclusion as a Means for Reducing Aflatoxin in Maize in Africa." World Mycotoxin Journal 12(2):103-12. Poteete, Amy R. and Elinor Ostrom. 2004. "Heterogeneity, Group Size and Collective Action : The Role of Institutions in Forest Management." Development and Change 
35(3):435-61.

Pretari, Alexia, Vivian Hoffmann, and Lulu Tian. 2019. "Post-Harvest Practices for Aflatoxin Control : Evidence from Kenya.” Journal of Stored Products Research 82:31-39.

Ragasa, Catherine and Jennifer Golan. 2014. "The Role of Rural Producer Organizations for Agricultural Service Provision in Fragile States.” Agricultural Economics 45:537-53.

Reardon, Thomas, Christopher B. Barrett, Julio A. Berdegué, and Johan F. M. Swinnen. 2009. “Agrifood Industry Transformation and Small Farmers in Developing Countries.” World Development 37(11):1717-27.

Reardon, Thomas, Kevin Chen, Bart Minten, and L. Adriano. 2012. "The Quiet Revolution in Staple Food Value Chains: Enter the Dragon, the Elephant and the Tiger." Asian Development Bank 286.

Reardon, Thomas, David Tschirley, B. Minten, S. Haggblade, S. Liverpool-Tasie, M. Dolislager, J. Snyder, and C. Ijumba. 2015. “Transformation of African Agrifood Systems in the New Era of Rapid Urbanization and the Emergence of a Middle Class." ReSAKSS Annual Conference, "Beyond a Middle Income Africa” 1-16.

Rosenzweig, M. R. and H. P. Binswanger. 2016. "Wealth, Weather Risk and the Composition and Profitability of Agricultural Investments.” The Economic Journal 103(416):56-78.

Roy, Devesh and Amit Throat. 2008. "Success in High Value Horticultural Export Markets for the Small Farmers : The Case of Mahagrapes in India." World Development 36(10):1874-90.

Saenger, Christoph, Matin Qaim, Maximo Torero, and Angelino Viceisza. 2013. “Contract Farming and Smallholder Incentives to Produce High Quality: Experimental Evidence from the Vietnamese Dairy Sector." Agricultural Economics (United Kingdom) 44(3):297-308. 
Saenger, Christoph, Maximo Torero, and Matin Qaim. 2012. "Impact of Third-Party Contract Enforcement in Agricultural Markets - A Field Experiment in Vietnam.” Pp. 1220-38 in Agricultural \& Applied Economics Association's 2012 AAEA Annual Meeting, Seattle, Washington, August 12-14, 2012. Vol. 96.

Schilbach, Frank, Heather Schofield, and Sendhil Mullainathan. 2016. "The Psychological Lives of the Poor." American Economic Review 106(5):435-40.

Senghor, L. A., A. Ortega-Beltran, J. Atehnkeng, K. A. Callicott, P. J. Cotty, and R. Bandyopadhyay. 2020. “The Atoxigenic Biocontrol Product Aflasafe SN01 Is a Valuable Tool to Mitigate Aflatoxin Contamination of Both Maize and Groundnut Cultivated in Senegal." Plant Disease 104(2):510-20.

Shiferaw, Bekele, Jon Hellin, and Geoffrey Muricho. 2011. "Improving Market Access and Agricultural Productivity Growth in Africa: What Role for Producer Organizations and Collective Action Institutions?" Food Security 3(4):475-89.

Shirima, Candida P., Martin E. Kimanya, Michael N. Routledge, Chou Srey, and Joyce L. Kinabo. 2015. "A Prospective Study of Growth and Biomarkers of Exposure to Aflatoxin and Fumonisin during Early Childhood in Tanzania." Environmental Health Perspectives 123(2):173-79.

Shuaib, Faisal M. B., Pauline E. Jolly, John E. Ehiri, Nelly Yatich, Yi Jiang, Ellen Funkhouser, Sharina D. Person, Craig Wilson, William O. Ellis, Jia-Sheng Wang, and Jonathan H. Williams. 2010. “Association between Birth Outcomes and Aflatoxin B 1 Biomarker Blood Levels in Pregnant Women in Kumasi, Ghana.” Tropical Medicine \& International Health 15(2):160-67.

Smith, Douglas A. and Robert Brame. 2003. "Tobit Models in Social Science Research: Some Limitations and a More General Alternative.” Sociological Methods \& Research 31(3):364-88. 
Suri, Tavneet. 2011. "Selection and Comparative Advantage in Technology Adoption." Econometrica 79(1):159-209.

Tadesse, Getaw and Girma Tesfahun Kassie. 2017. "Measuring Trust and Commitment in Collective Actions Evidence from Farmers' Marketing.” International Journal of Social Economics 44(7):980-96.

The Star. 2019. "Unga Sales Dip over Safety Concerns."

Treurniet, Mark. 2019a. "Impact of Being Surveyed on the Adoption of Agricultural Technology." Working Paper.

Treurniet, Mark. 2019b. “The Potency of Quality Incentives: Evidence from the Indonesian Dairy Value Chain.” Working Paper.

Tschirley, D., Haggblade, S., Reardon, T., ed. 2014. Population Growth, Climate Change and Pressure on the Land - Eastern and Southern Africa.

Turner, P. C., A. Sylla, Y. Y. Gong, M. S. Diallo, A. E. Sutcliffe, A. J. Hall, and C. P. Wild. 2005. "Reduction in Exposure to Carcinogenic Aflatoxins by Postharvest Intervention Measures in West Africa: A Community-Based Intervention Study.” Lancet 365(9475):1950-56.

Turner, Paul C., Andrew C. Collinson, Yin Bun Cheung, Yunyun Gong, Andrew J. Hall, Andrew M. Prentice, and Christopher P. Wild. 2007. “Aflatoxin Exposure in Utero Causes Growth Faltering in Gambian Infants." International Journal of Epidemiology 36(5):1119-25.

UNIDO. 2015. “Meeting Standards, Winning Markets: Trade Standards Compliance.” Trade Standards Compliance Report.

Unnevehr, Laurian. 2015. "Food Safety in Developing Countries: Moving beyond Exports." Global Food Security 4:24-29.

Verbeke, Wim, Lynn J. Frewer, Joachim Scholderer, and Hubert F. De Brabander. 2007. 
"Why Consumers Behave as They Do with Respect to Food Safety and Risk

Information." Analytica Chimica Acta 586(1-2 SPEC. ISS.):2-7.

Verhofstadt, Ellen and Miet Maertens. 2014. "Smallholder Cooperatives and Agricultural

Performance in Rwanda : Do Organizational Differences Matter?”Agricultural

Economics 45:39-52.

Weaver, Mark A., Hamed K. Abbas, Lawrence L. Falconer, Tom W. Allen, H. C. (Lyle.

Pringle, and Gabe L. Sciumbato. 2015. "Biological Control of Aflatoxin Is Effective and Economical in Mississippi Field Trials.” Crop Protection 69:52-55.

WHO. 2006. "WHO Consultation to Develop a Strategy to Estimate the Global Burden of

Foodborne Diseases : Taking Stock and Charting the Way Forward."

WHO. 2015. "WHO Estimates of the Global Burden of Foodborne Diseases: Disease Burden Epidemiology Reference Group 2007-2015.”

Wild, Christopher P. and Yun Yun Gong. 2009. "Mycotoxins and Human Disease: A Largely Ignored Global Health Issue.” Carcinogenesis 31(1):71-82.

Wild, CP, JD Miller, and JD Groopman, eds. 2015. Mycotoxin Control in Low- and MiddleIncome Countries.

Williams, Helen M. and Lindsey J. Meân. 2004. "Measuring Gender Composition in Work Groups : A Comparison of Existing Methods." Organizational Research Methods $7(4): 456-74$.

Williams, Scott B., Dieudonne Baributsa, and Charles Woloshuk. 2014. “Assessing Purdue Improved Crop Storage (PICS) Bags to Mitigate Fungal Growth and Aflatoxin Contamination.” Journal of Stored Products Research 59:190-96.

Wu, Felicia, Shaina L. Stacy, and Thomas W. Kensler. 2013. "Global Risk Assessment of Aflatoxins in Maize and Peanuts : Are Regulatory Standards Adequately Protective ?" Toxicological Sciences 135(1):251-59. 
Xu, Zhiying, William J. Burke, Thomas S. Jayne, and Jones Govereh. 2009. "Do Input Subsidy Programs ' Crowd In ' or ' Crowd Out' Commercial Market Development? Modeling Fertilizer Demand in a Two-Channel Marketing System.” Agricultural Economics 40(1).

Zwane, Alix Peterson, Jonathan Zinman, Eric Van Dusen, William Pariente, Edward Miguel, Michael Kremer, Dean S. Karlan, Richard Hornbeck, Xavier Giné, Florencia Devoto, Bruno Crepon, Abhijit Banerjee, Eric S. Maskin, Alix Peterson Zwanea, Jonathan Zinmanbcd, Eric Van Dusen, William Parientecf, Clair Null, Edward Miguelbchi, Dean S. Karlanbcl, Richard Hornbeckh, Xavier Ginébm, Esther Duflobcn, Florencia Devotobc, and Michael Kremerb. 2014. "Being Surveyed Can Change Later Behavior and Related Parameter Estimates.” Proceedings of the National Academy of Sciences 108(5):182126. 


\section{Summary}

Food safety plays an important role in economic development, as it contributes towards the general health and well-being of people, improved nutrition, and reduced poverty. This thesis examines the role of technological innovation in improving i) the livelihood of farmers and ii) the safety of food consumed by farmers \& urban consumers in low and middle-income countries.

Chapter 1 highlights the importance of food safety in low and middle-income countries, provides a general background of the core chapters, and highlights the research questions used to evaluate the main objective. The chapter also provides an overview of the methods used in the thesis.

Chapter 2 studies the role of information in stimulating consumer demand for safe food. Results show that while providing consumers with information about the existing safer brands results in increased awareness of the existence of these brands, it does not increase the likelihood of consuming safer brands. Providing additional information on household exposure to hazard increases both the awareness and the likelihood of consuming safer brands. We learn that consumer demand, through the provision of relative risk information, can potentially be leveraged to indirectly incentivize the supply of safe food.

Chapter 3 studies the role of market-based instruments (a premium price) on the adoption of food safety technology by small-scale farmers. These farmers produce for home consumption but typically sell their surplus produce. A modest price premium did not affect the probability of adopting food safety technology. However, the premium increased the amount of technology adopted. While the main motivation for adopting the technology in this context was to produce safe food for home consumption, the premium increases the value of excess produce above home consumption needs, in case the farmer experiences a good harvest. In a bad season, the farmer has sufficient treated produce for home consumption. Therefore, a 
modest premium can have significant health benefits for the farmers and the consumers of their surplus. Farmers can also earn additional revenue from the sale of safe produce.

Chapter 4 studies the role of producer organizations in the adoption of food safety technology. Specifically, the chapter examines the correlation between members' adoption of a food safety technology and the structural characteristics of their producer organizations. Results show that a member's probability of adoption is negatively correlated with the size of the group and member heterogeneity in education, age, asset ownership, and scale of operation. Results suggest that these characteristics affect members' adoption by facilitating information sharing and learning among the members.

Chapter 5 tests the effectiveness of new technology in farmers' fields under varying levels of training and support. Farmers who received a one-time training acquired the necessary knowledge about the technology, but some failed to use the technology at the correct time. Farmers who received additional support above the one-off training were more likely to use the technology at the correct time, and thus the effectiveness of the technology for these farmers was significantly higher than for the farmers who received a one-time training. These results indicate that returns to new technologies, and the subsequent adoption, may depend on the level of farmer training and support. Also, sufficient farmer training and support is needed to realize the benefit of improved health.

Chapter 6 provides a general discussion of the new evidence generated in the thesis in the light of existing literature and provides some policy recommendations. The limitations of the current thesis are also highlighted, including recommendations for future work. 


\section{Acknowledgments}

This work would not have been possible without the help of several people. I would like to express my deepest gratitude to my co-promotors, Dr. Janneke Pieters and Dr. Vivian Hoffmann, who gave me the opportunity to pursue a Ph.D. program through their NWO funded project. Thank you to both of you for walking with me every step of the way, giving timely feedback, and always being ready to listen and offer guidance. Your support went beyond supervision to genuine concern for my welfare and that of my family. Your mentorship will always be an inspiration. Special thanks to Dr. Vivian for tirelessly working with me, even during Dr. Janneke's leave of absence, despite not being directly affiliated with WUR. I am grateful to my promotor Prof.dr Erwin Bulte for his supervision, timely review of my work, and invaluable comments.

Many thanks to my co-authors Vivian Hoffmann, Janneke Pieters, Mark Treurniet, Asha Bakari, Charity Mutegi and Ranajit Bandyopadhyay for the fruitful collaborations. Thank you, Mark, for your useful comments and insights in the rest of the chapters.

I would like to recognize all those who tirelessly worked in the field to ensure data collection and project implementation were a success. The Innovations for Poverty Action (IPA), especially Ginger Golob, Noel Mugo, and Boniface Kiragu, supported data collection. Indeed, working with IPA sharpened my skills in data collection and management. Thanks to the Cereal Growers Association, under Oswald Miriti and Eliud Mutembei for excellent project implementation support. I also recognize the input from the International Institute of Tropical Agriculture (IITA) led by Dr. Charity Mutegi, in facilitating access to the technology studied in this thesis and for support in project implementation and data collection. I would particularly like to thank Asha Bakari for always allowing me to contact her on details about the project and the technology and for her timely response. Special gratitude also goes to all the research assistants who worked tirelessly during data collection and project implementation. Lastly, I 
acknowledge all the respondents in all the studies for selflessly giving their valuable time and effort during data collection and implementation of the interventions.

Many thanks to Trevor for designing the cover page. I acknowledge the useful resources from freepik.com used in the design of the cover page.

I recognize the support, useful feedback, and friendship from the staff and Ph.D. candidates in the Developments Economics group. Special thanks to Dineke and Betty for always being there to offer administrative support.

Thank you to some of my friends who made the Ph.D. journey easier one way or the other; Jamlek, Emily, Wakaba, Triza, Mike, Yeshi, Jane, Mercy, Esther, Kelvin, Amos and Claris. I also would like to thank Nellie and Nico for the few times they offered me their room in Bennekom whenever I travelled to the Netherlands. Your concern and hospitality are highly appreciated.

My deep and sincere gratitude to my family for their love and support. Thank you to my husband, Migwi, for your love, friendship, encouragement, and for taking care of our son whenever I spent time away in the field or the Netherlands. Many thanks to our son, Maina, for being my greatest source of inspiration. Thanks to Lembert and Levi for being good friends to my son. Special thanks to Linda, Shiru, and our sister Charity for taking care of my family while I was away. My in-laws, Maina's family, have been incredibly supportive. I am forever grateful.

Lastly, I thank God for His strength, guidance, and protection in our lives. 


\begin{tabular}{|c|c|c|c|}
\hline Name of the learning activity & Department/Institute & Year & ECTS* \\
\hline \multicolumn{4}{|l|}{ A) Project related competences } \\
\hline Advanced Econometrics (AEP-60306) & WUR & 2017 & 6 \\
\hline $\begin{array}{l}\text { Behavioural and Experimental Economics } \\
\text { (ECH 51306) }\end{array}$ & WUR & 2017 & 6 \\
\hline $\begin{array}{l}\text { Experiments in developing countries methods } \\
\text { and applications }\end{array}$ & $\begin{array}{l}\text { University of Groningen- } \\
\text { Summer school }\end{array}$ & 2017 & 2 \\
\hline Writing research proposal & Wur & 2017 & 4 \\
\hline Project and time management & WGS & 2017 & 1.5 \\
\hline \multicolumn{4}{|l|}{ B) General research related competences } \\
\hline Introduction course & WASS & 2019 & 1 \\
\hline 'Can information drive demand for safer food? & Agriculture, Nutrition and & 2019 & 1 \\
\hline Impact of brand-specific recommendations and & Health Academy Week & & \\
\hline test results on product choice" & Research Conference & & \\
\hline Advanced Microeconomics (ECH-51806) & WUR & 2018 & 6 \\
\hline Economics of Farm Households & WASS & 2019 & 1 \\
\hline \multicolumn{4}{|c|}{ C) Career related competences/personal development } \\
\hline Career Perspectives & WGS & 2020 & 1.6 \\
\hline Total & & & 30.1 \\
\hline
\end{tabular}

*One credit according to ECTS is on average equivalent to 28 hours of study load 


The research described in this thesis was financially supported by the Netherlands Organization for Scientific Research (NWO) through the Food \& Business Global Challenges Program and the CGIAR Research Program on Agriculture for Nutrition and Health, hosted by the International Food Policy Research Institute (IFPRI). 

